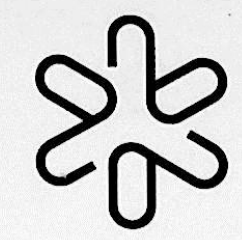

UNIVERSIDADE DE SÃO PAULO

INSTITUTO DE FÍSICA

\title{
ESPECTROSCOPIA POR RESSONÂNCIA MAGNÉTICA NUCLEAR LOCALIZADA : PROJETO E IMPLEMENTAÇÃO
}

\author{
Lionel Fernel Gamarra Contreras
}

Dissertação apresentada ao Instituto de

Física da Universidade de São Paulo para a obtenção do título de Mestre em Ciências.

Comissão examinadora:

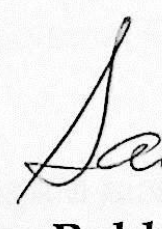

INSTITUTO DE FÍSICA

Prof. Dr. Said Rahnamaye Rabbani (Orientador)- IFUSP ex. 2

Prof. Dr. Masao Matsuoka - IFUSP

Prof. Dr. Erasmo Magalhães Castro de Tolosa-FMUSP

São Paulo -2001-

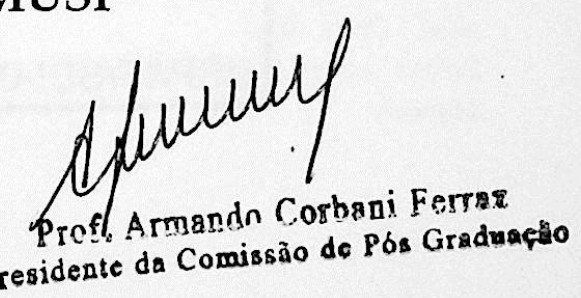




\section{FICHA CATALOGRÁFICA}

Preparada pelo Serviço de Biblioteca e Informação do Instituto de Física da Universidade de São Paulo

Gamarra Contreras, Lionel Fernel

Espectroscopia por Ressonância Magnética Nuclear Localizada: Projeto e Implementação. São Paulo, 2001.

Dissertação (Mestrado) - Universidade de São Paulo Instituto de Física - Departamento de Física Geral

Orientador: Prof. Dr. Said Rahnamaye Rabbani

Área de Concentração: Física da Matéria Condensada

Unitermos: 1. Ressonância Magnética Nuclear;

2. Espectroscopia Localizada; 3. Press; 4. RMN;
5. Espectroscopia. 


\section{AGRADECIMENTOS}

Embora seja dificil expressar a minha gratidão a todas as pessoas que direta ou indiretamente, contribuíram na efetivação deste trabalho, deixo aqui meus agradecimentos :

A Deus, pela presença em todos os momentos de minha vida.

Ao meu orientador, Prof. Dr. Said R. Rabbani por ter-me aceito como orientado, pela orientação, amizade, ensinamentos transmitidos e principalmente pela confiança depositada na minha pessoa.

Ao prof. Dr. Christovam Mendonça, pelas excelentes sugestões e discussões.

Aos meus colegas de trabalho no grupo de ressonância magnética nuclear, João Tertuliano, Joel Rodriguez, Javier Bustamante, Marcelo Alves e Renato, pelo compartimento a colaboração e pela experiência em equipe.

Ao Cassio Laranjeiras e a sua companheira Gloria Vargas pela valiosas sugestões vertidas neste trabalho.

Aos meus amigos de outros grupos Regina Reiko, Ana Carneiro e Guillermo Gonzáles.

Ao Carlos Márquez e Carlos F. de Siqueira pela assistência nos desenhos

A Doris Escriba pelo carinho, amizade e esforço dedicado para elaboração desta dissertação, que sempre me incentivou e me apoiou em todos os momentos.

Aos meus pais Rafael e Herlinda, pelo carinho e confiança dedicado à minha pessoa desde a distancia.

Aos meus irmãos e sobrinhos, pelo incentivo, carinho e amizade.

Ao CNPq, FAPESP, IFUSP, por ter proporcionado o suporte financeiro para a realização deste trabalho.

Em fim, a todas as pessoas que me ajudaram e que por um lapso de memória esqueci de mencionar. 


\section{ÍNDICE}

Resumo

Abstract.

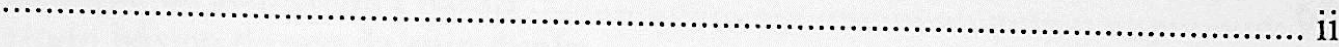

Capitulo I Teoria básica da Ressonância Magnética Nuclear (RMN)......................... 4

1.1 Princípios de Ressonância Magnética Nuclear ...................................................... 4

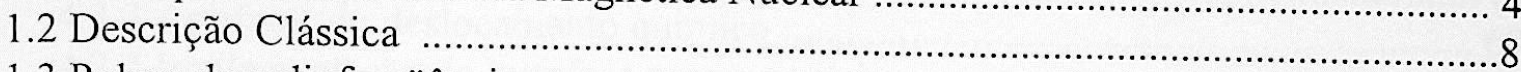

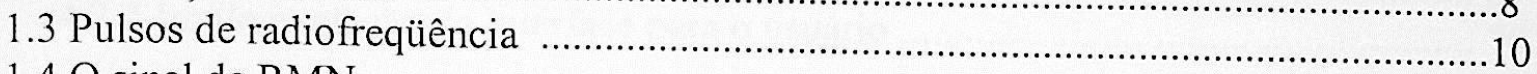

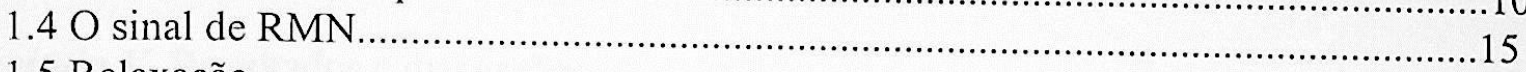

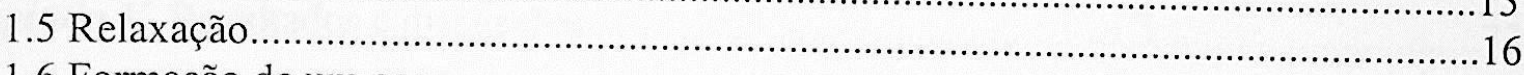

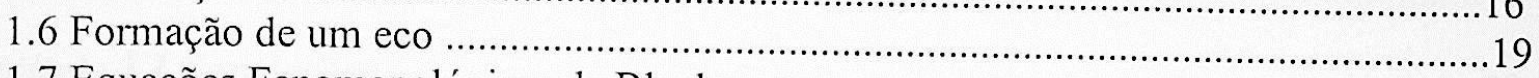

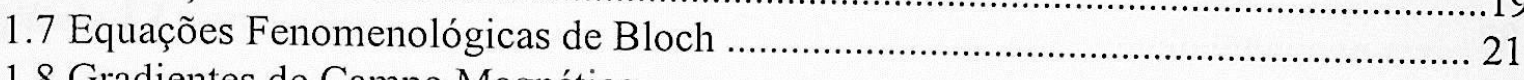

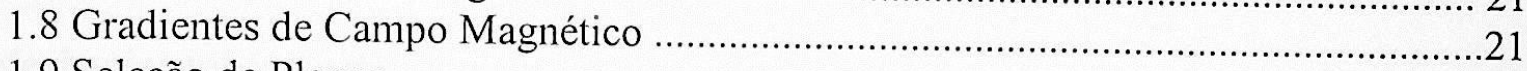

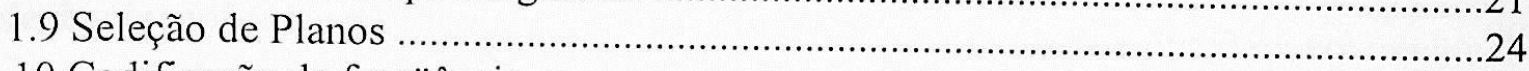

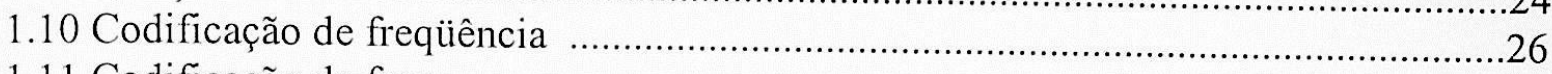

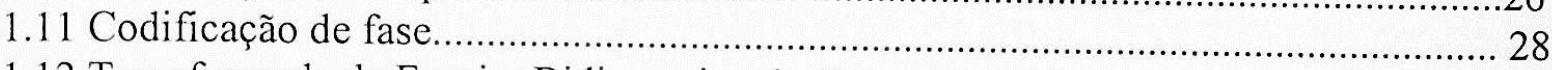

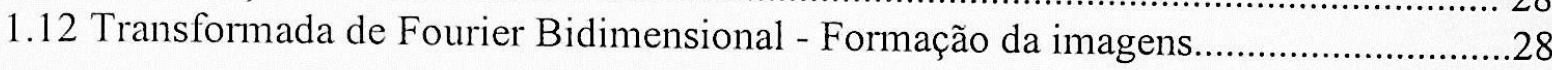

Capítulo II Aspectos relevantes da espectroscopia.........................................................

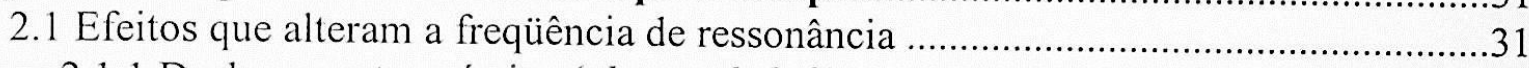

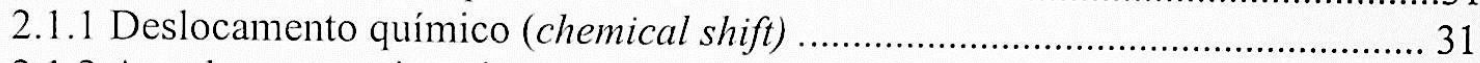

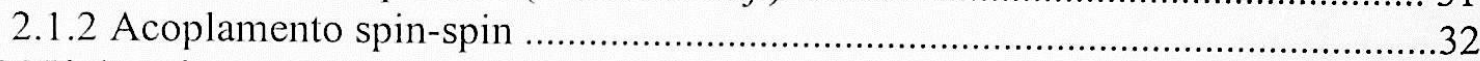

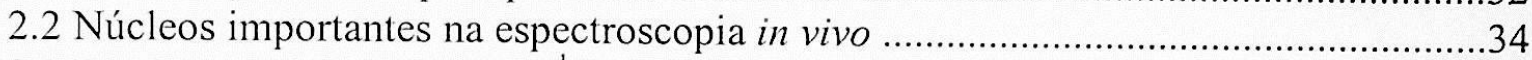

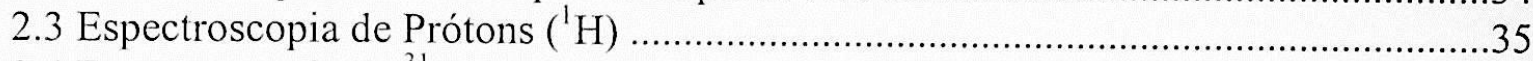

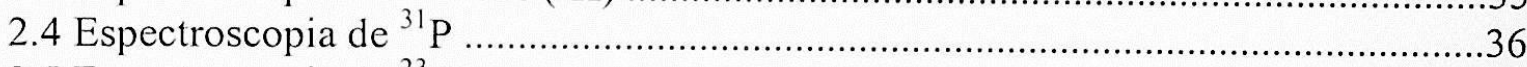

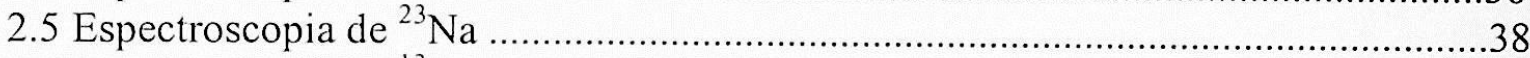

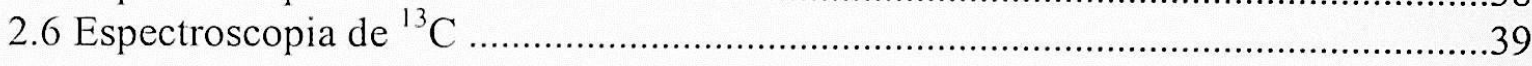

Capítulo III Técnicas de espectroscopia localizada.....................................................40

3.1 Classificação geral dos métodos de localização.......................................................40

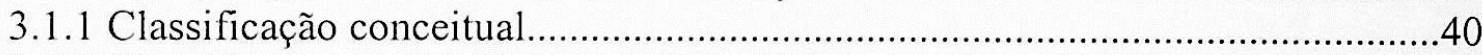

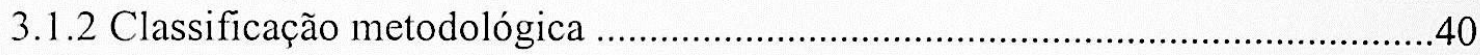

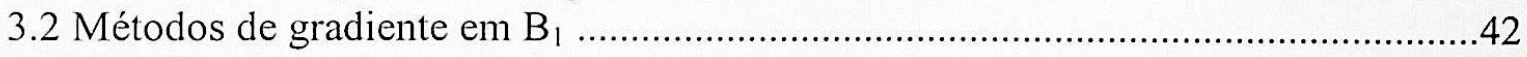

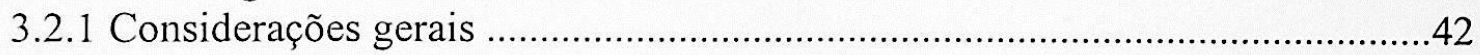

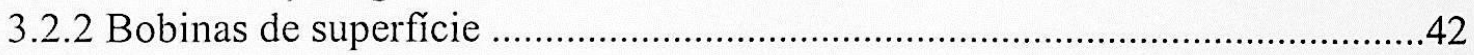

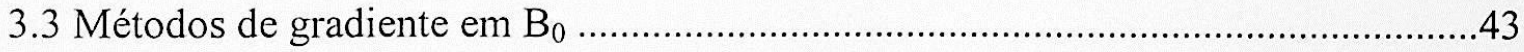

3.3.1 Depth-Resolved Surface Coil Spectroscopy (DRESS) .....................................43

3.3.2 Image-Selected "in vivo" Spectroscopy (ISIS) .................................................45

3.3.3 Stimulated Echo Acquisition Mode (STEAM) …............................................47

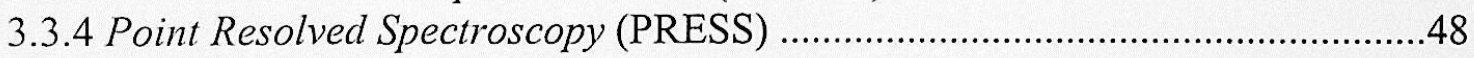

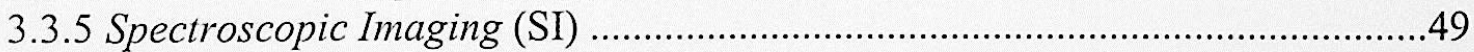

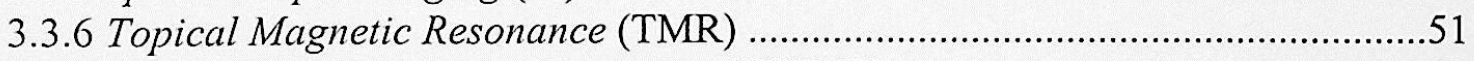

3.3.7 Chemical-Shift Selective Excitation (CHESS) ...............................................52 
Capítulo IV Procedimento experimental

4.1 Descrição dos sistemas de medida . 54

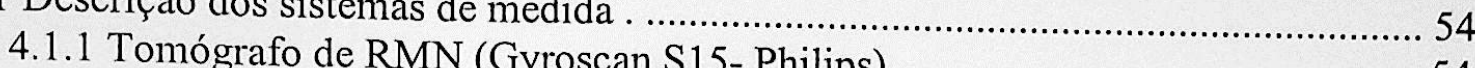

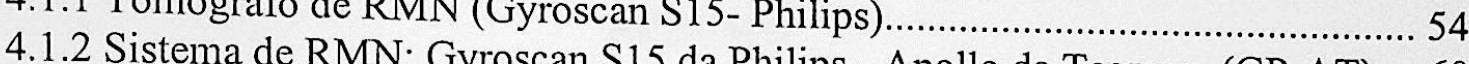

4.2 Implementação da seqüência PRESS da Philips - Apollo da Tecmag (GP-AT) ... 60

4.2.1 Método básico de eco de spin duplo

4.2.2 Erros de localização e sua eliminacão

A) Aparecimento de erros de localizacão

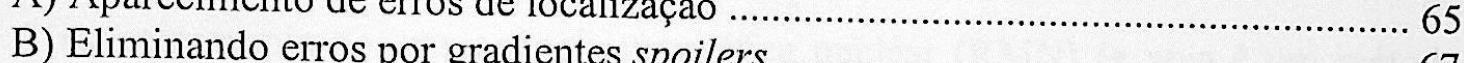

4.2.3 Artefatos do deslocamento químico ........

4.2.4 Implementação da interface para o usúrio

Capitulo V Resultados e discussões ............................................................................73

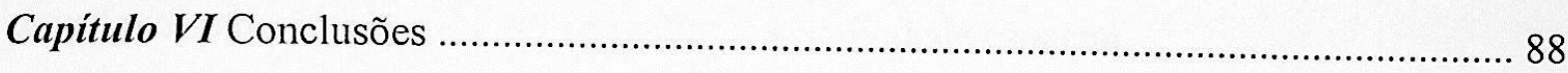

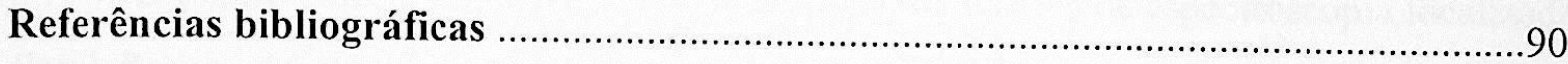




\section{RESUMO}

A espectroscopia por ressonância magnética nuclear (RMN) in vivo é um método não-invasivo que permite o estudo de metabolismos de regiões bem definidas em tecidos e órgãos de seres vivos, feito a partir de informações morfológicas dadas por imagens de RMN. Este método surge da necessidade de se obter dados significativos de sistemas complexos e heterogêneos com alto grau de seletividade espacial.

O objetivo deste trabalho é a implementação da técnica de espectroscopia localizada Point Resolved Spectroscopy (PRESS) no laboratório de Ressonância Magnética Nuclear do IF/USP, tendo em vista as vantagens que ela apresenta, principalmente para a espectroscopia de prótons. As principais contribuições deste projeto foram: (a) expandir a capacidade operacional de um tomógrafo comercial com a implantação da espectroscopia localizada, (b) introduzir um sistema de controle das bobinas de homogeneidade, (c) combinar com o tomógrafo um console (módulo que permitiu a geração da seqüência de pulsos próprias da técnica PRESS) e (d) foi elaborada uma interface para o usuário, para que este possa ter o controle total da seqüência. Também foram feitos scripts para o cálculo de fatia e o ângulo de excitação.

Foram obtidas as primeiras imagens no laboratório mediante a implementação da seqüência eco de spin, necessária para a localização do volume de interesse na espectroscopia de RMN localizada. 


\section{ABSTRACT}

In vivo nuclear magnetic resonance (NMR) spectroscopy is a non-invasive technique allowing the study of metabolism in well defined location in tissues and organs of live organisms, after morphologic data provided by NMR images. This method follows from the need to get further important informations about complex and heterogeneous systems presenting a high level of spatial selectivity.

This work has the purpose of implementing the localized NMR spectroscopic technique Point Resolved Spectroscopy (PRESS) in the Laboratory of Magnetic Resonance (IFUSP), chosen for its conveniences and advantages, especially for the spectra of protons. The main contributions of this project are: (a) the expansion of the operational capability of a commercial tomograph by adding the localized spectroscopy tool, (b) the introduction of the control system for the shimming coils, (c) to connect to the tomograph a new module, a NMR console that performed the pulse sequences characteristic of the PRESS technique and (d) the design of a user-friendly interface for the overall control of the process. Scripts for slice calculation and nutation angle were also developed.

In addition, images were first generated in the Laboratory through use of the spinecho sequence, necessary for the location of the volume of interest in the localized NMR spectroscopy. 


\section{INTRODUÇÃO}

Há mais de 50 anos o fenômeno da Ressonância Magnética Nuclear (RMN) foi observado pela primeira vez na matéria condensada (BLOCH 1946; PURCELL et al., 1946). Com a introdução em 1966 (ERNEST et al., 1966) da RMN pulsada, tornou-se uma ferramenta analítica importante utilizada pelos físicos e químicos. Mais recentemente os biofísicos e os bioquímicos vêm fazendo uso desta técnica no estudo das conformações e estruturas moleculares.

A utilização da RMN para a obtenção de imagens do corpo humano foi proposta inicialmente nos anos 70 (DAMADIAND, 1971; LAUTERBUR, 1973; KUMAR et al., 1975; MANSFIELD et al., 1978). Desde então surgiram várias inovações que tornaram as imagens por RMN uma das mais poderosas técnicas no que diz respeito ao diagnóstico clínico in vivo.

O primeiro espectro de RMN in vivo foi do ${ }^{31} \mathrm{P}$, presente no músculo do rato, registrado por HOULT et al., 1974. Este estudo foi importante pois a partir dele descobriuse o potencial da espectroscopia in vivo.

Tendo em vista que seria impossível obter dados significativos por RMN de sistemas complexos e heterogêneos, como os corpos dos seres vivos, foi necessário localizar regiões bem definidas em tecidos e órgãos para o estudo do metabolismo.

A tomografia por RMN permite obter informações estruturais de forma nãoinvasiva baseada nas diferenças de densidade do hidrogênio, enquanto a espectroscopia clássica nos traz informações sobre o ambiente químico das amostras investigadas, permitindo-nos distinguir as diferentes substâncias presentes numa amostra. A espectroscopia localizada é o resultado da combinação destas técnicas, espectroscópicas e de imagens, permitindo relacionar a informação espectral com a informação espacial, de forma que o sinal do espectro localizado provém de uma região bem definida da amostra.

Antes dos anos 70 a localização espacial não era um dos principais objetivos da espectroscopia por RMN em sistemas biológicos; os estudos limitavam-se às soluções homogêneas de biomoléculas, estudadas em magnetos convencionais. Foram necessários estímulos financeiros e intelectuais para o desenvolvimento de componentes de "hardware" (particularmente grandes magnetos de campos homogêneos e sistemas de gradientes) que se tornaram elementos essenciais na espectroscopia localizada. 
Assim, nos anos 80 os especialistas em RMN que desejavam estudar o metabolismo em seres vivos (GORDON et al., 1980; ACKERMANN et al., 1980; SHAKA et al., 1985) depararam-se com o problema de como adquirir espectros de RMN com alto grau de seletividade espacial de partes específicas de uma amostra heterogênea, uma vez $\searrow$ que sem a localização espacial é impossível estudar as propriedades espectrais dos diferentes sistemas vivos.

O sucesso das imagens por RMN na produção de mapas de densidade da água em sistemas vivos heterogêneos levou à crença de que a espectroscopia localizada seria possível. Entretanto, duas diferenças significativas entre a espectroscopia e a imagem por RMN impediram a aplicação direta dos procedimentos de imagem por ressonância magnética (IRM) para a obtenção da espectroscopia localizada. Primeiro, os procedimentos para IRM normalmente usam um gradiente de campo durante a obtenção do sinal fazendo com que a freqüência do sinal de RMN dependa da localização espacial. Mas esse \ procedimento é válido apenas se um único tipo de núcleo quimicamente equivalente está presente, o que é quase verdadeiro para a IRM, porque o sinal da água é predominante. Entretanto, essa conversão é verdadeira em qualquer estudo de espectroscopia por ressonância magnética (ERM) se assumimos que os vários núcleos existentes podem ser diferenciados pelas suas freqüências naturais únicas. Segundo, as intensidade dos sinais são centenas de vezes menores em ERM biológicos quando comparados com IRM.

Para entender os procedimentos usados para RMN localizada é importante considerar que existem duas condições importantes para a resolução do volume. Uma condição essencial é que a relação sinal/ruído seja considerável para o núcleo que queremos detectar no volume. Caso tenhamos um sinal insuficiente para o volume escolhido, a única coisa que podemos fazer é aumentar o seu tamanho. A segunda condição está relacionada com a eficiência da seqüência de localização, dado que algumas seqüências detectam apenas metade do sinal disponível, enquanto que em outras pode ocorrer uma atenuação significativa do sinal devido à relaxação durante o processo de localização. $O$ conhecimento da resolução final do volume é complicado porque requer o cálculo da relação sinal/ruído de um dado grupo de núcleos que uma determinada amostra pode produzir em determinadas condições. Esses cálculos requerem o conhecimento de vários fatores que dependem do equipamento e da amostra, além da intensidade do campo estático, tipo e tamanho das bobinas de radiofreqüência (RF), tamanho e parte do corpo que está sendo estudado e a localização do volume de interesse dentro do corpo. Assim, é também difícil predizer exatamente a eficiência da seqüência escolhida para a detecção do 
sinal, que depende de vários detalhes tais como a seleção de pulsos usada, o acoplamento spin-spin e as taxas de relaxação.

Apesar dessas limitações da teoria os resultados obtidos são a base para a especulação, devido ao fato que a concentração de água nos tecidos é tipicamente $10^{5}$ vezes maior do que as concentrações dos metabólitos de interesse para a ERM localizada (no caso de prótons). Portanto, é preciso que o volume necessário para uma relação sinal/ruído aceitável para a ERM localizada deva ser da ordem de $10^{4}$ vezes maior do que para IRM.

Com as técnicas de ERM localizada é possível observar o sinal de RMN de outros núcleos além dos prótons $\left({ }^{1} \mathrm{H}\right)$, como ${ }^{31} \mathrm{P},{ }^{13} \mathrm{C},{ }^{23} \mathrm{Na}$ e ${ }^{7} \mathrm{Li}$ entre outros, abrindo assim um amplo espaço para novas aplicações.

Portanto, a espectroscopia localizada in vivo, que resulta das técnicas espectroscópicas e de imagens permitindo relacionar informação espacial com a espectral de um volume definido da amostra, torna-se cada vez mais importante como método auxiliar no diagnóstico médico e na pesquisa de processos biológicos.

A proposta deste trabalho é implementar a técnica de espectroscopia localizada Point Resolved Spectroscopy (PRESS) no laboratório de Ressonância Magnética Nuclear do IF/USP.

No capítulo I deste trabalho serão introduzidos os princípios básicos da ressonância magnética nuclear e seus princípios na geração de imagens.

No Capítulo II, serão discutidos os efeitos que alteram a freqüência de ressonância, assim como serão mostradas as características dos núcleos mais importantes na espectroscopia in vivo.

No capítulo III, serão discutidas as diferentes técnicas de espectroscopia localizada, comentando alguns aspectos práticos dessa tecnologia, assim como suas vantagens e desvantagens.

No capítulo IV, apresentaremos as características dos equipamentos de RMN utilizados para a implementação da seqüência PRESS. As condições para a implementação desta última e a implementação da interface para o usuário serão discutidas em maiores detalhes com vistas à otimização da seqüência.

No capítulo V, mostraremos e discutiremos os resultados obtidos do processo da implementação. Adicionalmente apresentaremos as primeiras imagens obtidas em nosso laboratório, necessárias para a localização do volume de interesse.

Finalmente no capitulo VI, serão apresentadas as conclusões do presente trabalho. 


\title{
Capítulo I
}

\section{TEORIA BÁSICA DA RESSONÂNCIA MAGNÉTICA NUCLEAR (RMN)}

\begin{abstract}
Neste capítulo, discutiremos as bases teóricas da RMN, e seus princípios na geração de imagens utilizando Transformada de Fourier Bidimensional (2DFT).
\end{abstract}

\subsection{Princípios de Ressonância Magnética Nuclear}

A ressonância é um dos fenômenos mais estudados pela Física, pois aparece em quase todos os sistemas mecânicos, acústicos, elétricos, ópticos e magnéticos, sempre que ocorrem estímulos cuja freqüência seja próxima às suas frequiências naturais de vibração. $\mathrm{O}$ aproveitamento desse fenômeno estende-se a diversas situações que fazem parte do nosso cotidiano como, por exemplo, a sintonia de um receptor de rádio, onde ajustamos numa mesma freqüência o circuito de sintonia do receptor e a onda transmitida pela estação emissora.

O fenômeno da ressonância manifesta-se também nos níveis molecular, atômico e nuclear. No último caso, a ressonância é de natureza magnética e por esta razão recebe o nome de RMN, e surge do fato de determinados núcleos possuírem momento angular intrínseco (spin) e um momento magnético associado. Simplificando, podemos imaginar o comportamento dos núcleos atômicos como próximo ao de piões magnetizados cujos pólos se situam nos extremos de seu eixo de rotação (figura 1.1). Ao ser colocado sob a ação de um campo magnético $\vec{B}_{0}$, fica sob o efeito de um torque que o faz executar um movimento de precessão com freqüência angular $\omega$ proporcional a $\vec{B}_{0}$. Do mesmo modo, a força da gravidade faz um pião de brinquedo precessionar, fazendo com que seu eixo descreva um cone. Neste caso, a frequiência de precessão $\omega$ depende do momento angular $\mathbf{L}$, da intensidade do campo gravitacional $\vec{g}$ e das características mecânicas do pião. 
a)

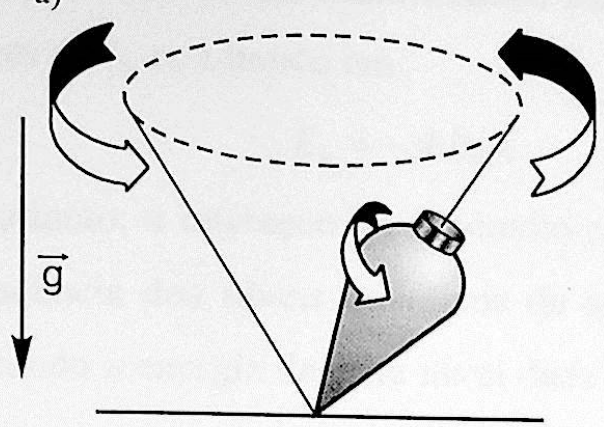

b)

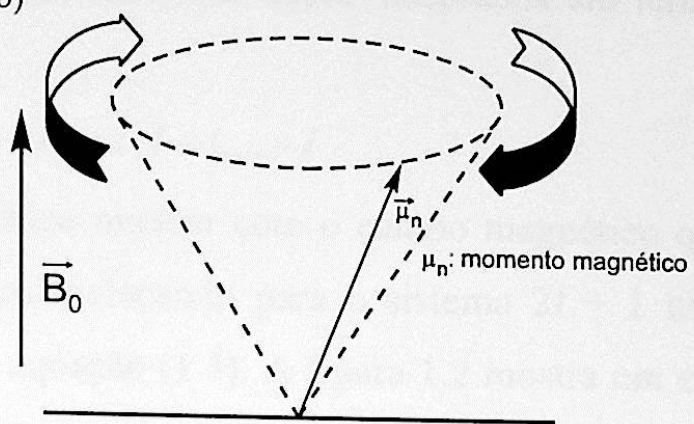

Figura 1.1 (a) Um pião precessando no campo gravitacional terrestre. (b) Um momento magnético $\vec{\mu}$ precessando sob a influência de um campo magnético aplicado.

A RMN é fundamentada na existência do núcleo atômico e suas propriedades intrínsecas, tais como o momento angular intrínseco (spin nuclear) e o momento magnético associado. Quando um campo magnético estático $\left(\vec{B}_{0}\right)$ é aplicado numa amostra de momento magnético nuclear $(\vec{\mu})$ não nulo a degenerescência dos níveis de energia de spin do sistema é levantada pela interação entre momentos magnéticos dos núcleos e o campo $\vec{B}_{0}$. Este efeito é comumente denominado efeito Zeeman nuclear e para descrevê-lo quantitativamente é necessário considerar o Hamiltoniano de interação entre o momento magnético do núcleo e o campo estático:

$$
\hat{C}=-\vec{\mu} \cdot \vec{B}_{0}
$$

Adotando um sistema de referência onde a direção $z$ coincida com a direção do campo $\vec{B}_{0}$, isto é, $\vec{B}_{0}=B_{0} \hat{z}$.

$$
\text { d'te }^{\prime \prime} \mu_{2} B_{0}
$$

Existe, no entanto, uma relação direta entre o momento magnético $\vec{\mu}$ e o spin nuclear $\vec{I}$, que é dada por:

$$
\vec{\mu}=\gamma \hbar \vec{I}
$$

onde $\gamma$ é denominado fator giromagnético e é uma característica intrínseca de um núcleo específico.

Substituindo a componente $z$ da equação vetorial (1.3) na equação (1.2) obtém-se o Hamiltoniano da interação Zeeman escrito em termos do operador $I_{z}$.

$$
\text { C } f=-\gamma \hbar B_{0} I_{z}
$$


Os autovalores do Hamiltoniano da equação (1.4) são agora calculados em termos dos autovalores de $I_{z}$, resultando em:

$$
E_{m}=-\gamma \hbar B_{0} m \quad m=I, I-1, \ldots,-I
$$

Portanto, a interação do momento magnético nuclear com o campo magnético quebra a degenerescência dos níveis quânticos de spin, estabelecendo para o sistema $2 I+1$ níveis de energia, sendo a energia de cada nível dada pela equação (1.5). A figura 1.2 mostra um esquema onde estão representados os níveis de energia para núcleos com spin $1 / 2$ e $3 / 2$, respectivamente.
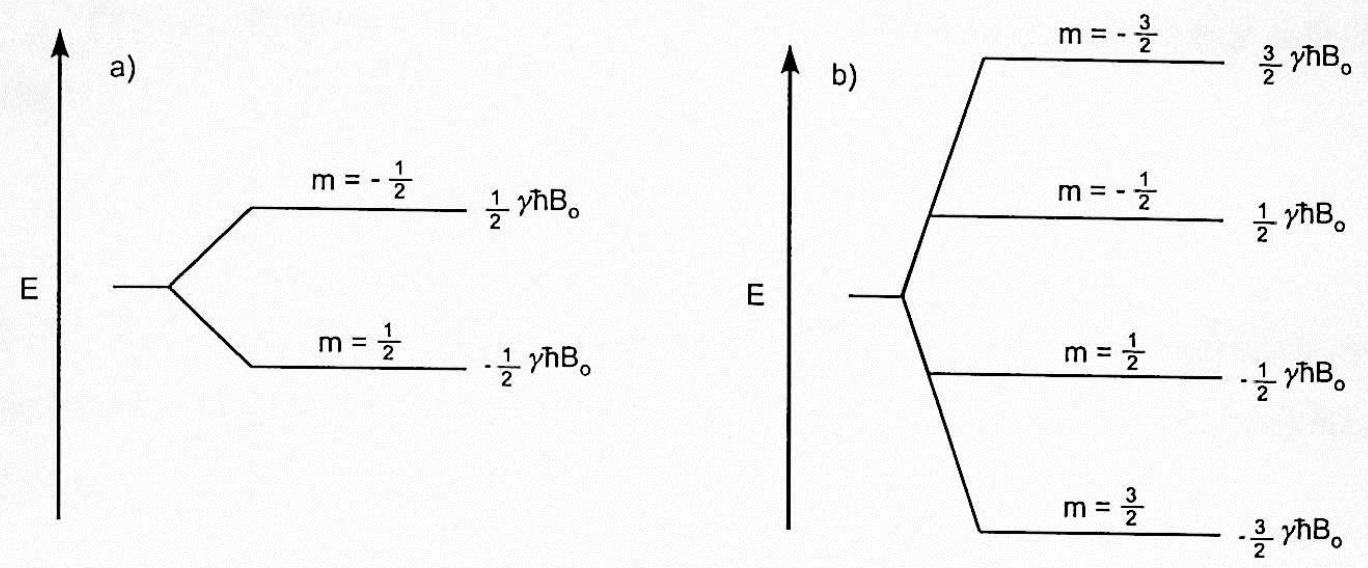

Figura 1.2 Esquema de níveis de energia para o desdobramento Zeeman para núcleos com $I=1 / 2$ e $3 / 2$.

Uma vez estabelecido o desdobramento Zeeman, deve-se perguntar como os níveis são populados, já que o número de núcleos presentes na amostra é da ordem do número de Avogadro. Para responder a esta questão recorre-se à teoria estatística, que diz que a população dos níveis é dada pela distribuição de Boltzmann aplicada a um grande número de spins idênticos em equilíbrio térmico com uma rede a uma temperatura $T$, assim temos:

$$
P_{m} \propto e^{-\frac{E_{m}}{k T}}
$$

onde $k$ é a constante de Boltzmann

Logo, os níveis de energia Zeeman não são igualmente populados, sendo os níveis de mais baixa energia mais populosos. Por existir essa diferença de população entre os vários níveis de energia, pode-se associar ao sistema uma magnetização líquida na direção do campo que é dada por:

$$
M_{0}=\sum_{m} \gamma \hbar m P_{m}
$$


Para um conjunto de spins $1 / 2$ se o nível mais energético for populado com $N_{+}$ spins e o nível menos energético com $N_{-}$a relação entre as populações será :

$$
\frac{N_{+}}{N_{-}}=\exp \left(-\frac{\Delta E}{k T}\right)=\exp \left(-\frac{\not \hbar B_{0}}{k T}\right)
$$

Onde $N_{+}$é o numero de núcleos com spin paralelo ao campo, $N_{-}$é o número de núcleos com spin antiparalelo, $T$ é a temperatura do sistema e $\boldsymbol{k}$ a constante de Boltzmann.

Para se promover transições entre dois níveis de energia, é necessário fornecer a energia

$$
\Delta E=\gamma \hbar B_{0}
$$

o que é geralmente feito através da aplicação de um campo eletromagnético na faixa de radiofrequência (RF). Pela lei de Planck, a energia $E_{r f}$ de um fóton com freqüência angular $\omega$ é igual a :

$$
E_{r f}=\hbar \omega
$$

A condição de ressonância para promover transições entre os níveis é então

$$
\omega=\gamma B_{0}
$$

a equação fundamental da RMN (relação de Larmor). Como mostrado na figura 1.3, depois de absorver a energia do campo eletromagnético e ir para o nível de maior energia (estado excitado) o sistema tende a emitir uma onda eletromagnética na freqüência de ressonância $\omega$, característica do núcleo em observação. 


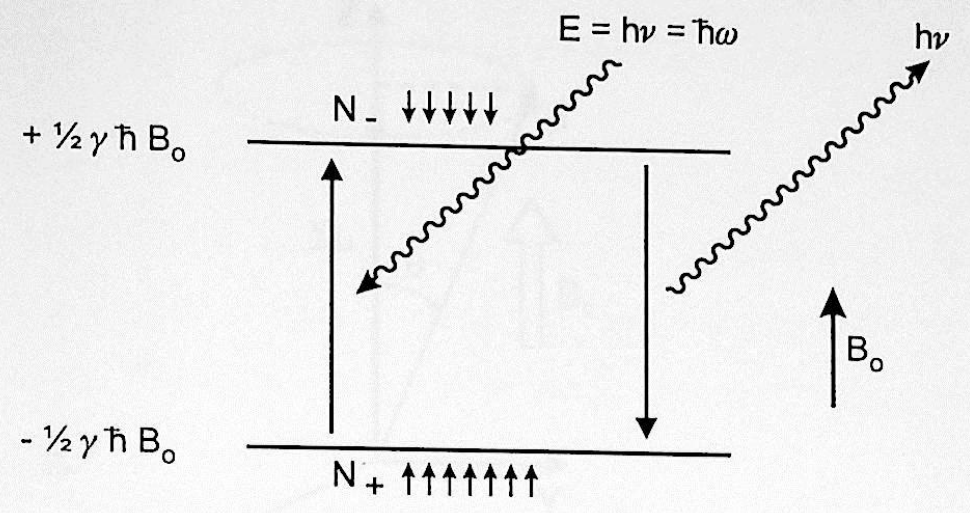

Figura 1. 3 : Esquema de transição entre os dois níveis de energia de um núcleo com $\operatorname{spin} 1 / 2$.

Este modelo quântico é importante na espectroscopia e para a interpretação de mecanismos de relaxação.

\subsection{Descrição Clássica}

Faremos agora uma descrição clássica do movimento. A presença de um campo magnético externo $\vec{B}_{0}$ produz um torque $(\vec{\tau})$ sobre o momento magnético $\vec{\mu}$ expresso por:

$$
\vec{\tau}=\vec{\mu} \times \vec{B}_{0}
$$

A equação de movimento que descreve essa taxa de variação do momento angular $\vec{J}=\hbar \vec{I}$ é

$$
\frac{d \vec{J}}{d t}=\vec{\mu} \times \vec{B}_{0}
$$

desde que $\vec{\mu}=\gamma \cdot \vec{J}$, nós podemos eliminar $\vec{J}$, tomando

$$
\frac{d \vec{\mu}}{d t}=\vec{\mu} x\left(\gamma \vec{B}_{0}\right)
$$

Em qualquer instante a variação de $\vec{\mu}$ é perpendicular a $\vec{\mu}$ e $\vec{B}_{0}$ que é estático, a evolução do vetor $\vec{\mu}$ descreverá um cone (veja figura 1.4). 


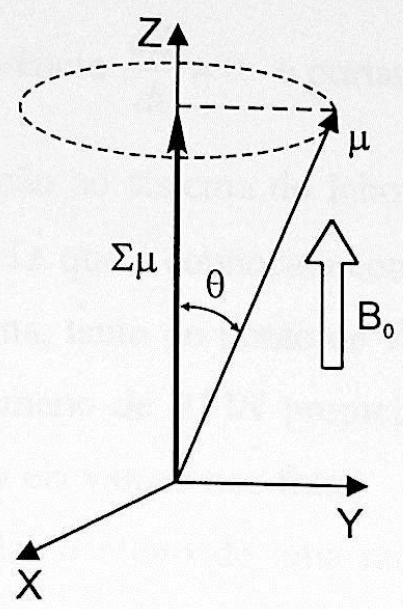

Figura 1.4 Núcleo com momento angular e magnético na presença de um campo magnético.

Caso não ocorram interações entre $\vec{\mu}$ e o exterior e, se o campo magnético $\vec{B}_{0}$ for estático, este movimento de precessão de $\vec{\mu}$ em torno do eixo $\hat{Z}$ será estacionário. Nesta situação a solução completa da equação (1.14) pode ser obtida de forma mais conveniente mediante uma transformação de coordenadas. Consideraremos um sistema de coordenadas girantes, tal que $\hat{Z}^{\prime}$ coincide com $\hat{Z}$, e $\hat{X}^{\prime}$ e $\hat{Y}^{\prime}$ girem em torno de $\hat{Z}^{\prime}(\hat{Z})$ com velocidade angular $\vec{\Omega}$.

Nesse novo sistema de coordenadas podemos reescrever a equação (1.14) da forma

$$
\frac{d \vec{\mu}}{d t}=\gamma \vec{\mu} \times\left(\vec{B}_{0}+\frac{\vec{\Omega}}{\gamma}\right)
$$

Essa equação mostra no sistema girante de coordenadas o momento magnético $\vec{\mu}$, que é basicamente a mesma equação descrita anteriormente, porém na presença de um campo efetivo $\vec{B}_{c f}$ dado por:

$$
\vec{B}_{e f}=\vec{B}_{0}+\frac{\vec{\Omega}}{\gamma}
$$

Se escolhemos um sistema tal que o campo efetivo seja igual a zero $\left(\vec{B}_{c f}=0\right)$, teremos:

$$
\vec{\Omega}=-\gamma \vec{B}_{0}
$$


Neste sistema de referência $\frac{d \vec{\mu}}{d t}=0$ e portanto $\vec{\mu}$ é estático com respeito a $\hat{X}^{\prime}, \hat{Y}^{\prime}$ e $\hat{Z}^{\prime}$, enquanto que em relação ao sistema do laboratório $\vec{\mu}$ precessiona no sentido antihorário com uma freqüência $\Omega$ que é conhecida como "freqüência de Larmor". Observa-se que essa freqüência é a mesma, tanto do ponto de vista clássico como quântico. Entretanto a descrição clássica do fenômeno de RMN propicia uma melhor compreensão de todo o comportamento dos spins, e a ela vamos nos fixar.

Podemos agora estudar o efeito de uma radiação eletromagnética que satisfaça a equação (1.17), e que determina a existência de um campo magnético de RF que gira com freqüência $|\vec{\Omega}|$ em torno de $\hat{Z}$. Este campo magnético alternado é gerado por uma bobina de RF.

\subsection{Pulsos de radiofreqüência}

Para transformar a magnetização líquida obtida a partir do efeito Zeeman em magnetização observável é necessário que se retire o sistema do equilíbrio estabelecido. Isto é feito através da aplicação de pulsos de radiofreqüência. Neste contexto, é interessante analisar o efeito da aplicação de um campo magnético oscilante linearmente polarizado perpendicular ao campo $\vec{B}_{0}$ dado por $\vec{B}_{1}(t)=2 B_{1} \cos (\Omega t) \hat{x}$. Este campo pode ser decomposto em duas componentes girantes com amplitude $B_{1}$, e que possuem freqüência $\Omega$ e $-\Omega$, tal como ilustrado na figura 1.5

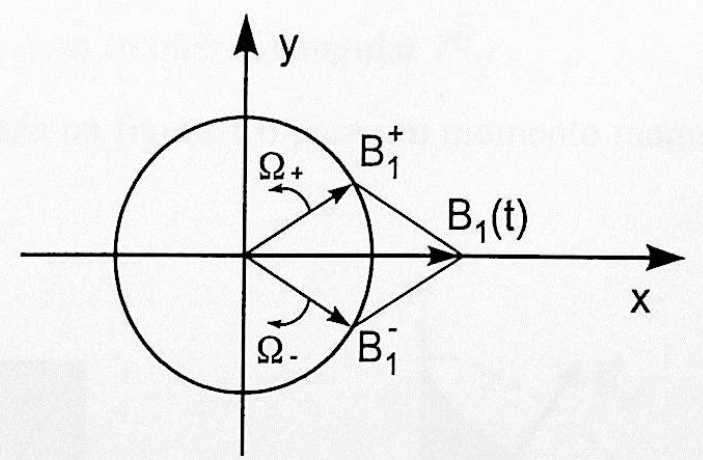

Figura 1.5 Decomposição do campo linearmente polarizado em duas componentes rotativas. 
Na figura (1.5) os campos $\vec{B}_{1}^{-}$e $\vec{B}_{1}^{+}$são dados por:

$$
\begin{aligned}
& \vec{B}_{1}^{+}=B_{1}(\hat{x} \cos (\Omega t)+\hat{y} \operatorname{sen}(\Omega t)) \\
& \vec{B}_{1}^{-}=B_{1}(\hat{x} \cos (\Omega t)-\hat{y} \operatorname{sen}(\Omega t))
\end{aligned}
$$

Se o campo oscilante estiver próximo da ressonância com o sistema de spins, isto é, se a freqüência do campo oscilante for aproximadamente igual à freqüência de Larmor ( $\Omega \cong \omega$ ) então o efeito da componente $\vec{B}_{1}^{+}$será muito pequeno e pode ser desprezado (SLICHTER, 1978), resultando que metade da energia do campo será desperdiçada. No entanto, essa é a forma de gerar este campo de RF na maioria dos espectrômetros, pela facilidade na implementação.

Assumiremos então que existe somente um campo $\vec{B}_{1}^{-}$, sem perda de generalidade. Quando o campo magnético estático esta na direção $\hat{z}$ e o campo de RF está girando no plano x-y, o campo magnético total é

$$
\vec{B}=B_{0} \vec{z}+B_{1}(\hat{x} \cos (\Omega t)-\hat{y} \operatorname{sen}(\Omega t))
$$

inserindo (1.20) em (1.16) temos:

$$
\vec{B}_{c f}=\left(\vec{B}_{0}+\frac{\vec{\Omega}}{\gamma}\right) \hat{z}^{\prime}+B_{1} \hat{x}^{\prime}
$$

Fisicamente, o momento $(\vec{\mu})$ comporta-se como se estivesse na presença de um campo magnético estático $\vec{B}_{c f}$. Assim, o momento $\vec{\mu}$ precessa em torno desse campo efetivo descrevendo um cone com freqüência angular $\gamma \vec{B}_{c f}$.

Esta situação é ilustrada na figura 1.6 para um momento magnético que em $\mathrm{t}=0$ está orientado na direção Z.

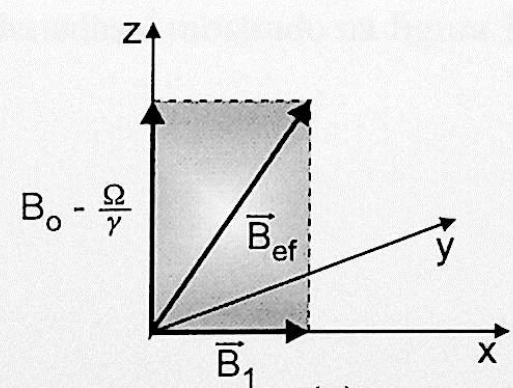

(a)

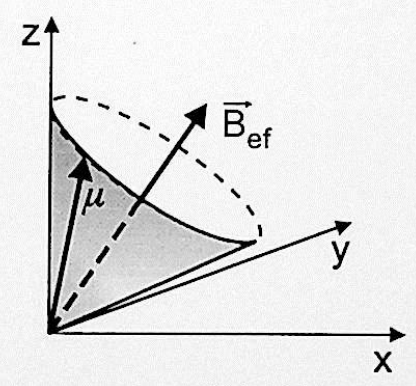

(b)

Figura 1.6 a) Campo efetivo, b) Movimento de $\vec{\mu}$ no sistema girante de coordenadas. 
Se a condição de ressonância for satisfeita, isto é se $\Omega=\gamma B_{0}$, o campo efetivo será então simplesmente $B_{1} \vec{x}^{\prime}$ e a freqüência angular $\gamma B_{1}$. O momento magnético, que é inicialmente paralelo ao campo estático, precessionará no plano $\mathrm{Y}-\mathrm{Z}$, ou seja, ele precessionará permanecendo sempre perpendicular a $\vec{B}_{1}$ por um curto período de tempo. Se a amplitude da radiofrequiência for constante e a mesma for aplicada durante um intervalo $t_{p}$ (um pulso de RF), então o momento magnético $\vec{\mu}$ irá girar de um ângulo $\alpha$ (ângulo de excitação) dado por :

$$
\alpha=\gamma B_{1} t_{p}
$$

Em forma geral os pulsos de radiofreqüência também possuem a amplitude dependente do tempo e o ângulo de excitação (HINSHAW, 1983) nestes casos é :

$$
\alpha=\gamma \int_{0}^{t_{1}} B(t) d t
$$

Escolhendo adequadamente o tempo de aplicação $t_{p}$ do campo $\vec{B}_{1}$ assim como a sua intensidade, o ângulo de precessão flipping pode ser de $\frac{\pi}{2}, \pi$ ou de qualquer valor que for necessário ao experimento. O pulso de $\alpha=\frac{\pi}{2}$ gira o momento ou a magnetização, da direção $\mathrm{Z}$ para a direção $\mathrm{Y}$, no plano transversal permitindo a observação da máxima componente transversal, enquanto que o pulso $\alpha=\pi$ é usado para inversão. Em seguida, cessado $\vec{B}_{1}$, a magnetização tende a retornar à posição de equilíbrio, apontando novamente na direção do campo magnético. O que pode ser observado de maneira geral na figura 1.7.

A evolução temporal do momento magnético no sistema do laboratório e no sistema girante de coordenadas é mostrado na figura 1.8 


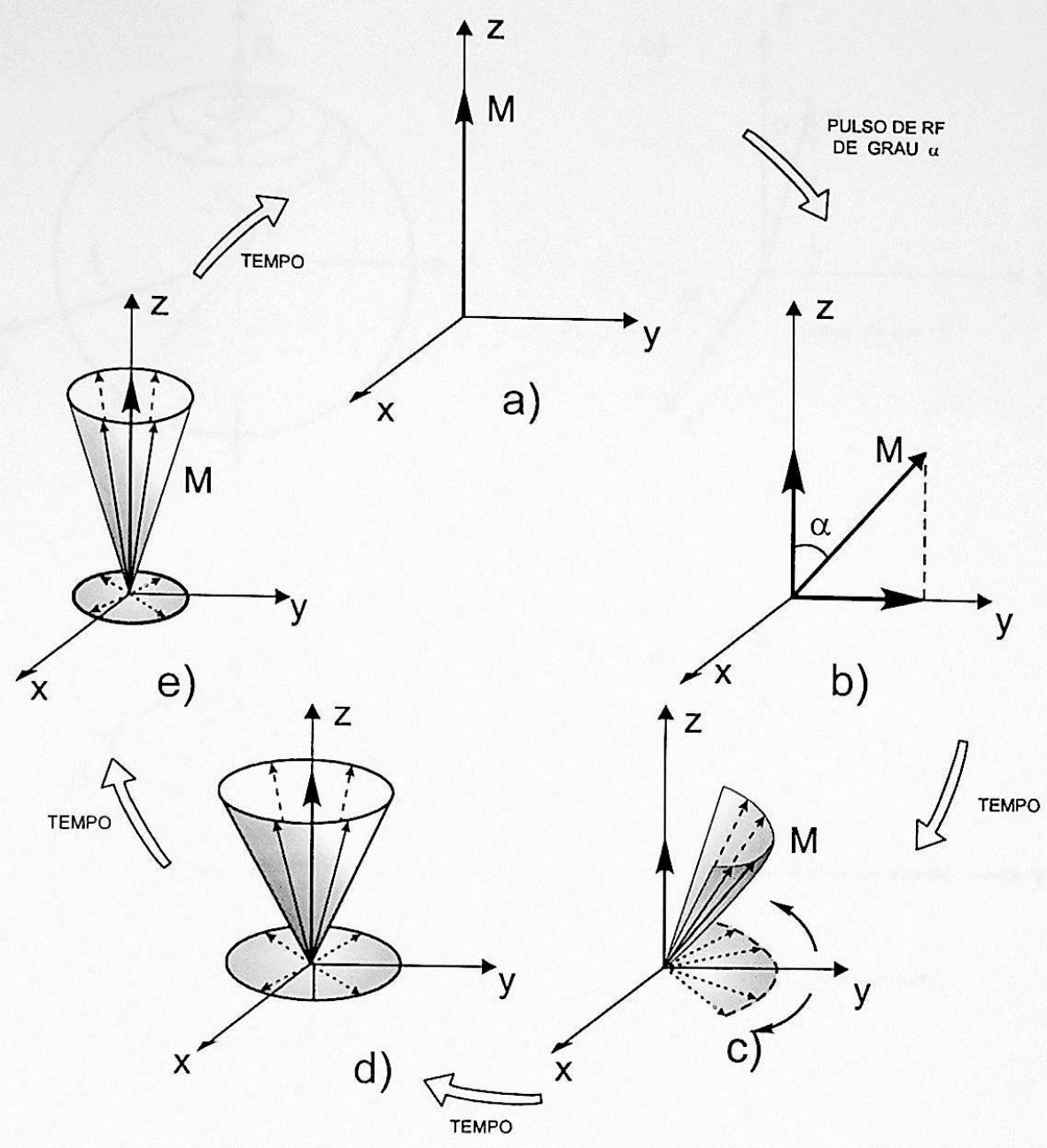

Figura 1.7 Retorno de $M$ ao equilíbrio após a aplicação de um pulso de grau $\alpha$. 

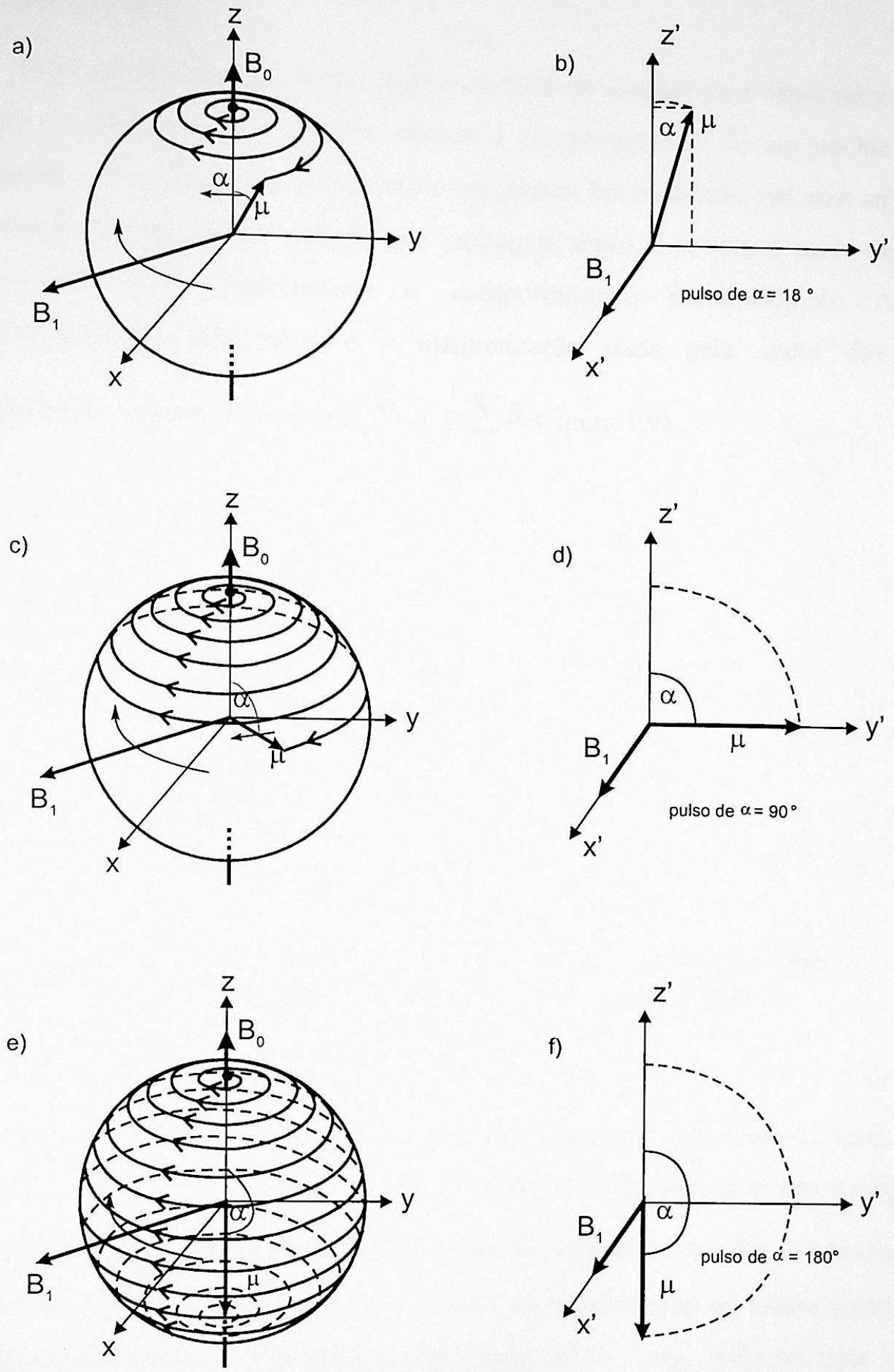

Figura 1.8 Evolução do momento magnético $\vec{\mu}$ sob a presença de pulsos de RF com ângulos de excitação de $\alpha=18^{\circ}$ (a, b), $\alpha=90^{\circ}$ (c, d), $\alpha=180^{\circ}$ (e, f), tanto no sistema do laboratório (esquerda) como no sistema girante de coordenadas (direita). 


\subsection{O sinal de RMN}

A aplicação de pulsos de RF sugere um método simples para observar a ressonância magnética. Entretanto, até agora estudamos o comportamento de um núcleo isolado na presença de campos magnéticos estáticos e oscilantes. Na realidade, em uma amostra temos uma coleção grande desses núcleos que interagem entre si e com o meio em que estão imersos, pelo que analisaremos o comportamento macroscópico. A grandeza macroscopicamente observável é a magnetização dada pela soma dos momentos magnéticos por volume de amostra: $\vec{M}_{0}=\frac{1}{V} \sum_{i} \vec{\mu}_{i}$ (figura 1.9)
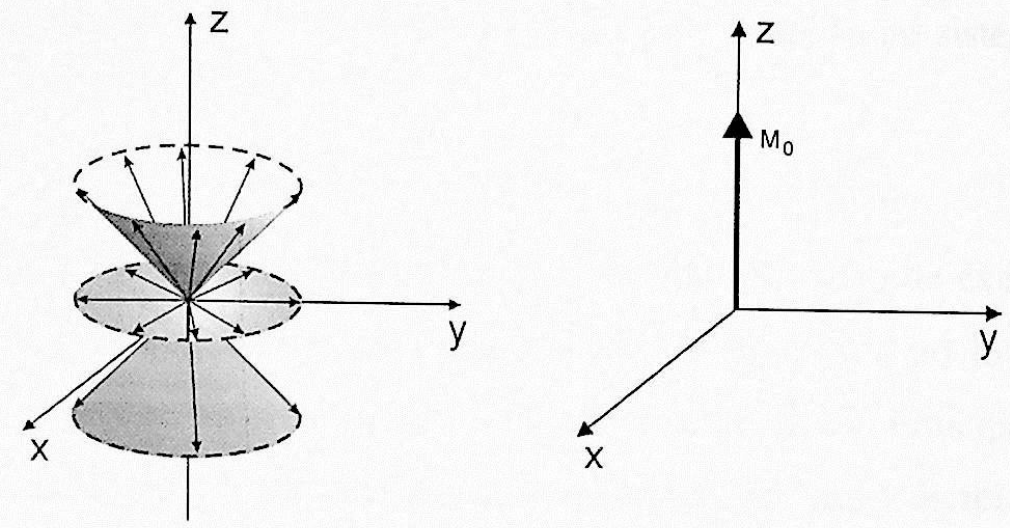

Figura 1.9 Magnetização total gerada pela soma dos momentos magnéticos dos núcleos presentes na amostra.

A deteç̧ão do sinal de RMN é feita geralmente colocando-se uma bobina de detecção com eixo perpendicular ao campo estático, conforme mostrado na figura 1.10a. Sendo assim, após a excitação dos spins parte da magnetização $\vec{M}_{0}$ é transferida para o plano transversal e no sistema de laboratório, irá precessionar no plano transversal com freqüência de Larmor. Conseqüentemente, pela lei de Lenz, induzirá uma corrente na bobina de recepção.

O sinal detectado desta forma, contém também informações valiosas sobre as características intrínsecas do sistema sendo denominado FID (Free Induction Decay). A figura 1.10b ilustra a dependência típica do FID com o tempo. Nessa figura, é interessante notar que o FID decai com o tempo. Este decaimento é caracterizado por um fenômeno denominado relaxação que será discutido a seguir. 

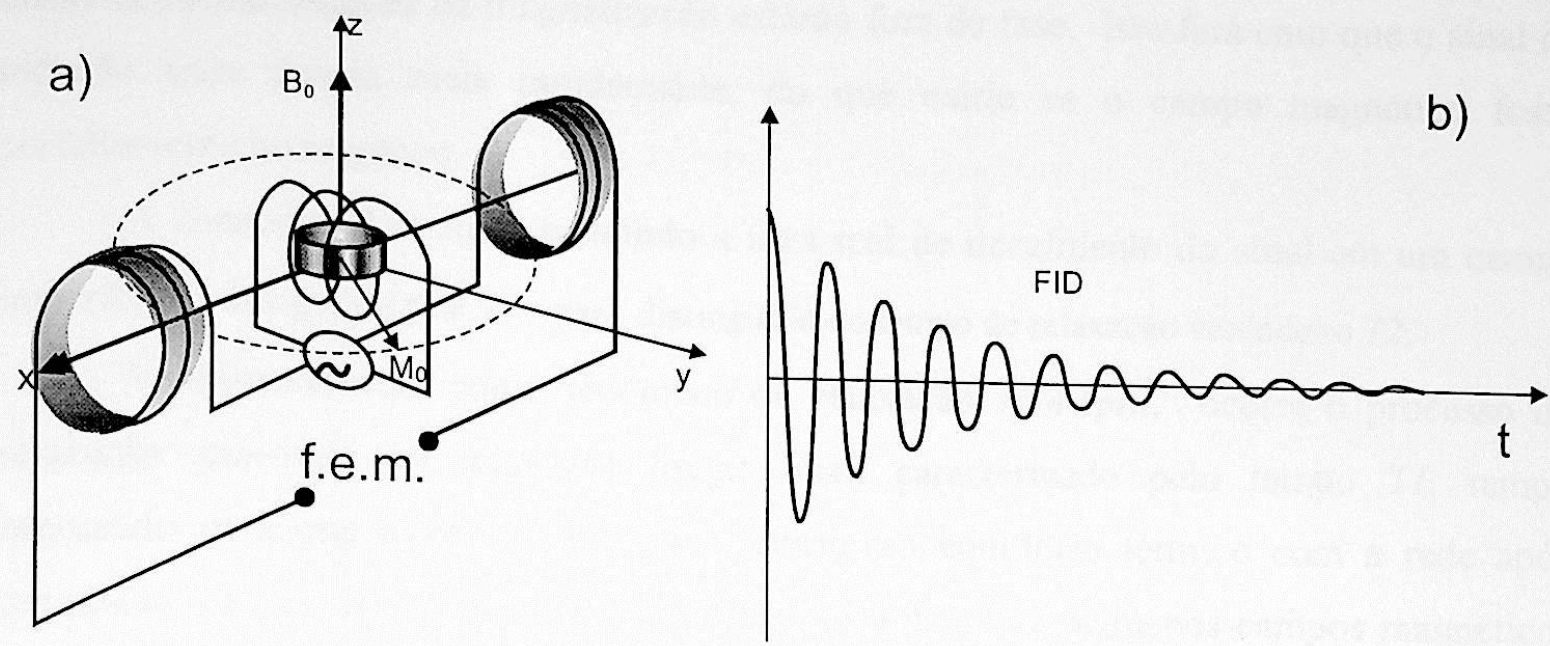

Figura 1.10 a) Esquema de configuração da bobina de recepção no sistema de laboratório. b) típico sinal de RMN captado pela bobina.

\subsection{Relaxação}

Como foi visto no ítem anterior, após o término do pulso de excitação, o vetor de magnetização do núcleo, retorna para sua posição de equilíbrio, ao longo do eixo Z. O retorno ao equilíbrio é caracterizado por dois tempos de relaxação principais, $T 1$ e $T 2$.

O tempo $T 2$, denominado tempo de relaxação spin-spin, ou tempo de relaxação transverso, descreve o decaimento da magnetização no plano X-Y. A duração de $T 2$ é diferente para sólidos e líquidos: em líquidos a duração de $T 2$ é da ordem de segundos, enquanto que em sólidos é da ordem de microsegundos.

O fenômeno de relaxação spin-spin influencia o tempo de vida natural do sinal de indução livre (FID). Quando o pulso de excitação termina, cada núcleo continua a sentir não somente o campo estático externo $\vec{B}_{0}$, mas também os campos locais vizinhos, associados com as distribuições dos núcleos vizinhos, e a não homogeneidade do campo $\vec{B}_{0}$. Como resultado disto os núcleos terão pequenas diferenças nas freqüências de precessão, provocando defasagem na indução livre.

Se o campo magnético estático fosse perfeitamente uniforme, T2 poderia ser determinado simplesmente pela medida da taxa de decaimento do sinal de indução livre (figura 1.10b).

Entretanto, mesmo os melhores ímãs apresentam pequenas imperfeições e, conseqüentemente, diferentes partes da amostra estarão submetidas a diferentes campos. Assim, a magnetização daquelas porções da amostra com campos magnéticos um pouco maiores, irão precessar mais rápido do que aquelas com um campo menor e portanto, as 
diferentes contribuições da magnetização estarão fora de fase. Isto fará com que o sinal de indução livre decaia mais rapidamente, do que cairia se o campo magnético fosse perfeitamente homogêneo.

A constante de tempo definindo a taxa real de decaimento do sinal em um campo imperfeito é designada por $T_{2}^{*}$, para distinguí-la do tempo de relaxação verdadeiro $T 2$.

Simultaneamente como fenômeno de relaxação spin-spin, ocorre o processo de relaxação spin-rede ou relaxação longitudinal, caracterizado pelo tempo $T 1$, tempo necessário para que o sistema de spins retorne ao equilíbrio térmico com a rede após terminado o pulso de RF. Este tipo de relaxação é devida a pequenos campos magnéticos oscilantes gerados pelos átomos vizinhos, que estão em movimento térmico. A componente transversal desses campos locais com freqüências perto da ressonância é responsável pela relaxação longitudinal.

O retorno de $\vec{M}$ ao equilíbrio traduz-se numa transferência de energia à rede. Esta transferência pode ser induzida diretamente pelos fônons que modulam a interação dipolar entre núcleos ou, no caso de metais, à parte flutuante da interação hiperfina com os elétrons de condução, ou por outros processos de acoplamento com a rede que se traduzem, ao nível do núcleo, por um campo flutuante onde a densidade espectral na freqüência nuclear não é nula e pode induzir transições. A taxa de relaxação medida (1/T1), é a soma de todas as contribuições.

Este processo de relaxação pode ser fraco (em sólidos rígidos), ou muito forte (em soluções ou sólidos que apresentem movimento molecular). Em sólidos, $T 1$ pode adquirir valores muito maiores que $T 2$, enquanto que em líquidos, aproxima-se de $T 2$. Na figura 1.11 ilustramos os processos de relaxação de $T 1$ e $T 2$, a saber:

a) $\mathrm{O}$ vetor de magnetização encontra-se em sua posição de equilíbrio, denotada como $\mathrm{M}_{0}$, sendo igual à magnetização longitudinal $\left(\mathrm{M}_{\mathrm{L}}\right)$;

b) Um pulso de RF de $\alpha=90^{\circ}$ (excitação), causa a inclinação do vetor $\vec{M}$, aparecendo no plano $\mathrm{X}-\mathrm{Y}$, onde a magnetização transversal $\left(\mathrm{M}_{\mathrm{T}}\right)$ é igual a $\mathrm{M}_{0}$. Mas para $\alpha$ qualquer aparecerá uma componente no plano X-Y;

c) As componentes da magnetização começam a precessar com diferentes taxas, devido à interação magnética dos núcleos com a inomogeneidade do campo e o campo local;

d) A componente da magnetização total, no plano X-Y diminui, e a amplitude do sinal de RMN, decai exponencialmente com uma constante de tempo $T_{2}^{*}$; 
e,f) Pode-se notar simultaneamente o aumento da componente longitudinal, de acordo com o retorno de $\mathrm{M}_{\mathrm{L}}$ ao equilíbrio (g), definindo $T$ 1.

A recuperação do equilíbrio térmico e o decaimento da magnetização transversal seguem leis exponenciais como também são mostrados na figura 1.11, com constante de tempo $T 2<T 1$. Isto acontece porque para que os spins entrem em equilibrio com a rede é necessário que estejam em equilíbrio entre si (ABRAGAM, 1994).
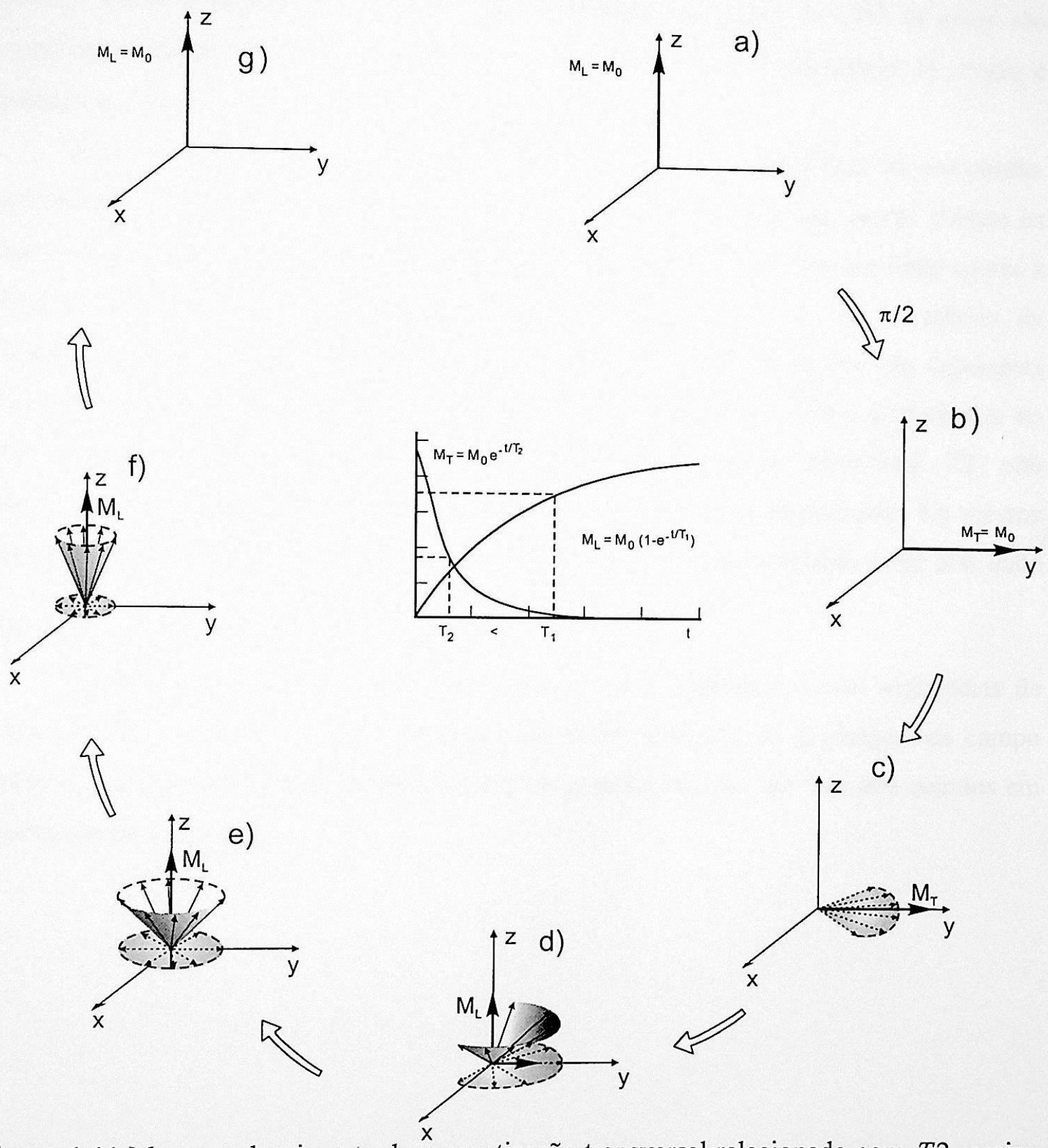

Figura 1.11 Mostra o decaimento da magnetização transversal relacionado com $T 2$, assim como a volta da magnetização longitudinal ao equilíbrio térmico $\mathrm{M}_{0}$ devido a relaxação $T 1$, aplicando um pulso de excitação de $90^{\circ}$. 


\subsection{Formação de um eco}

Os ecos de spin foram observados e interpretados primeiramente por HAHN em 1950, o que representou uma grande avanço nos experimentos de NMR, pois são bastante apropriados para realização dos experimentos de imagens.

Uma seqüência de pulsos típica capaz de originar um eco de spin consiste de um pulso de $90^{\circ}$, um intervalo $\tau$ e um pulso de $180^{\circ}$. O pulso de $90^{\circ}$ transfere a magnetização longitudinal para o plano transversal e durante o intervalo de tempo $\tau$ os spins se espalham devido à inomogeneidade de campo. Com a aplicação do pulso de $180^{\circ}$ os spins são invertidos no plano transversal e tendem a se refocalizar depois de um tempo $2 \tau$, como é ilustrado na figura 1.12.

Agora é interessante fazer algumas considerações sobre a amplitude do eco obtido. $\mathrm{Na}$ verdade, o eco possui uma amplitude diferente do FID inicial. Isto ocorre porque os efeitos da relaxação $T 2$ não são refocalizados e nunca se conseguirá um eco onde ocorra a refocalização total dos spins como foi ilustrado na figura 1.12. Já os efeitos da inomogeneidade de campo serão todos refocalizados e a amplitude do eco não dependerá dela. Isto é muito interessante pois a diferença entre a amplitude o FID e a amplitude do ECO estará relacionada diretamente com o tempo de relaxação transversal $T 2$, não havendo portanto influência da inomogeneidade do campo neste decaimento. Na mesma figura são ilustradas as amplitudes do FID e do ECO, bem como a relação entre elas dada pela expressão $e^{-\frac{2 \tau}{T 2}}$.

Existem outras formas de se gerar ecos de spin, utilizando outras seqüências de pulsos de RF e também há ecos obtidos a partir da aplicação de gradientes de campo magnético adequados. Estas outras maneiras de geração de ecos são bastante comuns em experimentos de imagens. 


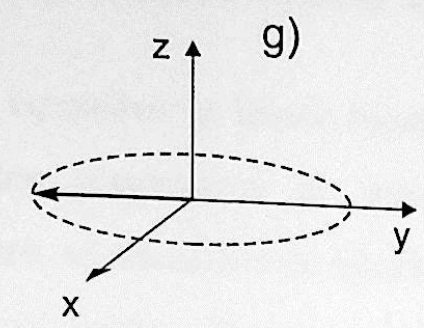

$\pi \quad t=2 \tau$
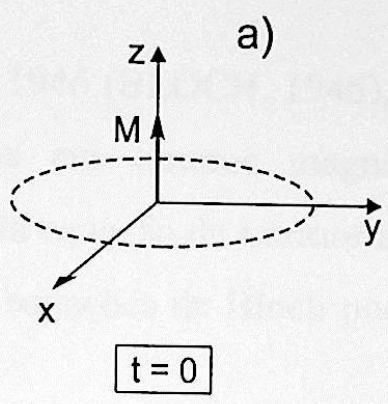

$\bigcup_{\gamma}^{\pi / 2}$
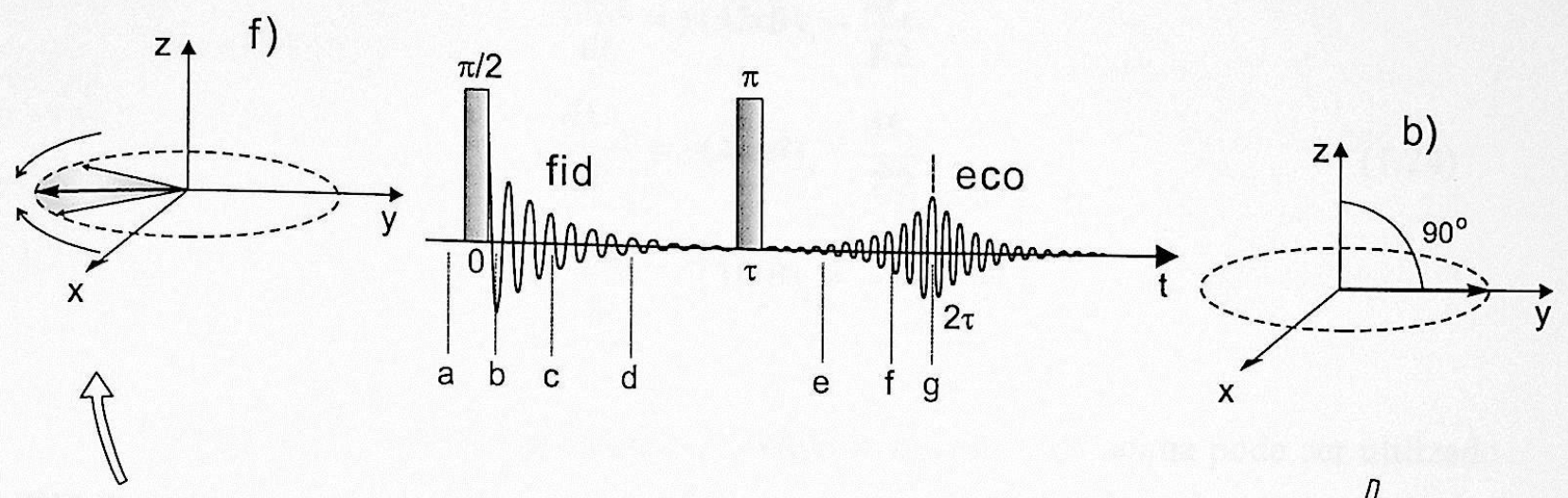

e)

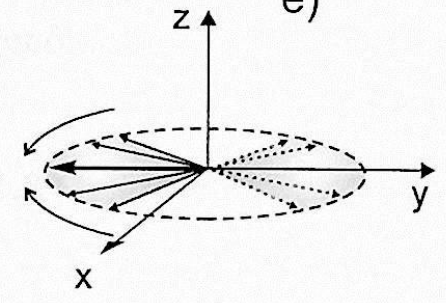

d)
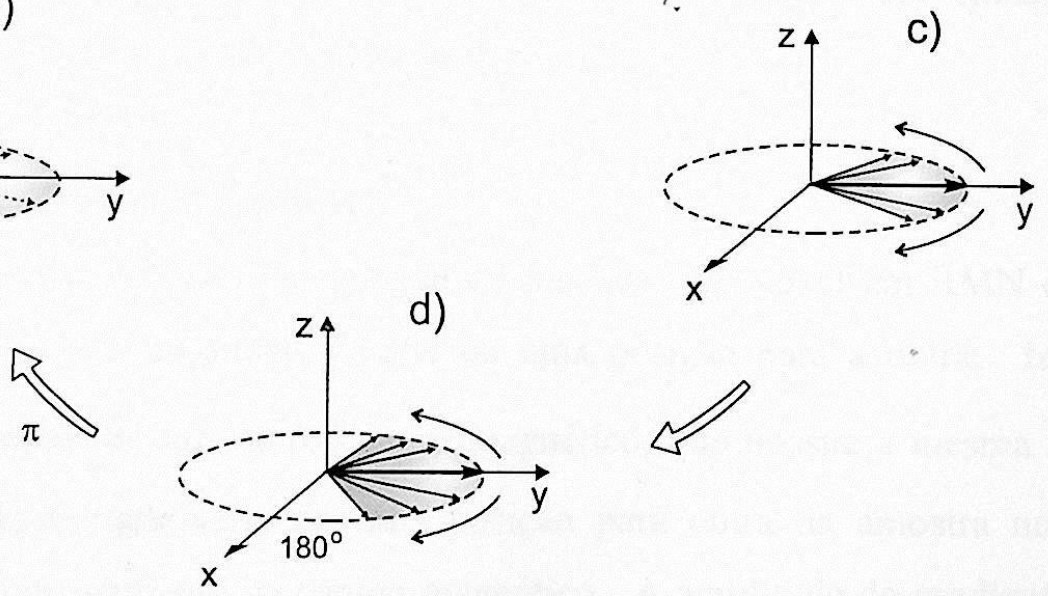

Figura 1.12 Evolução do sistema de spins no processo de formação de um eco. (a) A magnetização $M$ inicialmente em sua condição de equilíbrio ao longo do eixo $Z$, (b) o pulso de $90^{\circ}$ transfere os spins para o plano transversal, (c) por causa da ausência de uniformidade do campo magnético aplicado sobre a amostra, aparece uma distribuição de freqüências de precessão,(d) com a conseqüente perda de coerência do estado inicial. (e) Essa defasagem pode ser invertida pela aplicação de um pulso de $180^{\circ}$, que provoca uma rotação de $180^{\circ}$ dos spins dos núcleos individuais em torno do eixo $\mathrm{X}$, (f) um refasamento (g) e a regeneração de um sinal (refocalização) no instante $2 \tau$, chamado eco de spin . 


\subsection{Equações Fenomenológicas de Bloch.}

As equações de Bloch foram formuladas em 1946 (BLOCH, 1946), e descrevem as propriedades magnéticas de amostras de núcleos em campos magnéticos externos. Basicamente, as equações de Bloch são formadas pela equação de Larmor acrescentada dos efeitos de relaxação. No sistema do laboratório as equações de Bloch podem ser escritas como:

$$
\begin{aligned}
& \frac{d M_{x}}{d t}=\gamma(\vec{M} x \vec{B})_{x}-\frac{M_{x}}{T 2}, \\
& \frac{d M_{y}}{d t}=\gamma(\vec{M} x \vec{B})_{y}-\frac{M_{y}}{T 2}, \\
& \frac{d M_{z}}{d t}=\gamma(\vec{M} x \vec{B})_{z}+\frac{M_{0}-M_{z}}{T 1} .
\end{aligned}
$$

Colocando-se campos adequados, o conjunto de equações acima pode ser utilizado para prever com precisão o comportamento dos spins nos experimentos de imagem, Podese ainda acrescentar termos que caracterizam o fluxo e difusão dos spins, caso estes fenômenos estejam presentes na evolução do sistema.

\subsection{Gradientes de Campo Magnético.}

Para fazer a codificação da imagem ou localizar um voxel em RMN é necessário que o campo magnético na amostra varie de uma posição para a outra. Isto é obtido superpondo ao campo $\vec{B}_{0}$ um outro campo magnético, que possue a mesma direção $\vec{B}_{0}$, porém com amplitude que varia de uma posição para outra na amostra numa direção específica, isto é, um gradiente de campo magnético. A amplitude do gradiente de campo nas direções $\mathrm{x}, \mathrm{y}, \mathrm{z}$ é dada por:

$$
\begin{aligned}
& G_{x}=\frac{\partial B_{z}}{\partial x} \\
& G_{y}=\frac{\partial B_{z}}{\partial y} \\
& G_{z}=\frac{\partial B_{z}}{\partial z} .
\end{aligned}
$$


Para produzir os gradientes nas direções $x, y$ e $z$ utilizam-se bobinas especialmente construídas para este fim. Na direção $z$, geralmente o gradiente é gerado por um par de Maxwell, enquanto que nas direções x e y se utilizam bobinas tipo Golay (MORRIS, 1986). A geometria das bobinas com os vetores de $\vec{B}_{0}$ e seus respectivos gradientes, como também o perfil de campo estão ilustrados na figura 1.13. Para se gerar um gradiente em uma direção que não seja $\mathrm{x}, \mathrm{y}$ ou $\mathrm{z}$, os gradientes $G_{x}, G_{y}, G_{z}$ podem ser combinados de modo que o gradiente resultante tenha a direção desejada.

Basicamente, o efeito da aplicação de um gradiente $\vec{G}$ na evolução do sistema de spins sob a presença de um campo estático, é mudar a freqüência de precessão de Larmor ao longo da direção do mesmo. Isto é evidente, pois com a aplicação de gradientes os spins em posições diferentes na amostra experimentarão diferentes campos magnéticos e, conseqüentemente, possuirão diferentes freqüências de precessão. A freqüência de precessão de um spin numa posição definida pelo vetor posição $\vec{r}$ é dada por:

$$
\omega(r, t)=\gamma\left(B_{0}+\vec{G} \cdot \vec{r}\right)
$$

Na equação (1.26), é conveniente notar que a freqüência de precessão dos spins tem uma dependência linear com a posição dos mesmos, o que mostra a codificação da posição em frequiência. 
a)

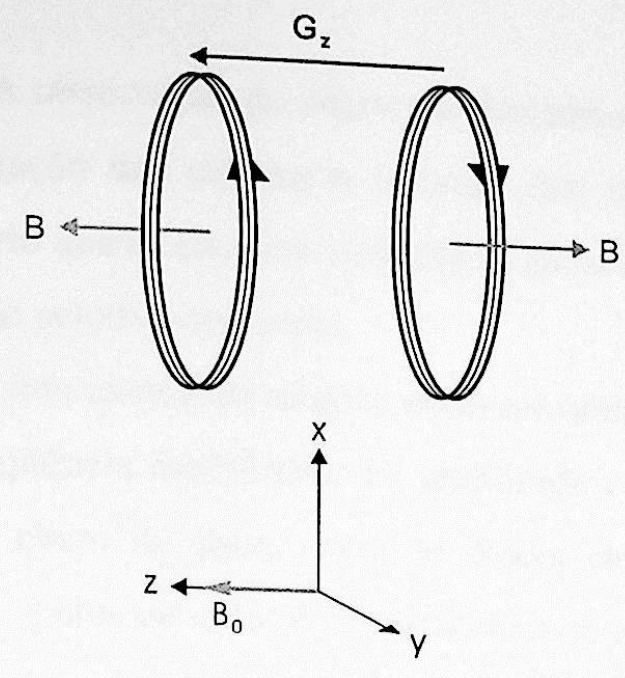

b)

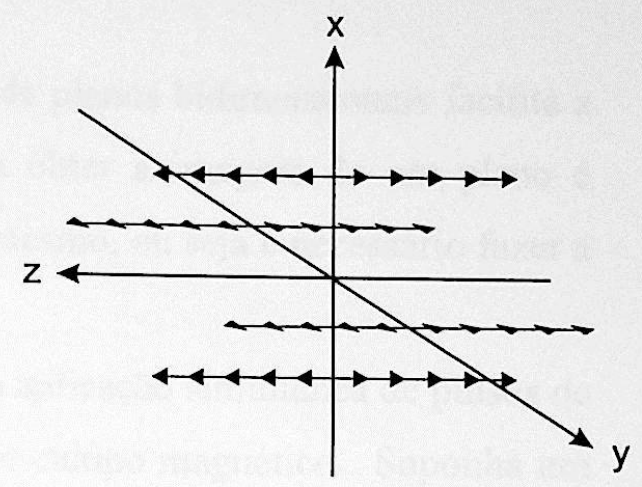

c)
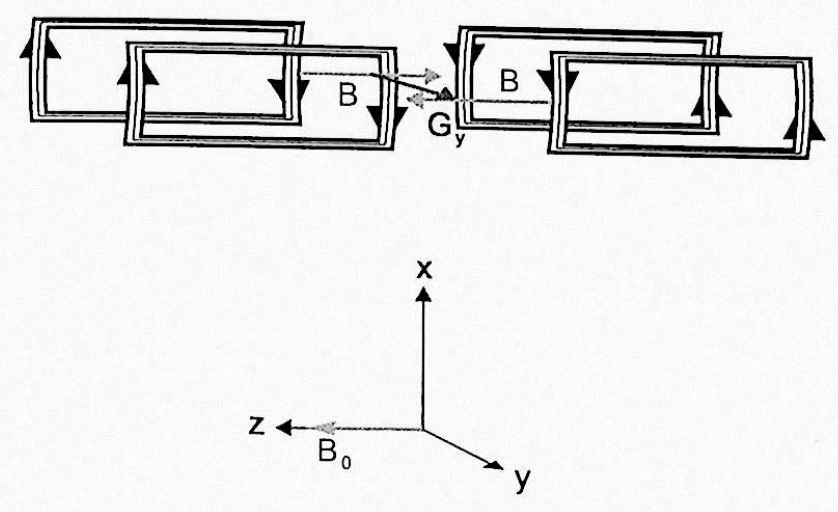

d)

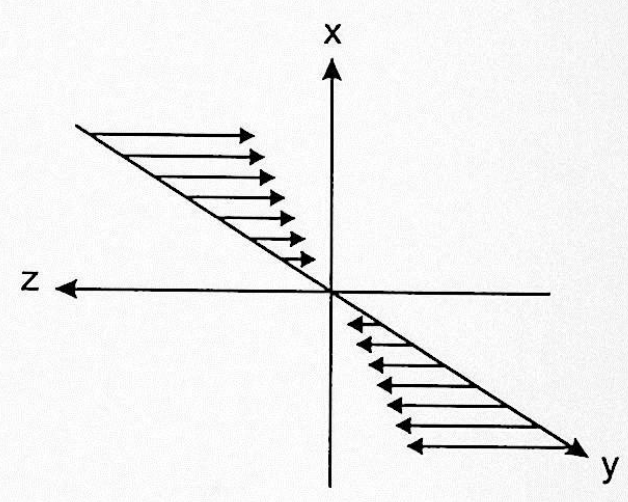

e)

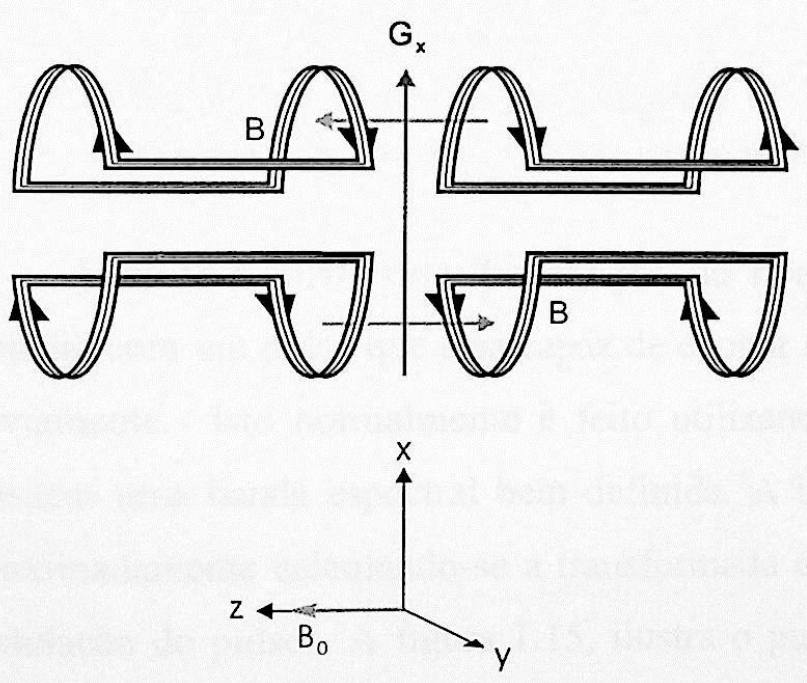

f)

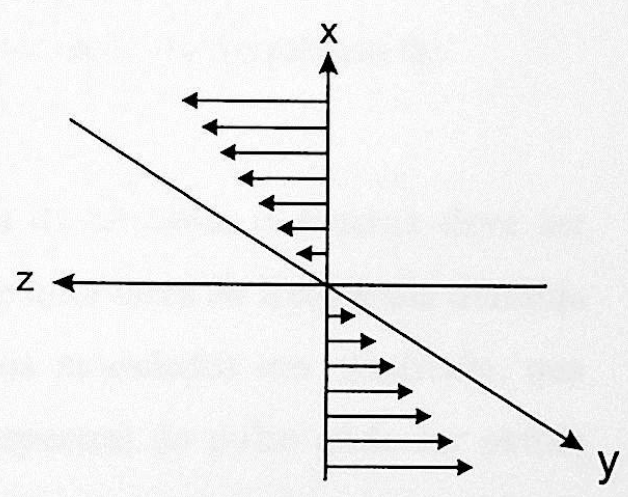

Figura 1.13 Bobinas utilizadas para gerar os gradientes $G_{x}, G_{y}, G_{z}$ e perfil do campo (HINSHAW, 1983), gerado pelas mesmas: a) par de Maxwell; c) e e) bobinas de Golay. 


\subsection{Seleção de Planos.}

A observação de objetos tridimensionais através de planos bidimensionais facilita a interpretação das estruturas internas dos mesmos. Para obter a imagem de um plano é necessário que se excitem somente os spins contidos no mesmo, ou seja é necessário fazer a excitação seletiva dos spins.

Uma excitação seletiva pode ser obtida através da aplicação simultânea de pulsos de radiofreqüência modulados em amplitude e gradientes de campo magnético. Suponha um cilindro cheio de água, onde se deseja excitar apenas os spins contidos numa fatia do mesmo. Antes de tudo, é necessário associar a cada posição da amostra ao longo do eixo z uma freqüência característica. Isto é feito com a aplicação de um gradiente, conforme ilustrado na figura 1.14 .
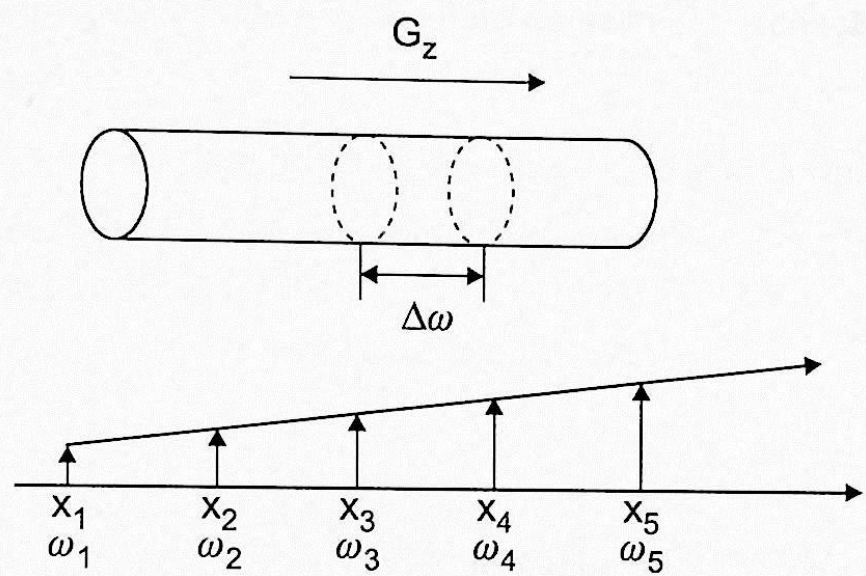

Figura 1.14 Aplicação do gradiente $G_{z}$ para associação da freqüência de precessão dos spins com sua posição na amostra.

Uma vez criada esta distribuição de freqüências da amostra, o sistema deve ser excitado com um pulso que seja capaz de excitar somente uma faixa de freqüência definida previamente. Isto normalmente é feito utilizando pulsos modulados em amplitude, que possuem uma banda espectral bem definida. A banda espectral do pulso pode ser obtida aproximadamente calculando-se a transformada de Fourier temporal da forma de onda da modulação do pulso. A figura 1.15, ilustra o pulso sinc de três lobos, que é comumente utilizado em experimentos de imagem, e a transformada de Fourier do mesmo mostrando sua banda espectral. Utilizando estes pulsos, somente os spins cujas freqüências estejam dentro da banda espectral serão excitados e, conseqüentemente consegue-se excitar somente um intervalo de freqüências, ou seja, uma fatia da amostra. Como pode ser 
visualizado na figura 1.14 , a direção do plano selecionado é perpendicular à direção de aplicação do gradiente.
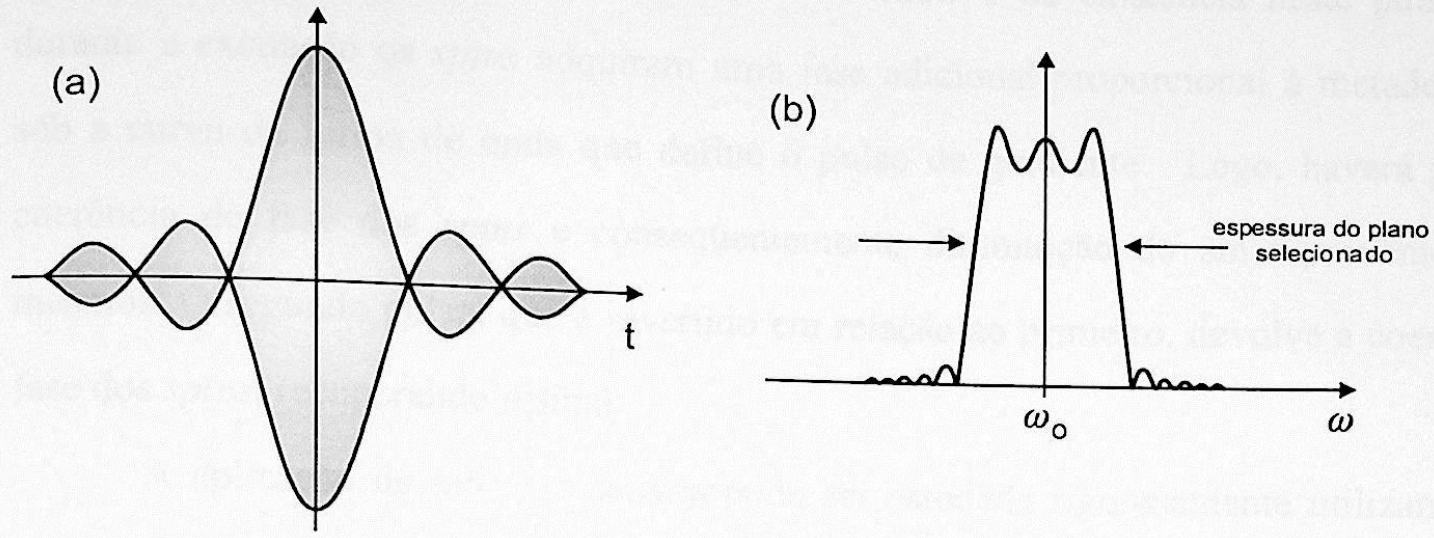

Figura 1.15 Pulso de excitação com modulação tipo sinc (a), e sua transformada de Fourier mostrando a banda de excitação do mesmo (b). A largura do plano selecionado é definida pela largura a meia altura do perfil de excitação.

Uma vez que o gradiente e o pulso de excitação estejam definidos, pode-se calcular a largura do plano da imagem a partir da seguinte expressão:

$$
\Delta z=\frac{\Delta \omega_{p}}{\gamma G_{z}}
$$

onde $\omega_{p}$ é a largura da banda de excitação de pulso de RF e $\Delta z$ é a largura do plano excitado.

O gradiente utilizado na seleção do plano, é aplicado simultaneamente com a excitação, sendo desligado depois que os spins já foram excitados, tratando-se portanto de um pulso de gradiente, comumente denominado gradiente de seleção. A figura 1.16 mostra o pulso de gradiente e o pulso de RF aplicados simultaneamente.

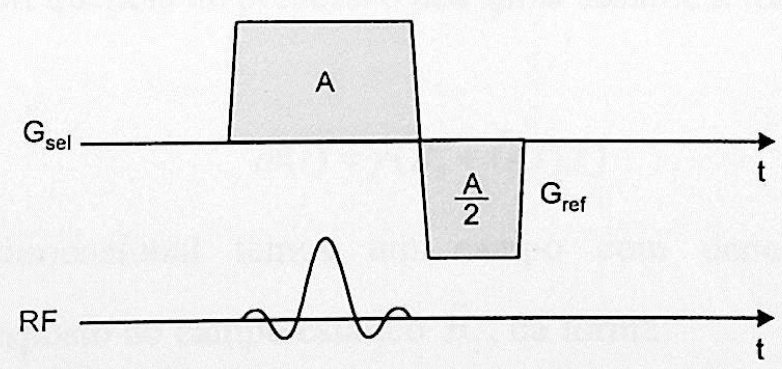

Y Figura 1.16 Gradiente de refocalização. A defasagem dos spins durante o pulso de RF é proporcional à metade da área $\mathrm{A}$ do gradiente de seleção. Essa defasagem é compensada na parte negativa do gradiente. 
Na figura 1.16, um segundo pulso de gradiente, cuja área é a metade da curva do primeiro é aplicado logo após a excitação. O motivo da existência deste pulso é que durante a excitação os spins adquirem uma fase adicional proporcional à metade da área sob a curva da forma de onda que define o pulso de gradiente. Logo, haverá perda de coerência de fase dos spins e conseqüentemente diminuição do sinal proveniente dos mesmos. O segundo pulso, que é invertido em relação ao primeiro, devolve a coerência de fase dos spins, recuperando o sinal.

A aplicação de pulsos seletivos pode ser estudada rigorosamente utilizando-se as equações de Bloch. Maiores detalhes sobre a seleção de planos em imagens podem ser encontrados na referência (BONAGAMBA, 1986).

\subsection{Codificação de freqüência}

Os sinais de RMN registrados são, de fato uma medida de relaxação de um sistema de spins nucleares, e as diferentes intensidades nas imagens (bidimensionais) reconstruídas a partir deles refletem a distribuição espacial da densidade $\rho_{n}(r)$.

Essa codificação é conseguida colocando-se o objeto em um campo $\vec{B}$, cuja magnitude depende da posição, de modo que os spins em diferentes posições da amostra precessem em freqüências diferentes. A dependência espacial do campo $\vec{B}$ é introduzida superpondo-se ao campo $\vec{B}_{0}$ um campo $\vec{G}(r, t) \cdot \vec{r}$ possuindo um gradiente $\vec{G}(r, t)$, que faz com que o campo $\vec{B}$ durante a leitura do sinal seja função da posição:

$$
B=B_{0}+\vec{G}(r, t) \cdot \vec{r} .
$$

Conseqüentemente, a freqüência de precessão dos spins assume a forma:

$$
\omega(t)=\gamma\left(B_{0}+\vec{G}(t) \cdot \vec{r}\right) .
$$

No caso unidimensional temos um campo com dependência linear em $\mathbf{z}$ ( $G_{x}=\frac{d B}{d x}=c t e$.) superposto ao campo estático $\vec{B}_{0}$, da forma:

$$
B(x)=B_{0}+G_{x} \cdot x ; \omega(x)=\gamma\left(B_{0}+G_{x} \cdot x\right)
$$


Se agora colocamos na presença desse campo três tubos pequenos preenchidos com diferentes quantidades de água, nas posições $\mathrm{x}_{1}, \mathrm{x}_{2}$ e $\mathrm{x}_{3}$, ocorrerá que cada tubo percebe um campo magnético diferente $B\left(x_{1}\right), B\left(x_{2}\right)$ e $B\left(x_{3}\right)$.

Ao serem excitados com um pulso de RF de $90^{\circ}$, cada tubo gerará um sinal de RMN com freqüência característica:

$$
\omega_{1}=\gamma B\left(x_{1}\right) ; \omega_{2}=\gamma B\left(x_{2}\right) ; \omega_{3}=\gamma B\left(x_{3}\right)
$$

O sinal detectado $S(t)$ será resultante da composição da contribuição de cada freqüência afetada pela relaxação transversal,

$$
S(t)=\left[A_{1} \cos \left(\omega_{1} t\right)+A_{2} \cos \left(\omega_{2} t\right)+A_{3} \cos \left(\omega_{3} t\right)\right] e^{-\frac{t}{T_{2}}} .
$$

Mediante a transformada de Fourier unidimensional do sinal $S(t)$, obtemos uma função que é proporcional a $M(x)$, fornecendo as amplitudes $A_{i}$ nas freqüências $\omega_{i}$, mostrada na figura 1.17. O espectro de frequiências de $S(t)$ dará a informação de quanto material (água) existe nas posições $x_{i}$ determinadas pelas freqüências $\omega_{i}$.

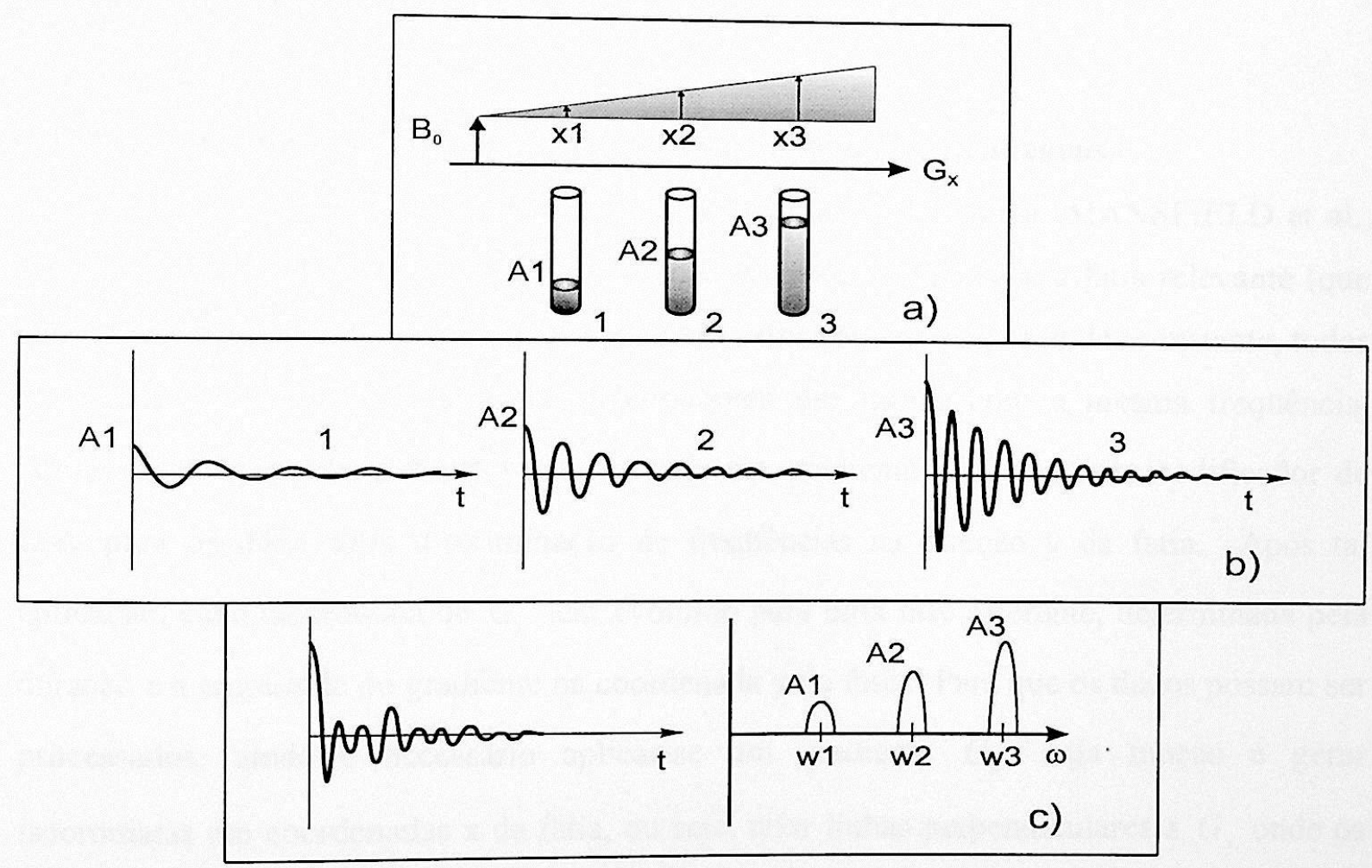

Figura 1.17 Três tubos contendo colunas diferentes de amostra (água), sob a ação de um gradiente $G_{x}$ superposto ao campo $B_{0}$ (a), e os prótons contribuem com diferentes componentes de freqüência (b). A transformada de Fourier do sinal observado (composto) fornece informação sobre a posição e a quantidade de prótons existentes em cada um (c). 


\subsection{Codificação de fase}

Considerando a seleção de planos (que limitam a região de interesse) assim como a codificação em freqüência (que dá uma projeção unidimensional do plano), precisa-se de um terceiro gradiente para obter uma imagem bidimensional, chamado gradiente de codificação de fase.

E conveniente para a codificação na segunda dimensão adicionar informação de fase ao sinal antes que esta seja codificada em freqüência. Se aplicamos o gradiente de fase na direção y com duração $t_{y}$ a fase acumulada será dada por :

$$
\varphi(y)=\gamma\left(B_{0}+G_{y} y\right) \cdot t_{y}
$$

A discriminação de fase é normalmente executada repetindo-se a aquisição com diferentes valores para o gradiente de codificação de fase, portanto o sinal é observado múltiplas vezes. Dessa maneira, obtemos um conjunto de sinais codificados em freqüência durante a aquisição, sendo que cada uma das aquisições, representa um passo de codificação de fase.

\subsection{Transformada de Fourier Bidimensional - Formação da imagens}

No método da transformada de Fourier bidimensional direta (MANSFIELD et al., 1982 e CROOKS, 1980), através da excitação seletiva, seleciona-se a fatia relevante (que suporemos pertencer ao plano x-y) e cria-se uma situação em que, num dado instante, todos os núcleos atômicos nela situados precessionam em fase e com a mesma freqüência. Aplica-se em seguida, por um breve instante um gradiente $G_{y}$, chamado codificador de fase, para produzir uma discriminação de freqüências na direção y da fatia. Após tal aplicação, cada isocromata de $G_{y}$, terá evoluído para uma fase diferente, determinada pela duração e a amplitude do gradiente na coordenada y da fatia. Para que os dados possam ser processados, ainda é necessário aplicar-se um gradiente $G_{x}$, cuja função é gerar isocromatas em coordenadas $\mathbf{x}$ da fatia, ou seja, criar linhas perpendiculares a $G_{x}$ onde os núcleos possuem uma mesma freqüência de ressonância. No entanto, a ação prévia de $G_{y}$ já produziu uma codificação de fase ao longo desses isocromatas, como mostra a figura 1.18. Como conseqüência, haverá contribuições de diferentes isocromatas na composição do sinal de RM, cujas amplitudes e fase ficam dependentes da codificação precedente. Para 
conseguir dados suficientes à reconstrução de uma imagem, todo esse processo precisa ser repetido, mudando-se de cada vez a codificação de fase, isto é, aumentando-se a intensidade do gradiente $G_{y}$.
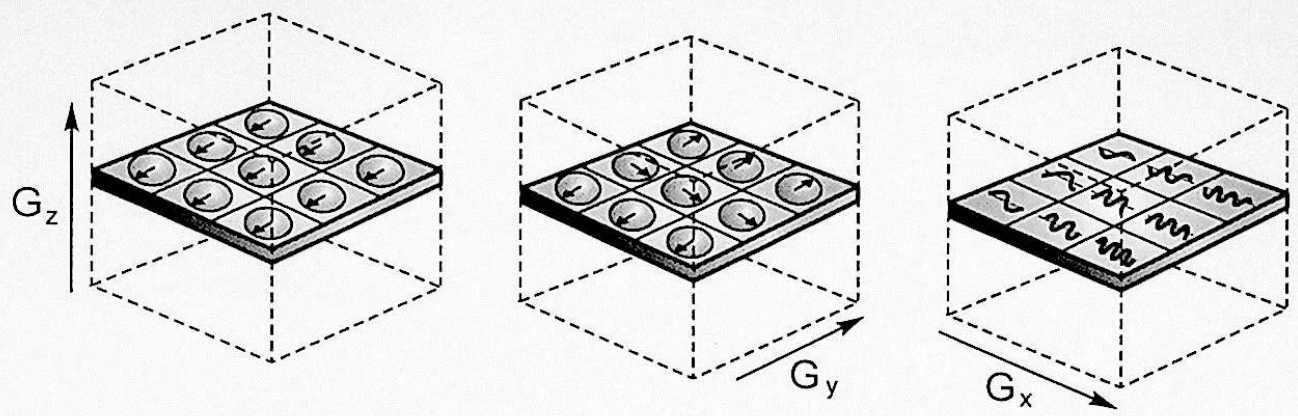

Figura 1.18 Aplicação dos gradientes de campo $G_{z}$, para seleção do plano e $\mathrm{G}_{y}$ e $\mathrm{G}_{x}$ para a codificação de fase e freqüência respectivamente

A técnica mais convencional utilizada na obtenção de imagens bidimensionais é a técnica de eco de spin. Esta seqüência consiste de dois pulsos de RF seletivos $\left(90^{\circ}\right.$ e $180^{\circ}$, respectivamente) e de três formas de ondas para os gradientes (gradiente de leitura, seleção e codificação de fase), tal como ilustrado pela figura 1.19 .

O tempo entre excitação e o máximo do eco é denominado tempo de eco (TE) e o tempo entre aquisições consecutivas é denominado tempo de repetição (TR).

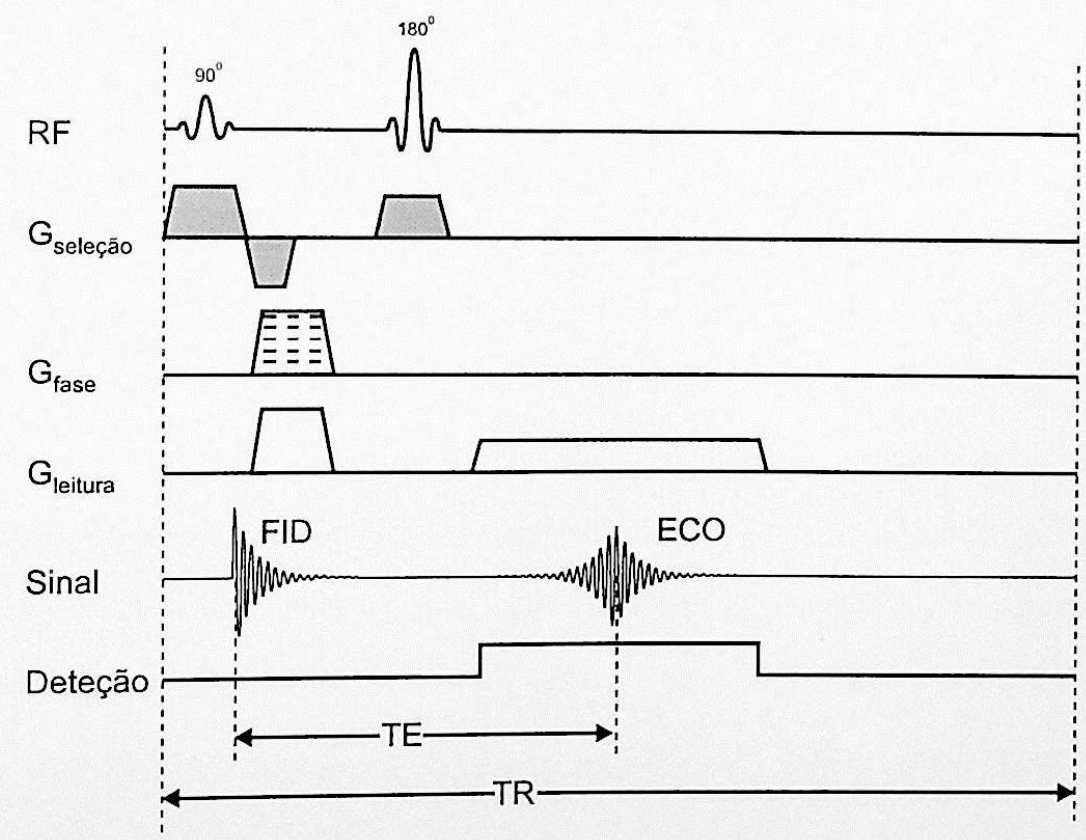

Figura 1.19 Seqüência de pulsos para obtenção de imagens bidimensionais pela técnica de eco de spin. 
Existem várias outras técnicas de aquisição de imagens (MANSFIELD et al., 1982), cujas características das imagens obtidas podem, além de proporcionar a visualização da anatomia, trazer informações complementares importantes para o diagnóstico clínico. 


\section{Capítulo II}

\section{ASPECTOS RELEVANTES DA ESPECTROSCOPIA DE RMN}

\subsection{Efeitos que alteram a freqüência de ressonância}

Os principais efeitos que os núcleos experimentam por interação com sua vizinhança, os quais são responsáveis pela estrutura final do espectro obtido são: o deslocamento químico (chemical shift), acoplamento spin-spin, acoplamento dipolar magnético e iteração quadrupolar elétrica.

$\mathrm{Na}$ espectroscopia in vivo os efeitos que têm mais importância são os dois primeiros, pois o acoplamento dipolar resultante da interação entre dois dipolos magnéticos idênticos num líquidos seu efeito é atenuado pelo movimento browniano isotrópico. A interação quadrupolar elétrica, que surge quando se estuda núcleos com spins I $>1$, os quais possuem uma distribuição assimétrica de cargas elétricas e interagem com os gradientes de campo elétrico presentes internamente na amostra, não possui grande importância na espectroscopia, devido a que na maioria dos casos são usados núcleos com spin 1/2, também pelo fato de que o movimento browniano promedia a interação quadrupolar.

\subsubsection{Deslocamento químico (chemical shift)}

A condição de ressonância dada na equação (1.11) é válida estritamente para núcleos isolados no espaço livre. No entanto, na realidade, os núcleos estão localizados na matéria como parte das moléculas e são rodeados por nuvens eletrônicas, por tanto, há varias interações entre os núcleos e sua vizinhança, uma delas causará variações locais na freqüência de spins localizados em diferentes moléculas, causadas pelas interações destas nuvens eletrônicas com o campo magnético externo aplicado, onde este campo magnético induz uma circulação adicional dos elétrons nas nuvens eletrônicas, as quais geram, nos diferentes sítios dos núcleos atômicos, campos magnéticos locais secundários, $\vec{B}_{\text {local }}$, que são diretamente proporcionais ao campo magnético externo aplicado, $\vec{B}_{0}$, e portanto o campo magnético resultante, $\vec{B}_{\text {resul }}$, visto pelo núcleo atômico, será: 


$$
\vec{B}_{\text {resul }}=\vec{B}_{0}+\vec{B}_{\text {local }}, \vec{B}_{\text {resul }}=\vec{B}_{0}-\sigma \vec{B}_{0}, \quad \vec{B}_{\text {resul }}=(1-\sigma) \vec{B}_{0}
$$

onde $\sigma$ é uma constante de blindagem magnética, de caráter tensorial, que depende do entorno químico do núcleo, isto é, da configuração eletrônica que rodeia o núcleo.

A nova freqüência de ressonância de um núcleo atômico será dada por:

$$
\omega_{e f}=(1-\sigma) \gamma B_{0}
$$

A ordem de grandeza do deslocamento químico é de $10^{-6}$ ou partes por milhão (ppm) (PURCELL et al., 1946). Podemos expressar o hamiltoniano de deslocamento químico pela seguinte expressão:

$$
\text { \% } t=\vec{I} \cdot \overrightarrow{\vec{\sigma}} \cdot \vec{B}_{0}
$$

onde $\vec{I}$ é o momento angular de spin do núcleo, $\vec{\sigma}$ é o tensor deslocamento químico.

Para determinar o deslocamento de freqüência de ressonância para os núcleos atômicos de mesma espécie, presentes em diferentes grupos químicos, escolhe-se em cada grupo destes a freqüência de ressonância de referência $v_{\text {ref }}$. No caso de ${ }^{1} \mathrm{H} \mathrm{e}{ }^{13} \mathrm{C}$ a substância padrão utilizada como referencia é o tetrametilsilano $\mathrm{Si}\left(\mathrm{CH}_{3}\right)_{4}$ (TMS). Para o núcleo de ${ }^{31} \mathrm{P}$ é o ácido fosfórico $\left(\mathrm{H}_{3} \mathrm{PO}_{4}\right)$. A forma mais comum de expressar o deslocamento químico é:

$$
\delta(p p m)=\frac{\left(v_{i}-v_{r e f}\right)}{v_{r e f}} \times 10^{\circ}
$$

onde $v_{i}$ é a freqüência do núcleo em analise

No caso de espectroscopia in vivo são usadas referências internas comumente encontradas nos tecidos biológicos, como a água para espectroscopia de prótons com um deslocamento químico de 4,7 ppm, fosfocreatina para o caso de ${ }^{31} \mathrm{P}$ com $0 \mathrm{ppm}$, entre outros.

\subsubsection{Acoplamento spin-spin.}

Denominado também acoplamento $J$, resultado de um efeito quântico entre os spins de dois núcleos numa molécula, transmitido por meio dos elétrons da ligação química, formando uma estrutura fina presente no espectro. Para um melhor entendimento analisaremos o espectro do ${ }^{1} \mathrm{H}$ no etanol. Como resultado do deslocamento químico, 
observamos 3 linhas correspondentes aos grupos $\mathrm{OH}, \mathrm{CH}_{2}$ e $\mathrm{CH}_{3}$, com intensidades na proporção 1:2:3 respectivamente mostradas na figura 2.1. Observamos assim mesmo que duas de suas linhas desdobram-se em outras, em multipletos, resultado da iteração nuclear spin - spin. O próton é uma partícula de spin $1 / 2$, e denominamos $\alpha$ o estado para $\mathrm{m}=1 / 2$ e $\beta$ a $m=-1 / 2$.

$\mathrm{O}$ grupo $\mathrm{CH}_{2}$ apresenta 4 linhas devido ao acoplamento $\mathrm{J}$ entre os prótons deste grupo com os do grupo $\mathrm{CH}_{3}$. Os núcleos do grupo $\mathrm{CH}_{3}$ agem como se constituíssem apenas um núcleo de spin $3 / 2$ cujas orientações possíveis da componente $z$ do momento magnético são: $3 / 2,1 / 2,-1 / 2$ e $-3 / 2$ como é mostrado na tabela 2.1 . Assim, os núcleos de prótons do grupo $\mathrm{CH}_{3}$, produzem 4 componentes de campo magnético adicionais sobre cada spin do grupo $\mathrm{CH}_{2}$, induzindo a aparecimento das 4 linhas. $\mathrm{O} \mathrm{CH}_{3}$ apresenta 3 linhas devido ao acoplamento $\mathrm{J}$ entre os prótons deste grupo com os do grupo $\mathrm{CH}_{2}$. Os núcleos do grupo $\mathrm{CH}_{2}$ agem com spin 1 cujas orientações são: $1,0,-1$, e o que justifica as 3 linhas observadas. Finalmente, o $\mathrm{OH}$ não apresenta desdobramento ou acoplamento $\mathrm{J}$, devido à troca química muito rápida.

\begin{tabular}{|c|c|c|c|c|c|}
\hline$\sum \mathrm{m}$ & Grupo- $\mathrm{CH}_{2}$ & Degenerescência & $\sum \mathrm{m}$ & Grupo- $\mathrm{CH}_{3}$ & Degenerescência \\
\hline+1 & $\alpha \alpha$ & 1 & $3 / 2$ & $\alpha \alpha \alpha$ & 1 \\
\hline+0 & $\alpha \beta, \alpha \beta$ & 2 & $1 / 2$ & $\alpha \alpha \beta, \alpha \beta \alpha, \beta \alpha \alpha$ & 3 \\
\hline-1 & $\beta \beta$ & 1 & $-1 / 2$ & $\beta \beta \alpha, \beta \alpha \beta, \alpha \beta \beta$ & 3 \\
\hline & & & $3 / 2$ & $\beta \beta \beta$ & 1 \\
\hline
\end{tabular}

Tabela 2.1 Combinações possíveis da orientação do spin para o os grupos $\mathrm{CH}_{2}$ e $\mathrm{CH}_{3}$.

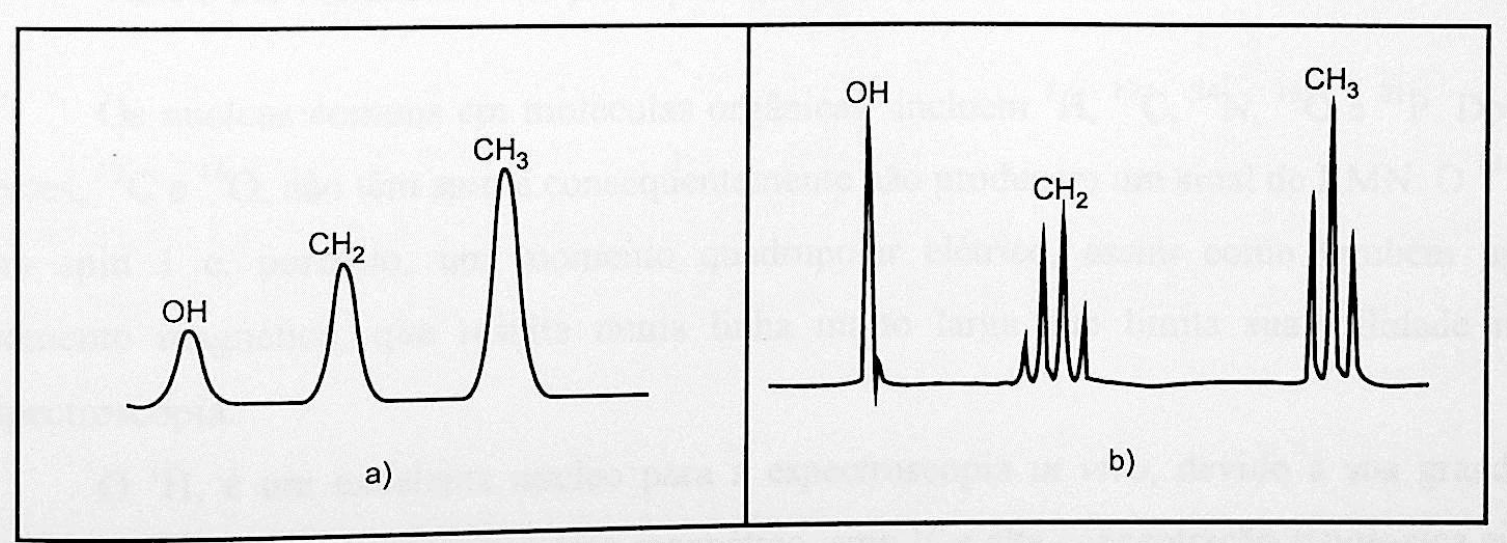

Figura 2.1 (a) Espectro de próton do etanol para baixa resolução, (b) e alta resolução mostrando os multipletos correspondentes ( CHANG, 1997). 
O acoplamento spin-spin, que é realizado pelas nuvens eletrônicas, pode ser expresso através da seguinte hamiltoniana:

$$
\mathscr{\varrho}=\vec{I} \cdot \overrightarrow{\vec{J}} \cdot \vec{S}
$$

onde $\overrightarrow{\vec{J}}$ é o tensor acoplamento entre os spins $\vec{S}$ e $\vec{I}$.

\subsection{Núcleos importantes na espectroscopia in vivo}

Dois fatores necessitam ser considerados quando escolhemos os núcleos para estudos mediante espectroscopia in vivo; primeiramente as propriedades magnéticas dos núcleos (Tabela 2.2) e em seguida a bioquímica requerida para ser estudada. Devemos ter presente, ademais, que só nos núcleos com spin diferente de zero, será possível realizar experimentos de ressonância magnética.

\begin{tabular}{|c|c|c|c|c|c|}
\hline Núcleo & Spin & $\begin{array}{c}\text { Sensibilidade } \\
\text { relativa }\end{array}$ & $\begin{array}{c}\text { Sensibilidade } \\
\text { absoluta }\end{array}$ & $\begin{array}{c}\text { Abundancia } \\
\text { natural(\%) }\end{array}$ & $\begin{array}{c}\text { Freqüência (MHz) } \\
\mathrm{B}_{0}=1 \text { Tesla }\end{array}$ \\
\hline${ }^{1} \mathrm{H}$ & $1 / 2$ & 1,00 & 1,00 & 99,98 & 42,57 \\
\hline${ }^{13} \mathrm{C}$ & $1 / 2$ & $1,59 \times 10^{-2}$ & $1,76 \times 10^{-4}$ & 1,11 & 10,71 \\
\hline${ }^{14} \mathrm{~N}$ & 1 & $1,01 \times 10^{-3}$ & $1,01 \times 10^{-3}$ & 99,63 & 3,08 \\
\hline${ }^{15} \mathrm{~N}$ & $1 / 2$ & $1,03 \times 10^{-3}$ & $3,85 \times 10^{-6}$ & 0,37 & 4,31 \\
\hline${ }^{17} \mathrm{O}$ & $5 / 2$ & $2,92 \times 10^{-2}$ & $1,08 \times 10^{-5}$ & 0,04 & 5,77 \\
\hline${ }^{19} \mathrm{~F}$ & $1 / 2$ & 0,83 & 0,83 & 100 & 40,05 \\
\hline${ }^{23} \mathrm{Na}$ & $3 / 2$ & $9,25 \times 10^{-2}$ & $9,25 \times 10^{-2}$ & 100 & 11,26 \\
\hline${ }^{31} \mathrm{P}$ & $1 / 2$ & $6,63 \times 10^{-2}$ & $6,63 \times 10^{-2}$ & 100 & 17,23 \\
\hline
\end{tabular}

Tabela 2.2 Parâmetros dos principais núcleos estudados em RMN

Os núcleos comuns em moléculas orgânicas incluem ${ }^{1} \mathrm{H},{ }^{12} \mathrm{C},{ }^{14} \mathrm{~N},{ }^{16} \mathrm{O}$ e ${ }^{31} \mathrm{P}$. Dois destes, ${ }^{12} \mathrm{C}$ e ${ }^{16} \mathrm{O}$, não têm spin e conseqüentemente não produzem um sinal de $\mathrm{RMN} . \mathrm{O}{ }^{14} \mathrm{~N}$ tem spin 1 e, portanto, um momento quadrupolar elétrico, assim como também um momento magnético, que resulta numa linha muito larga que limita sua utilidade na espectroscopia.

$\mathrm{O}{ }^{1} \mathrm{H}$, é um excelente núcleo para a espectroscopia in vivo, devido à sua grande abundância natural, intenso momento magnético, spin $1 / 2$ e alta concentração fisiológica em seres vivos. Além disso apresenta uma faixa muito estreita de deslocamentos químicos 
(aproximadamente $12 \mathrm{ppm}$ ), com tempos de relaxação $T 1$ no intervalo de $200 \mathrm{~ms}$ a $2 \mathrm{~s}$, e $T 2$ no intervalo de 50 a $500 \mathrm{~ms}$.

$\mathrm{O}$ isótopo ${ }^{31} \mathrm{P}$ é também um núcleo interessante em $\mathrm{RMN}$ in vivo. Ele tem spin $1 / 2$, alta abundância natural, grande momento magnético, apresenta um maior intervalo de deslocamento químico (aproximadamente 30ppm), mas a concentração fisiológica em relação ao ${ }^{1} \mathrm{H}$ é menor. Possui tempos de relaxação $T 1$ no intervalo $500 \mathrm{~ms}-5 \mathrm{~s}$, e $T 2$ no intervalo de $10-100 \mathrm{~ms}$.

O isótopo de carbono, ${ }^{13} \mathrm{C}$, tem spin igual a $1 / 2$, com um deslocamento químico de aproximadamente $200 \mathrm{ppm}$, facilitando a separação dos sinais das várias substâncias presentes numa amostra biológica. Possui tempos de relaxação $T 1$ no intervalo de $50 \mathrm{~ms}$ a $1,5 \mathrm{~s}$, e $T 2$ no intervalo de 10 a $100 \mathrm{~ms}$. $\mathrm{O}{ }^{13} \mathrm{C}$ tem uma baixa abundância natural.

Os demais núcleos citados na tabela 2.2 possuem momento magnético pequeno, pouca abundância natural, e alguns spins diferentes de $1 / 2$, gerando um momento de quadrupolo elétrico, o que, na presença de possíveis gradientes de campo elétrico, pode ter como conseqüência alargamento da linha de ressonância.

\subsection{Espectroscopia de Prótons $\left({ }^{1} \mathrm{H}\right)$}

A ERM (Espectroscopia por ressonância magnética) de prótons se beneficia por produzir um sinal intenso, a ocorrência de uma variedade de substâncias biológicas (metabólitos) observáveis de grande importância, e podem ser implementados em sistemas de IRM(Imagem por ressonância magnética). O maior problema de ERM de prótons está relacionado ao sinal da água e da gordura, que são muito intensos, para o qual é necessário a utilização de técnicas para a supressão do sinal da água (REDFIELD et al., 1975; GUPTA, 1976; HOULT, 1976; SKLENÁR et al., 1982; HAASE et al., 1985; ERNST et al., 1995).

Os metabólitos mais importantes encontrados nos espectros de prótons (figura 2.2) que trazem informações sobre os processos no nível celular, são: Colina (Cho), que dá uma linha intensa em 3,2ppm; Creatina (Cr), que tem uma linha intensa em 3,03ppm; Inositol (Ins), com um deslocamento químico de 3,5ppm; N-Acetil Aspartato (NAA), que dá um pico intenso em 2,0ppm e é um dos mais predominantes no espectro do cérebro normal. O grupo aspartil do NAA possui ressonância em 2,48; 2,60 e 2,64 ppm; o Lactato (Lac) tem duas linhas de ressonância em 4,1ppm e 1,32ppm.

Vários estudos de ERM de próton têm sido direcionados na diagnose e na identificação do estágio de tumores cerebrais (FULHAM et al. 1992; KUGEL et al., 1992; 
CHANG et al., 1991). Embora ainda não de forma definitiva, a ERM de próton permite distinguir entre tumores cerebrais de alto ou baixo grau de malignidade, através do incremento da concentração de colina, redução da creatina ou incremento do lactato (NEGENDANK et al., 1992).

Em cérebros normais tem-se observado pouca quantidade de lactato. Assim, o aparecimento de lactato pode ser um indicador importante do estado do tecido; o que faz com que seu metabolismo seja muito estudado por ERM de próton.

HASHIMOTO et al., 1997 realizaram estudos em pacientes com autismo e retardo mental e observaram uma diminuição de NAA apenas em pacientes com retardo mental. Em pacientes com autismo, não apresentam diferenças em níveis de NAA.

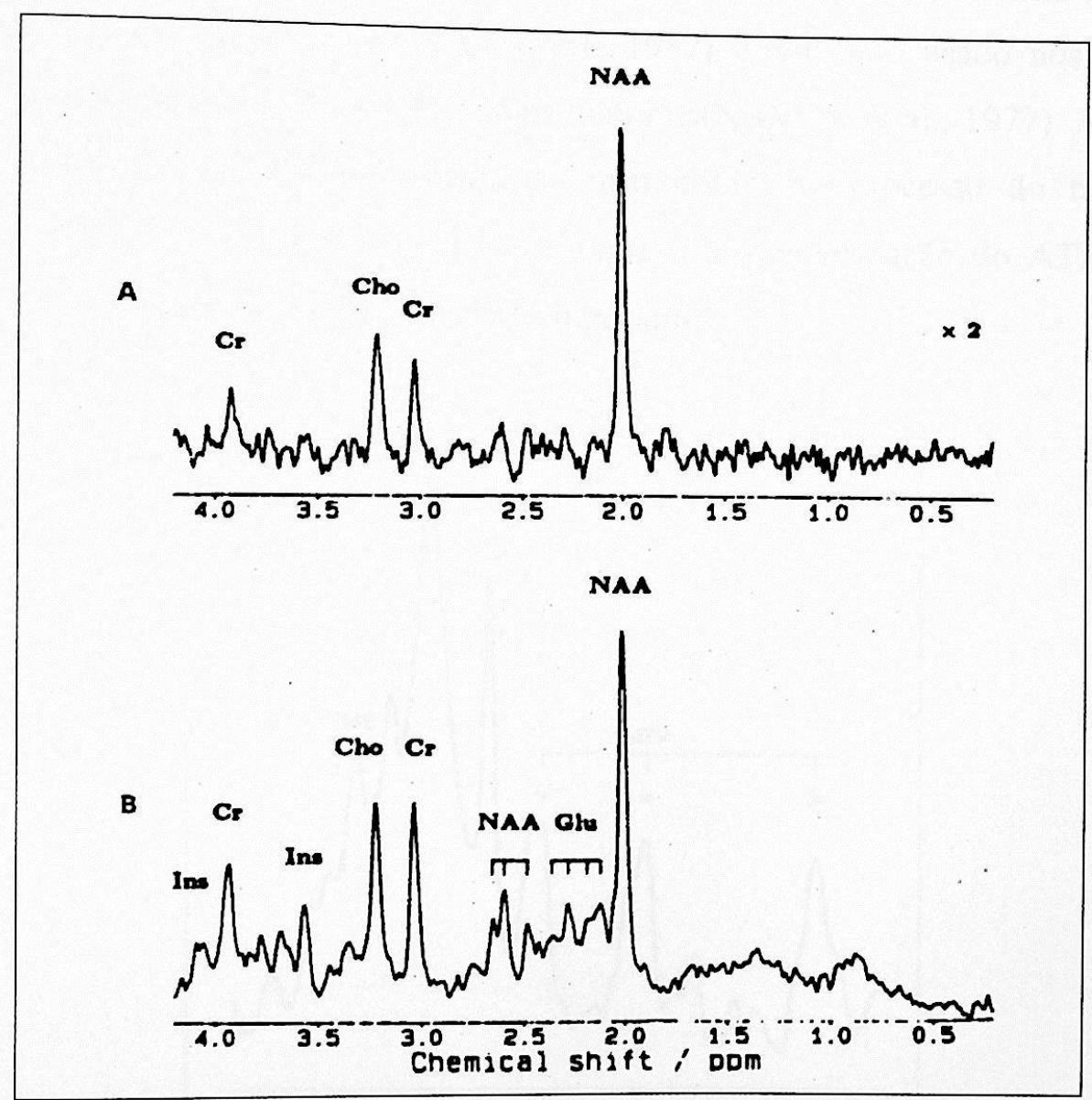

Figura 2.2 Espectros de prótons do cérebro humano, mostrando os metabólitos mais importantes, com tempo de eco de (A) 270ms e (B) 20ms. (ORRISON et al., 1995)

\subsection{Espectroscopia de ${ }^{31} \mathrm{P}$}

O espectro de compostos que contêm fósforo dá informações valiosas do metabolismo energético do tecido, sendo complementares à informação dada pelo ${ }^{1} \mathrm{H}$. A 
ERM de ${ }^{31} \mathrm{P}$ é um método preciso para monitorar de forma não-invasiva mudanças no metabolismo energético sob condições normais e patológicas. Infelizmente, a ERM de ${ }^{31} \mathrm{P}$ pode ter limitações no ambiente clínico devido a sua pouca resolução espacial, que restringe as medidas no cérebro a volumes não menores que aproximadamente $20 \mathrm{ml}$ usando os métodos convencionais (BARKER et al., 1993). Medidas feitas com várias aquisições melhoram a resolução, mas são susceptíveis a artefatos de movimento.

Vários metabólitos podem ser medidos com ERM de ${ }^{31} \mathrm{P}$ como é mostrado na figura 2.3. A fosforocreatina ( $\mathrm{PCr}$ ), em $0 \mathrm{ppm}$, adotado como referência para o deslocamento químico, é importante para armazenar e transportar energia dentro das células e permite a re-síntese de Adenosina trifosfato (ATP). O fosfato inorgânico ( $\mathrm{Pi}$ ) dá um pico estreito em 4,8 ppm. O deslocamento do pico de $\mathrm{Pi}$ em relação ao $\mathrm{PCr}$ é freqüentemente usado como indicador do $\mathrm{PH}$ do tecido (BESSMAN et al., 1982) e tem sido usado nos estudos de gradientes de PH nas membranas das células tumorais(NAVON et al., 1977). A adenosina difosfato (ADP) e o ATP são substâncias primordiais no processo do metabolismo energético: ATP $+\mathrm{H}_{2} \mathrm{O} \leftrightarrow \mathrm{ADP}+\mathrm{Pi}+\mathrm{H}^{+}$, que é a transformação do ATP em ADP, fornecendo energia para os demais processos bioquímicos.

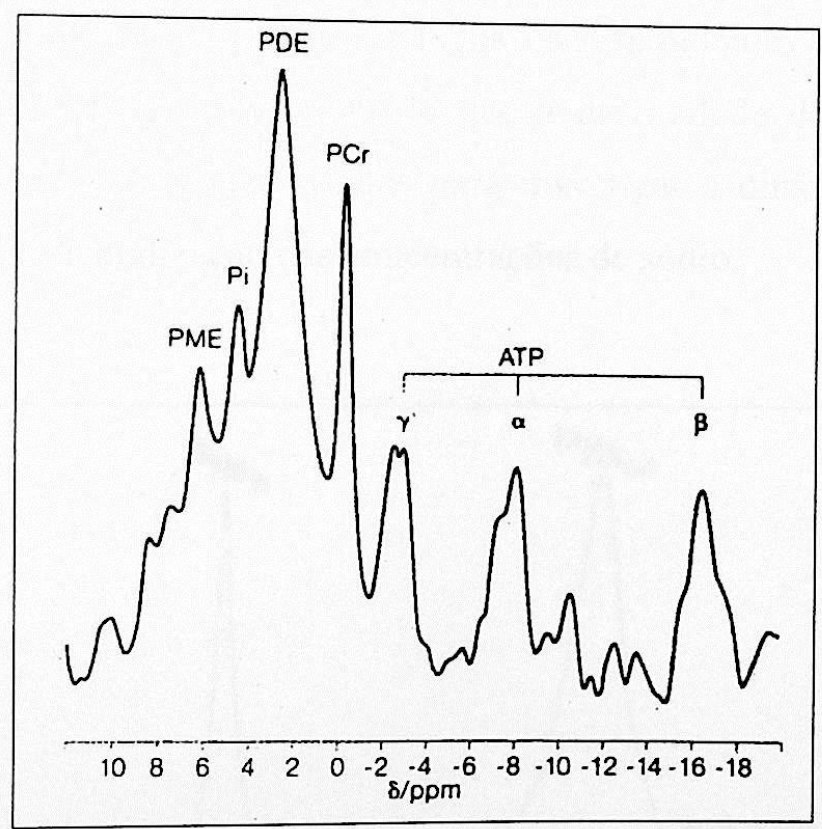

Figura 2.3 Espectro do ${ }^{31} \mathrm{P}$ da região normal do cérebro. Metabólitos representados: Fosforomonoester (PME) a 6,8ppm; Fosfato inorgânico (Pi) a 4,8ppm; Fosforodiester (PDE) a 2,9ppm; Fosforocreatina (PCr) a 0ppm; e $\alpha-, \beta-, \gamma-$, Adenosina trifosfato (ATP) a 7,6ppm, -16,3ppm e -2,6ppm respectivamente.( SAUTER et al., 1992). 


\subsection{Espectroscopia de ${ }^{23} \mathrm{Na}$}

O sinal de ${ }^{23} \mathrm{Na}$ in vivo é forte, refletindo a abundância natural do isótopo $(100 \%)$ visível por ERM, além da alta concentração em sistemas biológicos. A concentração de sódio no corpo humano é $44 \mathrm{mM}$, comparada com $387 \mathrm{mM}$ de fósforo e aproximadamente $99,9 \mathrm{M}$ de prótons. A sensibilidade total para o ${ }^{23} \mathrm{Na}$ no corpo humano é $4,1 \times 10^{-5}$, enquanto que a do ${ }^{31} \mathrm{P}$ é $25,7 \times 10^{-5}$, assumindo a sensibilidade do ${ }^{1} \mathrm{H}$ como 1 (NARAYANA et al., 1988; SPRINGERS et al., 1987). Entretanto, na prática a sensibilidade total do NMR para ${ }^{23} \mathrm{Na}$ pode ser melhor do que a do ${ }^{31} \mathrm{P}$ porque o sinal deste se estende sobre o de vários outros metabólitos, enquanto que o espectro de ${ }^{23} \mathrm{Na}$ é muito simples (Figura. 2.4). Além disso, o sódio possui normalmente tempo de relaxação $T 1$ mais curto, o que permite taxas de repetição mais rápidas.

A concentração intracelular de ${ }^{23} \mathrm{Na}$ é pequena comparada à do meio extracelular, mas sob circunstâncias normais essa concentração do sinal em um único pico permite formar imagens dos níveis regionais do sódio, apesar das imagens serem de baixa resolução e de contraste pobre. Podem-se ver diferenças entre os íons de sódio intra e extracelular usando reagentes de deslocamento paramagnético que alteram o deslocamento químico dos íns das diferentes regiões(NARAYANA et al., 1988). Nesse caso, o espectro de ${ }^{23} \mathrm{Na}$ consiste de dois componentes maiores: os picos correspondentes aos níveis de $\mathrm{Na}$ nas regiões intra e extracelular. Mesmo achando que a diversidade do espectro é limitada, estudos de ${ }^{23} \mathrm{Na}$ são freqüentemente usados para investigar a dinâmica do transporte na membrana e a compartimentalização das concentrações de sódio.

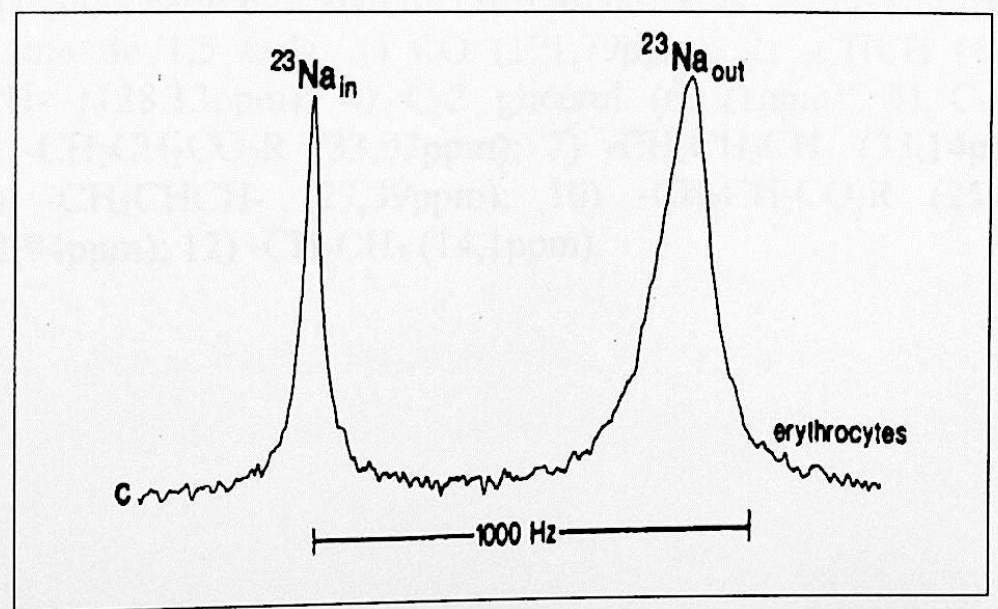

Figura 2.4 Espectro do ${ }^{23} \mathrm{Na}$ mostrando os picos correspondentes aos ions das regiões intra e extracelular de formas separadas.(PARTAIN et al., 1988) 
2.6 Espectroscopia de ${ }^{13} \mathrm{C}$

A baixa abundância natural do ${ }^{13} \mathrm{C}(1,1 \%)$ freqüentemente requer a administração de compostos suplementares marcados para obter um sinal de intensidade adequada. $\mathrm{O}$ isótopo ${ }^{13} \mathrm{C}$ produz um espectro muito rico, como seria esperado de um constituinte orgânico tão fundamental (Figura 2.5). No alcance do deslocamento químico temos vários picos visíveis, muito mais do que no espectro de próton e de fósforo. A ERM do ${ }^{13} \mathrm{C}$ de sistemas biológicos in vitro geralmente mostram vários picos estreitos em distintos deslocamentos químicos (COHEN, 1988).

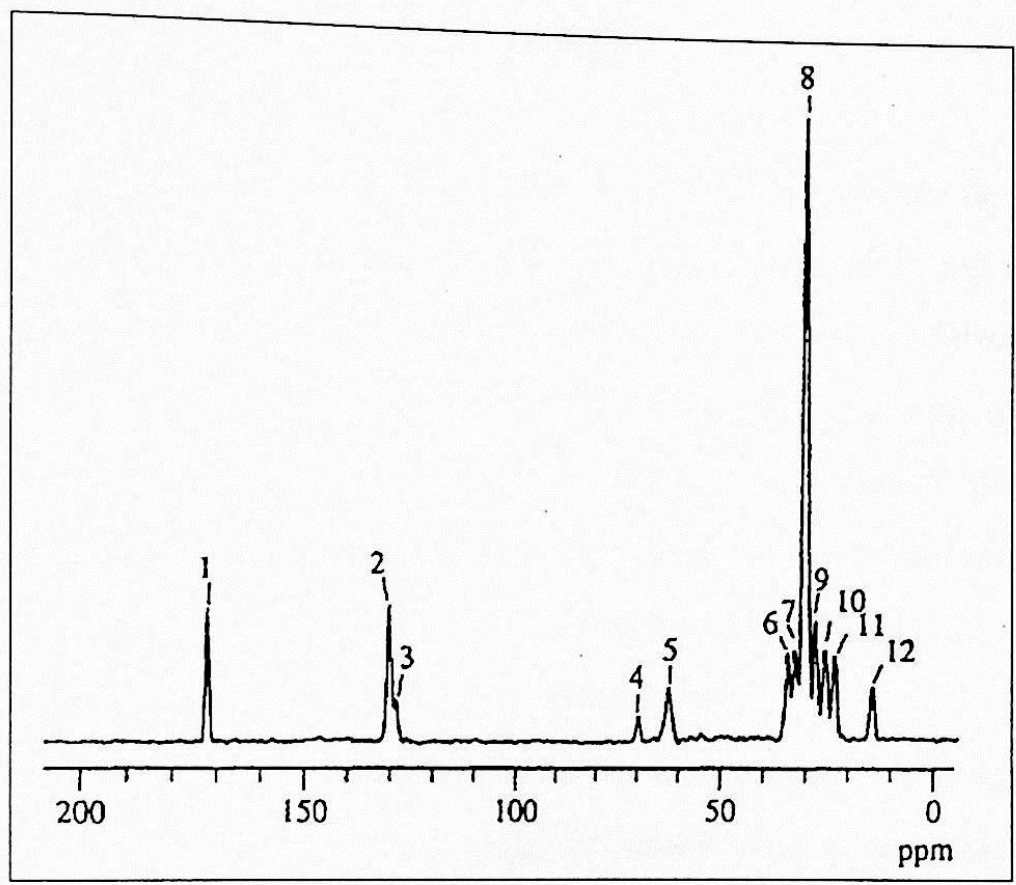

Figura 2.5 Abundância natural in vivo do espectro de ${ }^{13} \mathrm{C}$ do tecido adiposo humano obtido usando um sistema de 1,5 tesla. 1) $\mathrm{CO}(171,79 \mathrm{ppm})$; 2) $-\mathrm{CHCH}(129.83 \mathrm{ppm})$; 3) $\mathrm{CHCHCH}_{2} \mathrm{CHCH}-(128.13 \mathrm{ppm})$; 4) $\mathrm{C}-2$ glicerol (69,21ppm); 5) C-1, C-3, glicerol $\left.\left.(62,05 \mathrm{ppm}) ; 6)-\mathrm{CH}_{2} \mathrm{CH}_{2} \mathrm{CO}_{2} \mathrm{R}(33,93 \mathrm{ppm}) ; 7\right)-\mathrm{CH}_{2} \mathrm{CH}_{2} \mathrm{CH}_{3}(33,14 \mathrm{ppm}) ; 8\right)-\left(\mathrm{CH}_{2}\right)_{\mathrm{n}}$ (29,69ppm); 9) - $\left.\left.\mathrm{CH}_{2} \mathrm{CHCH}-(27,39 \mathrm{ppm}) ; 10\right)-\mathrm{CH}_{2} \mathrm{CH}_{2} \mathrm{CO}_{2} \mathrm{R} \quad(25,04 \mathrm{ppm}) ; 11\right)-$ $\left.\mathrm{CH}_{2} \mathrm{CH}_{2} \mathrm{CH}_{3}(22,94 \mathrm{ppm}) ; 12\right)-\mathrm{CH}_{2} \mathrm{CH}_{3}(14,1 \mathrm{ppm})$. 


\section{Capítulo III}

\section{TÉCNICAS DE ESPECTROSCOPIA LOCALIZADA}

O enorme desenvolvimento de métodos de espectroscopia localizada ocorre devido à inventividade dos procedimentos de localização propostos. Neste capítulo a discussão estará limitada aos métodos mais usados e àqueles que representaram grandes desenvolvimentos. Em particular, comentaremos alguns aspectos práticos do uso dessa tecnologia.

\subsection{Classificação geral dos métodos de localização.}

\subsubsection{Classificação conceitual}

Os métodos de localização (ORRISON et al., 1995) podem ser de volume único ou de multi-volume. Os métodos de volume-único são usados para obter um único espectro de NMR de um único volume de tecido de uma localização escolhida e definida. O método de multi-volume é usado para coletar, simultaneamente, espectros de um grande número de locais (tipicamente entre 2 e 1024 locais). Se o número de volumes for suficientemente grande, é possivel reformatar os dados produzindo uma imagem que mostra as variações espaciais na intensidade de um determinado núcleo. Essa técnica é conhecida como chemical shift imaging (CSI) ou spectroscopic imaging (SI).

A distinção entre essas duas classificações conceituais é principalmente prática. Obviamente, o método de volume-único pode ser usado para obter dados de uma grande seqüência de locais, permitindo assim a construção de SI (MAUDSLEY et al., 1983). No entanto, a necessidade de um tempo de varredura relativamente longo para obtermos uma relação sinal/ruído razoável junto com a inconstância temporal dos seres vivos ( tudo está em constante movimento) tornam essa técnica quase impraticável. Assim o método de multi-volume é mais prático devido a sua eficiência temporal; exceto quando o estudo for tão específico que o exame de um único-volume é suficiente. Por outro lado, o método de volume-único é mais fácil de ser implementado e os dados obtidos são mais fáceis de serem manipulados.

\subsubsection{Classificação metodológica}

As principais diferenças entre ressonância magnética e outras formas de espectroscopia química e de imagem radiológica levam normalmente a acreditar que os métodos de RMN 
localizados são triviais (ORRISON et al., 1995). Descrições imprecisas da teoria de RMN levam a acreditar que as técnicas de ERM e de IRM são muito parecidas com as de técnicas radiológicas de tomografia computadorizada de raios-X ou ultra-som que baseiam-se em absorção ou espalhamento de radiação. Isso dá a falsa idéia que a localização de RM deve ser simplesmente uma técnica de localização ou colimação das ondas de rádio, fazendo com que elas sejam absorvidas por um volume definido do tecido. O erro desta interpretação é aparente, quando se considera que as ondas de rádio usado geralmente em IRM e ERM possuem comprimentos de onda de vários metros. Nessas condições é impossível localizar ou colimar a radiação em um pequeno volume dentro do corpo humano. Todos os elementos de volumes que ficam na vizinhança da bobina receptora contribuem com o sinal; assim a localização consiste em suprimir o sinal de volumes que não estão em estudo ou em fazer com que o sinal de excitação atue apenas sobre o volume desejado, ou ambos.

A deteção do sinal de RMN, seja para IRM ou ERM, requer a presença de dois campos magnéticos perpendiculares entre si: O campo magnético $\vec{B}_{0}$ e o campo magnético oscilante $\vec{B}_{1}$ (produzido pelo fluxo da corrente elétrica na bobina de RF de transmissão) que envolve ou fica próxima ao volume em estudo. Todos os métodos de localização usam gradientes aplicados sobre $\vec{B}_{0}$ ou $\vec{B}_{1}$ (a dependência posicional de uma intensidade particular do campo). Os gradientes aplicados sobre $\vec{B}_{0}$ e $\vec{B}_{1}$ podem ser usados para manipular a freqüência do sinal do RMN, a fase ou intensidade em um volume específico, de maneira a localizá-lo. Os métodos de espectroscopia localizada em $\vec{B}_{0}$ usam gradientes no campo estático, da mesma forma que são usados em IRM. Os métodos em $\vec{B}_{1}$ usam bobinas de rádiofreqüência, variações ou inomogeinidades no campo $\vec{B}_{1}$. As bobinas são construídas especificamente para cada caso.

A diferença entre os métodos de localização por $\vec{B}_{0}$ e $\vec{B}_{1}$ está no fato de que no método $\vec{B}_{0}$ quase sempre são usados gradientes lineares, enquanto que no método $\vec{B}_{1}$ isso quase nunca ocorre. Quando o método por $\vec{B}_{0}$ é utilizado obtemos uma definição mais precisa do volume estudado (por exemplo, cubos ou prismas regulares) do que quando utilizamos o método de localização por $\vec{B}_{1}$. Portanto, o método por $\vec{B}_{0}$ é mais pratico quando se faz necessário uma melhor discrição do volume. 


\subsection{Métodos de gradiente em $\vec{B}_{1}$}

\subsubsection{Considerações gerais}

O método em $\vec{B}_{1}$ é vantajoso porque a intensidade do sinal e o ângulo de giro dependem de maneira conhecida da localização espacial do núcleo produtor do sinal quando um campo não homogêneo $\vec{B}_{1}$ é aplicado. A intensidade do sinal de uma região particular do espaço $S(x, y, z)$, produzido por um único pulso retangular é dada por:

$$
S(x, y, z)=k B_{1 x y}(x, y, z) \sin \left(\gamma B_{1 x y}(x, y, z) t_{p}\right)
$$

onde $\gamma$ é a relação, ou constante giromagnética, $t_{p}$ é a duração do pulso e $k$ é uma constante arbitrária que depende dos detalhes do instrumento. Nessa expressão foi assumido que a mesma bobina transmite e recebe o sinal no esquema de transformada de Fourier do pulso. Note que temos duas componentes. O ângulo de giro estão relacionados com o fato de que a magnetização de uma região dada, desloca-se do eixo-z de rotação para o plano transversal a essa que é característico da posição. O termo $B_{1 x y}(x, y, z)$ que multiplica o seno significa que a intensidade da sinal produzido depois do giro da magnetização depende da intensidade local do campo $\vec{B}_{1}$. Esse termo pode ser pensado como termo de recepção indicando que a bobina é mais sensível em locais onde consegue produzir campos $\vec{B}_{1}$ mais fortes; desta forma ela é mais sensível ao que acontece nas suas proximidades.

O método em $\vec{B}_{1}$ é vantajoso pelo fato de que podemos desenhar uma bobina de RF com um formato e tamanho especiais de maneira a obtermos a dependência espacial desejada em $\vec{B}_{1}$, e através da aplicação da expressão acima obter a localização espacial.

\subsubsection{Bobinas de superfície}

O método da bobina de superficie (ACKERMAN et al., 1980; BENDALL, 1986; ) é o método mais intuitivo entre todos os outros métodos de localização. Basta construir uma bobina oval ou circular, pequena quando comparada com as dimensões do corpo, é colocála na superfície do corpo próximo ao tecido em estudo. Normalmente a bobina é usada tanto como transmissora quanto como receptora do sinal. Esse é mais valioso quando não é necessário um alto grau de localização, porque a bobina é sensível a toda a região e a todos 
os tecidos que ela cobre. Não temos o controle sobre a localização do volume selecionado ajustando a largura (ou amplitude) dos pulsos de RF usado na excitação; pulsos mais longos ou mais intensos levam a excitação para regiões mais afastadas da superfície. A localização nas outras duas dimensões é definida pelo local onde se coloca a bobina. Normalmente é desejável suprimir o sinal proveniente das regiões próximas à superfície em favor dos tecidos mais profundos. Isso levou ao surface nulling pulse onde a duração do pulso de RF é ajustado para produzir um pulso de $180^{\circ}$ na superfície do corpo próxima ao centro da bobina; o que produz uma supressão parcial do sinal da superfície. Uma desvantagem desse método, é o formato irregular do volume estudado. Outra desvantagem é que as regiões próximas à bobina produzem sinais de fase oposta aos produzidos nas regiões mais profundas do corpo.

Esse método tem a vantagem de que a relação sinal/ruído é maior do que a obtida com qualquer outro método de localização. Outra vantagem é que o movimento do órgão pode ser minimizada se a bobina for fixada ao mesmo.

\subsection{Métodos de gradiente em $\vec{B}_{0}$}

Uma discussão dos métodos que serão apresentados dará uma introdução razoavelmente completa de espectroscopia localizada usando gradientes na direção de $\vec{B}_{0}$. Os métodos que usam gradientes lineares pulsados em $\vec{B}_{0}$ entre outros são: Depth-Resolved Surface Coil Spectroscopy (DRESS), Image-selected “in vivo" spectroscopy (ISIS), Stimulated Echo Acquisition Mode (STEAM), Point Resolved Spectroscopy (PRESS), Spectroscopic Imaging (SI). O método que usa gradientes não lineares em $\vec{B}_{0}$ é o Topical Magnetic Resonance (TMR) e técnicas relacionadas a espectroscopia localizada, entre outras temos o Chemical-shift Selective Excitation (CHESS).

Além desses, outros procedimentos têm sido propostos; os mais conhecidos são extensões ou modificações ou combinações desses procedimentos básicos.

\subsubsection{Depth-Resolved Surface Coil Spectroscopy (DRESS)}

DRESS (BOTTOMLEY et al., 1984) é o mais simples procedimento para exemplificar o uso de seleção de fatias de IRM para fazer ERM localizada. Neste procedimento, um gradiente linear em $\vec{B}_{0}$ é aplicado quando a magnetização está na orientação de equilíbrio. Isso faz com que a freqüência de ressonância nuclear torne-se 
dependente de sua posição ao longo da direção do gradiente. Um pulso seletivo de RF, semelhante ao usado em IRM para seleção de fatia, pode ser usado para produzir um giro de $90^{\circ}$ para o núcleo que tem a freqüência dentro de uma faixa definida. Isto que equivale a produzir um giro de $90^{\circ} \mathrm{em}$ uma fatia definida de tecido orientada perpendicularmente à direção do gradiente, enquanto deixa a magnetização nuclear de todas as outras regiões ao longo do eixo $\mathbf{z}$ como é mostrada na figura 3.1. Essa descrição diz apenas como se dá a seleção de volume em uma única direção. A localização nas outras duas dimensões é obtida usando uma bobina de superfície para a deteção do sinal.

A fatia selecionada é paralela ao plano da bobina de superficie. Desta forma, o sinal proveniente desta fatia, que está fora do raio da bobina de superfície, não é detectado. $\mathrm{O}$ DRESS, então, produz um volume aproximadamente cilíndrico. A espessura desse cilindro e sua localização são definidas pelo gradiente em $\vec{B}_{0}$ e pelo pulso de RF, e o raio desse cilindro é definido pelo diâmetro da bobina de superfície.

A primeira vantagem do DRESS é a simplicidade: é de fácil entendimento e implementação. Sua principal desvantagem é que o volume nem sempre tem forma ideal para alguns estudos e, também a localização de duas das três dimensões depende da colocação da bobina. Mais ainda, a função espacial da sensibilidade da bobina faz com que a sensibilidade do método diminua com o aumento da profundidade do tecido. Assim, o DRESS é muito usado para o estudo de tecidos grandes e homogêneos localizados próximos à superfície do corpo. Um problema é que o sinal coletado logo após o término do pulso de gradiente é influenciado pelas correntes induzidas, sendo assim, necessário fazer correção após o processo de medida.

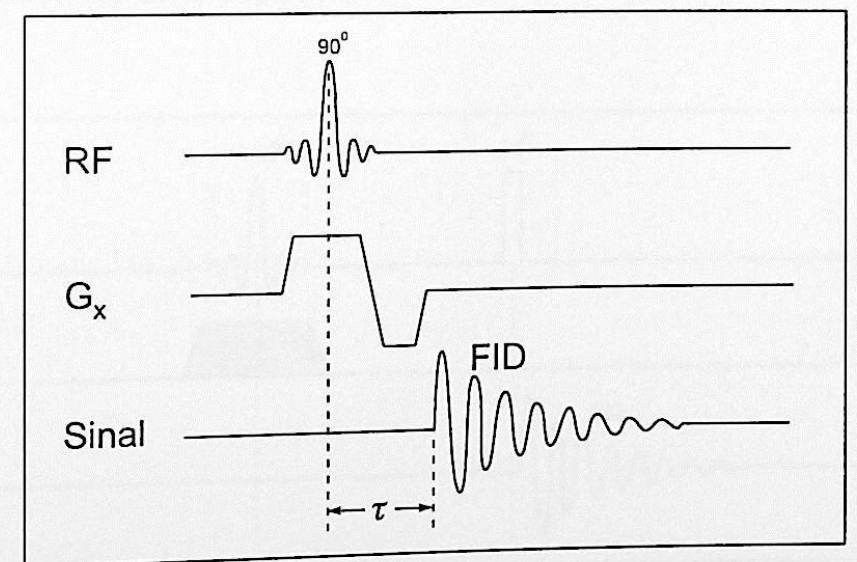

Figura 3.1 A seqüência de pulso para DRESS. Um tempo de espera é introduzido entre o pulso de RF e o começo da aquisição de dados para minimizar efeitos de eddy currents. 


\subsubsection{Image-selected "in vivo" spectroscopy (ISIS)}

O método ISIS (ORDIDGE et al., 1986; CONELLY et al., 1988; LUYTEN et al., 1989; BURGER et al., 1992) usa pulsos de RF seletivos na presença do gradiente em $\vec{B}_{0}$ para conseguir a localização diferindo do DRESS por usar apenas pulsos de $180^{\circ}$ e por implementar um esquema onde a magnetização nuclear de um dado volume é tida ao longo do eixo $\mathbf{z}$ do sistema girante. Isso é vantajoso porque minimiza os artefatos produzidos pelas correntes induzidas e também é vantajoso para o estudo de materiais que tem o tempo de relaxação $\mathrm{T}_{2}$ curto. Ele tem sido usado principalmente para estudos de RMN de ${ }^{31} \mathrm{P}$ porque a maioria dos metabólitos de fósforo possuem sinais que infelizmente são afetados pelo uso de seqüências de spin-eco, devido à modulação J ou relaxação transversal.

O ISIS baseia-se em um procedimento diferente que é mais facilmente entendido em termos de localização unidimensional (Figura 3.2). São usadas duas aquisições de dados feitas separadamente para a localização unidimensional. Em uma delas, um pulso não seletivo de $90^{\circ}$ é aplicado para obtermos todo o volume ao qual a bobina é sensível. $\mathrm{Na}$ outra aquisição, o mesmo pulso de $90^{\circ}$ é precedido por um pulso seletivo de fatia de $180^{\circ}$ aplicado na presença do gradiente em $\vec{B}_{0}$. Isso produz um espectro de todo o volume, porém o sinal proveniente da fatia selecionada é invertido em relação ao sinal do resto do volume. O espectro da fatia é então obtido fazendo a diferença ponto a ponto entre os dois espectros. Na ausência de movimento ou de outros fatores complicadores, o sinal de fora da fatia é idêntico nas duas aquisições, o que torna limpo o espectro da fatia. Por outro lado, os sinais de dentro da fatia têm sinais opostos nas duas aquisições, e desta forma, ele é somado fazendo-se a diferença de dois espectros.

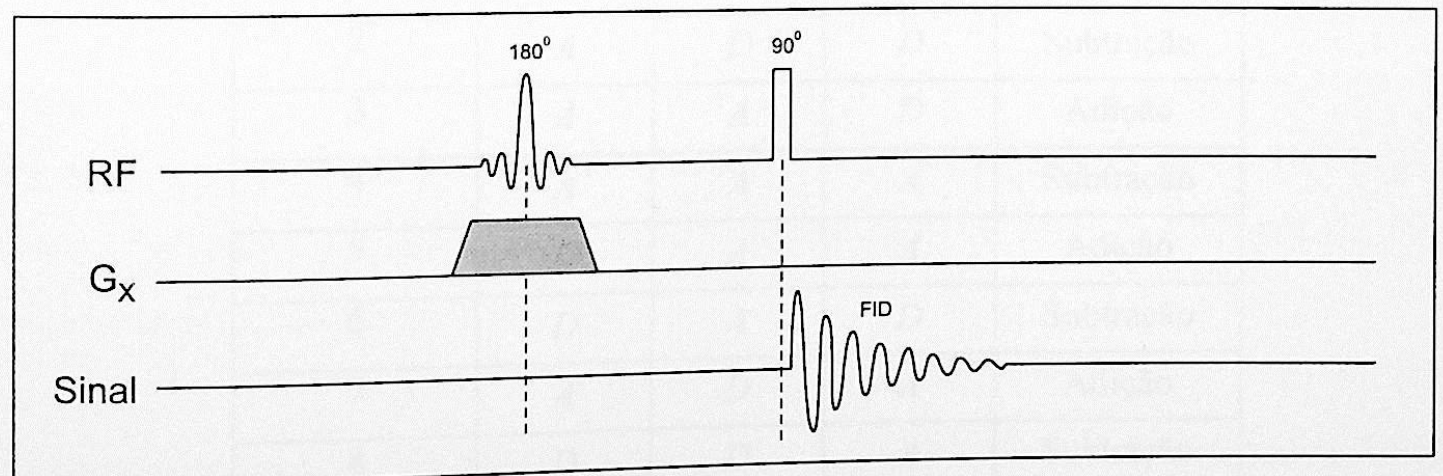

Figura 3.2 Seqüência de pulsos ISIS para localização unidimensional. 
A extensão dessa explicação para o caso de 3-dimensões não é intuitivamente óbvio. No procedimento em três dimensões são feitas oito aquisições separadas e pulsos seletivos são usados para inverter os sinais de dentro de três fatias ortogonais selecionadas. Em cada uma das oito aquisições são usadas diferentes combinações de pulsos de maneira que a subtração/adição de resultados resultem no espectro do volume localizado na intersecção das três fatias. A seqüência ISIS com localização completa em três dimensões é mostrada na figura 3.3 e o esquema de subtração/adição com os respectivos gradientes ligados ou desligados é dado na tabela 3.1. Desta forma, o ISIS pode ser usado para se obter espectros de volumes retangulares localizados em qualquer região onde a bobina seja sensível.

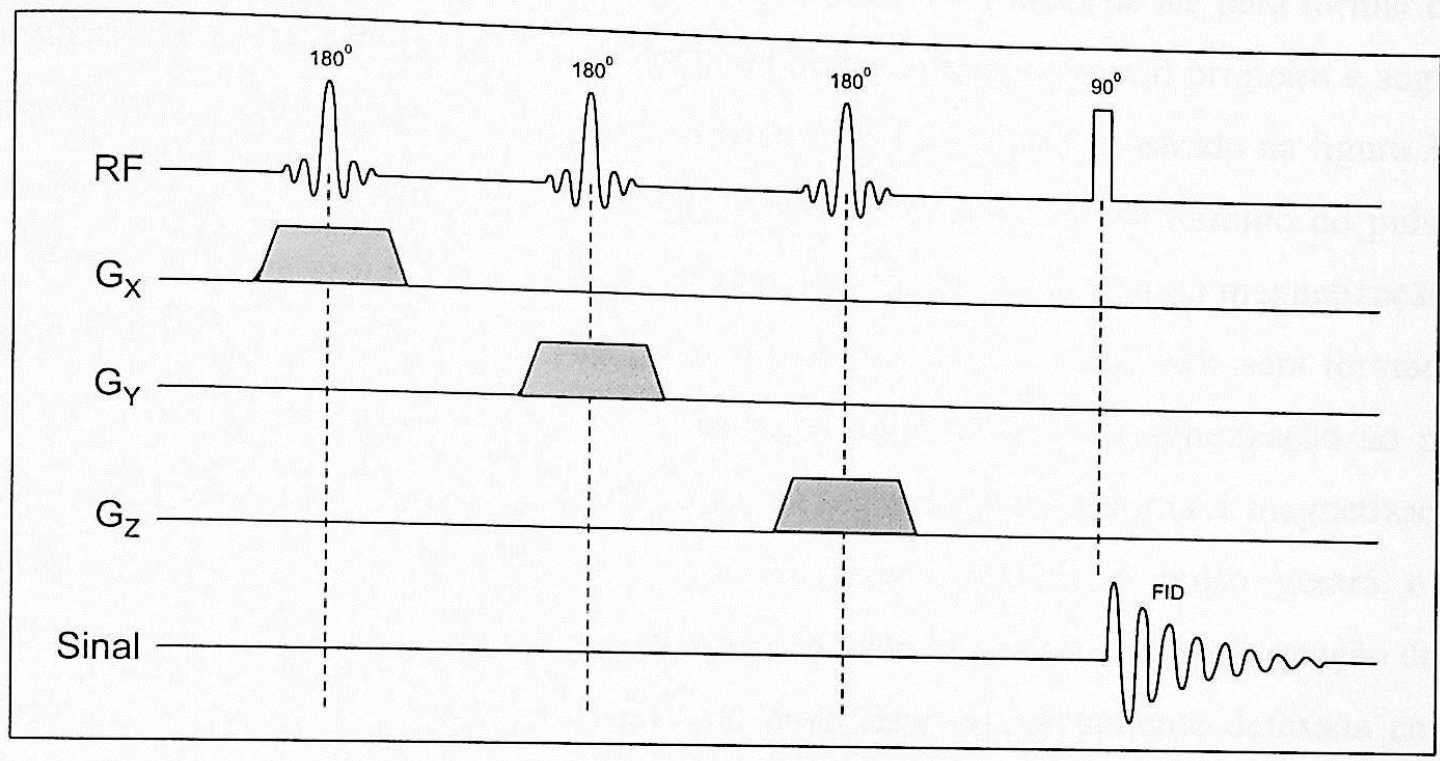

Figura 3.3 Seqüência de pulsos ISIS para o caso tridimensional

\begin{tabular}{|c|c|c|c|c|}
\hline \multirow{2}{*}{$\begin{array}{c}N^{\circ} \text { de } \\
\text { experimento }\end{array}$} & \multicolumn{2}{|c|}{ Pulsos de inversão seletiva } & \multirow{2}{*}{$\begin{array}{c}\text { Adição ou } \\
\text { subtração }\end{array}$} \\
\cline { 2 - 4 } & $\mathrm{G}_{\mathrm{x}}$ & $\mathrm{G}_{\mathrm{y}}$ & $\mathrm{G}_{\mathrm{z}}$ & Adição \\
\hline 1 & $D$ & $D$ & $D$ & Subtração \\
\hline 2 & $A$ & $D$ & $D$ & Adição \\
\hline 3 & $A$ & $A$ & $D$ & Subtração \\
\hline 4 & $A$ & $A$ & $A$ & Adição \\
\hline 5 & $D$ & $A$ & $A$ & Subtração \\
\hline 6 & $D$ & $A$ & $D$ & Adição \\
\hline 7 & $A$ & $D$ & $A$ & Subtração \\
\hline 8 & $D$ & $D$ & $A$ & \\
\hline
\end{tabular}

Tabela 3.1 Esquema de adição/subtração para a seqüência ISIS.

Onde, $A$ (ativado) e $D$ (desativado). 
O ISIS pode ser usado em várias situações devido a sua flexibilidade na definição da localização, tamanho e formato do volume escolhido. Sua principal desvantagem são os movimentos entre as aquisições fazendo com que o espectro das regiões externas às fatias não se anulem nas diferenças. Esta pode ser uma enorme complicação em estudos de ERM de ${ }^{1} \mathrm{H}$ (prótons) onde o sinal dos lipídios externos à fatia é mais largo do que o sinal dos metabólitos internos.

\subsubsection{Stimulated Echo Acquisition Mode (STEAM)}

STEAM ( GRANOT et al., 1986; FRAHM et al., 1987, 1989; MOONEN et al., 1990; KIMMICH et al., 1987) é um método que utiliza três pulsos de RF para formar o eco estimulado (HAHN, 1950). Se na seqüência de pulsos o tempo entre o primeiro e segundo pulso é $T_{E} / 2$ e o tempo entre o segundo e o terceiro é $T_{M}$, como é mostrado na figura 3.4, a maximização do eco estimulado ocorre no tempo $T_{E} / 2$ após último termino do pulso de RF. O eco estimulado é formado por três pulsos de RF, produzindo uma magnetização em qualquer giro que não seja $0^{\circ}$ ou $180^{\circ}$, mas o máximo do eco estimulado será formado se cada pulso produzir um giro de $90^{\circ}$. O primeiro pulso levará a magnetização ao plano transversal permanecendo um tempo de $\mathrm{T}_{\mathrm{E}} / 2$. O segundo pulso retorna a magnetização á direção longitudinal, permanecendo $T_{M}$, e finalmente o terceiro pulso gerará o eco estimulado depois de um tempo de $T_{E} / 2$. Outra condição importante para a formação do eco estimulado é que a magnetização transversal deve estar completamente defasada entre o primeiro e o segundo pulsos, e entre o terceiro pulso e a formação do eco.

Cada um dos três pulsos de RF é feito de maneira a séleciōnar uma fatia usando gradientes pulsados ortogonais em $\vec{B}_{0}$ de tal forma que o eco estimulado se dê no volume de intersecção das três fatias escolhidas. Assim, esse método é capaz de produzir espectros de prismas retangulares localizados em qualquer região dentro da bobina de RF. Normalmente são usados pulsos de gradiente adicionais (spoilers) nos tempos $T_{E} / 2$ e $T_{M}$ de maneira a promover a completa defasagem da magnetização transversal. Esses spoilers também eliminam, por defasagem, sinais provenientes de regiões externas ao volume escolhido, mais ainda dentro das fatias.

O STEAM tem várias vantagens práticas, o que explica sua larga utilização, especialmente para ERM de próton. O mais notável é que ele é relativamente insensível aos ângulos de giro dos pulsos selecionadores de fatia. A relação sinal/ruído será menor se não forem usados pulsos de $90^{\circ}$, mas o eco estimulado será ainda formado, mesmo se os 
ângulos de giro forem bastante diferentes de $90^{\circ}$. Isso é uma vantagem onde, as vezes é difícil produzir com precisão giros de mais de $90^{\circ}$, que são essenciais para vários outros métodos. Mais ainda, não é necessário um grande cuidado na hora de ajustar o ângulo de giro antes da tomada dos dados. Outra vantagem é que a localização é obtida em uma única aquisição.

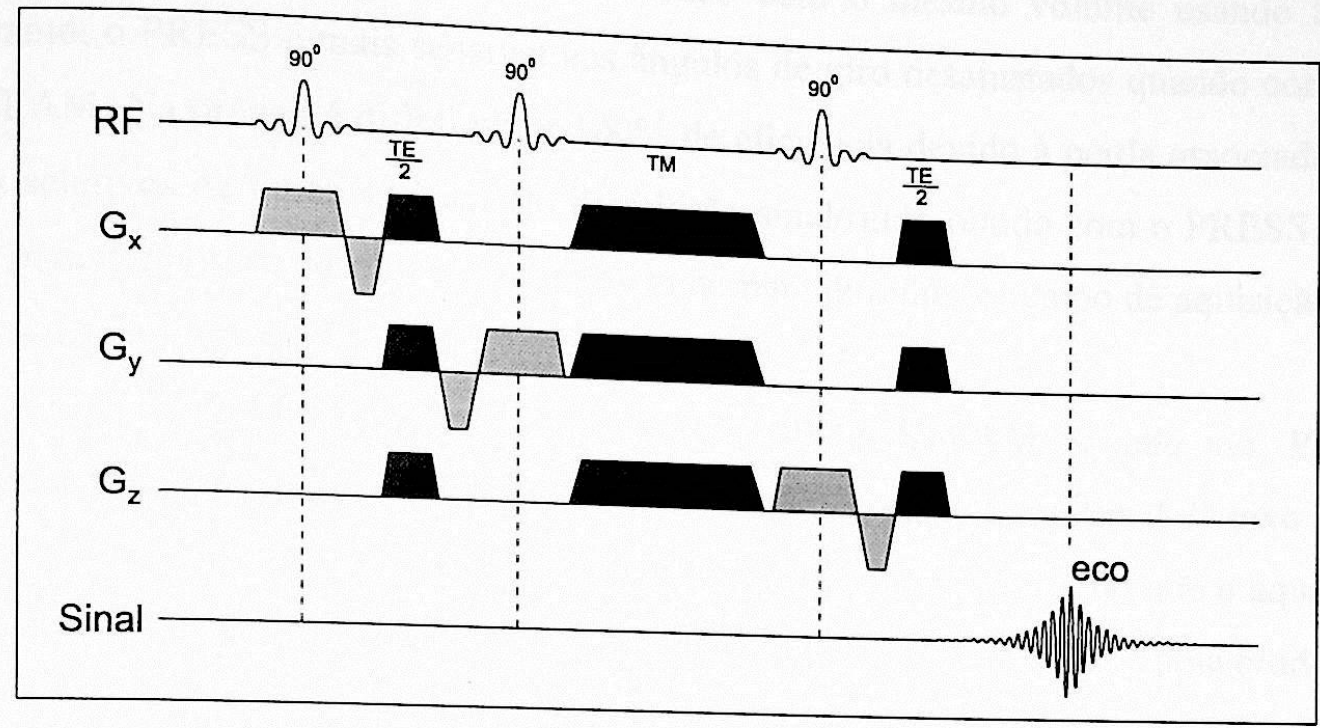

Figura 3.4 Seqüência de pulsos para experimentos de espectroscopia localizada STEAM, com aplicação de gradientes spoilers para reduzir os efeitos de eddy currents.

\subsubsection{Point Resolved Spectroscopy (PRESS)}

O PRESS (BOTTOMLEY, 1984, 1987; MOONEN et al 1989) difere do STEAM na maneira de localização; usa o eco de spin ao invés do eco estimulado. Com o PRESS a localização é obtida usando gradientes em $B_{0}$ e pulsos de RF seletivos para produzir a seleção de três fatias ortogonais. O primeiro é um pulso seletivo de $90^{\circ}$ que excita os spins em uma direção, e um pulso de inversão os refocaliza. O segundo pulso de $180^{\circ}$ é seletivo em uma segunda direção ortogonal à primeira, onde o eco gerado por estes dois pulsos (primeiro eco) trás informação dos dois planos selecionados (Interseção de dois planos). Para localizar um volume em forma de um cubo será necessário aplicar um terceiro pulso seletivo de $180^{\circ}$ ortogonal as duas anteriores gerando assim um segundo eco que vai trazer informação do volume da interseção dos três planos, denominado volume de interesse (VOI).

Normalmente são adicionados gradientes de pulsos em $B_{0}$, entre os pulsos de RF, de forma a eliminar sinais provenientes das regiões externas ao volume escolhido. PRESS é vantajoso em relação ao STEAM. A localização no PRESS é feita usando uma única 
aquisição que pode junto com IMR ou com técnicas de imagem espectroscópica ser usado como modo de excitação ou para ajustar a homogeneidade em $\mathrm{B}_{0}$. Mas, as semelhanças entre eles fazem com que tenham aplicações semelhantes. Ambos têm sido muito usados para medidas de ERM de próton, particularmente para estudos cerebrais.

$O$ uso do eco de spin duplo no PRESS resulta na relação sinal/ruído que é teoricamente o dobro do que pode ser obtido com o mesmo volume usando STEAM. Entretanto, o PRESS é mais sensível aos ângulos de giro desajustados quando comparados ao STEAM. Na prática é difícil obter $100 \%$ de eficiência devido à perda associada com os pulsos seletivos de fatias. O aumento da relação sinal/ruído obtido com o PRESS pode ser usado para melhorar a resolução volumétrica ou para diminuir o tempo de aquisição, ambos sendo muito vantajosos na prática.

Outra diferença importante entre PRESS e STEAM é que no PRESS a magnetização do volume escolhido leva muito tempo no plano transversal do eixo principal ("rotating frame"). Assim, a aquisição no PRESS tem um maior $T_{E}$ do que a aquisição do STEAM, e desta forma é mais influenciado pelo tempo de relaxação $\mathrm{T}_{2}$ e pela modulação $\mathrm{J}$.

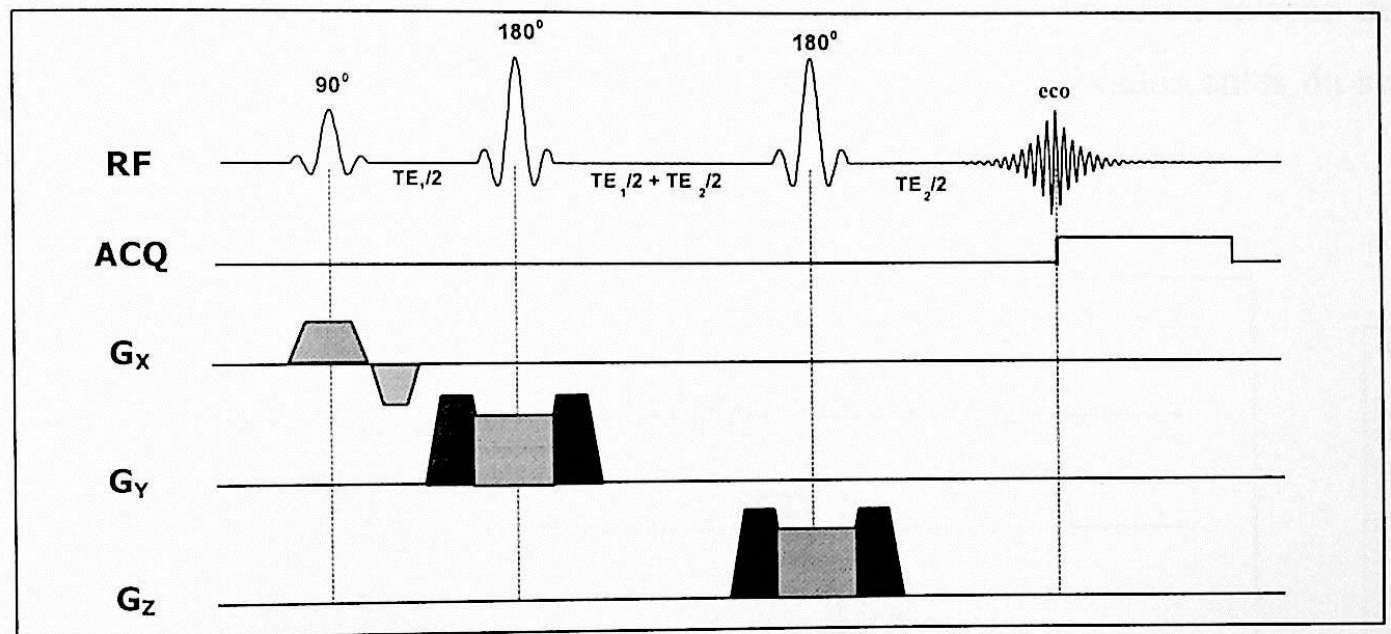

Figura 3.5 Seqüência de pulsos PRESS, com gradientes spoiler adicionais (cor cinza escuro), cuja função é a mesma que na seqüência STEAM.

\subsubsection{Spectroscopic Imaging (SI)}

A técnica Spectroscopic Imaging (MAUDSLEY et al., 1983; GONEN et al., 1997; BROWN et al., 1982), também chamada chemical shift imaging (CSI), usa métodos de codificação de fase para obter o espectro localizado. Esse procedimento é muito parecido com o usado em IRM convencional: são feitas várias aquisições onde diferentes amplitudes de gradiente de fase (ou largura) são aplicados em cada aquisição enquanto a magnetização está no plano transversal. Com o método de Fourier as mudanças de fase do sinal são 
induzidos pelos gradientes de fase para estabelecer o sinal gerador da localização. A única diferença significativa é que os sinais relativamente fracos de ERM necessitam pouca resolução espacial.

Em CSI 2D como mostra a figura 3.7 uma fatia da amostra é selecionada com um pulso de RF em conjunto com um gradiente de seleção. Dois gradientes de codificação de fase são utilizados para codificar as duas direções dentro da fatia. O sinal é adquirido na ausência de gradientes e a informação espectral é revelada pela transformada de Fourier ao longo do eixo temporal.

Vários procedimentos de CSI diferem em relação ao modo que a magnetização transversal de um volume relativamente grande é conseguido. O método pode ser tão simples como um pulso de $90^{\circ}$ não seletivo ( como CSI em 2D). Entretanto, algumas outras formas de selecionar volumes adicionais que usam antes a codificação de fase podem ser vantajosas por várias razões. Podemos desejar usar um código de fase em apenas 1 ou 2 dimensões (figuras 3.6 e 3.7), ao invés de 3 para reduzir o estudo. Nestas circunstâncias, é conveniente usar um procedimento de excitação de volume seletivo como o PRESS ou STEAM para excitar apenas um coluna ou uma fatia do tecido antes da seleção de fase. Mais ainda, algumas vezes os sinais indesejáveis podem ser eliminados antes da seleção, particularmente quando usada em baixa resolução.
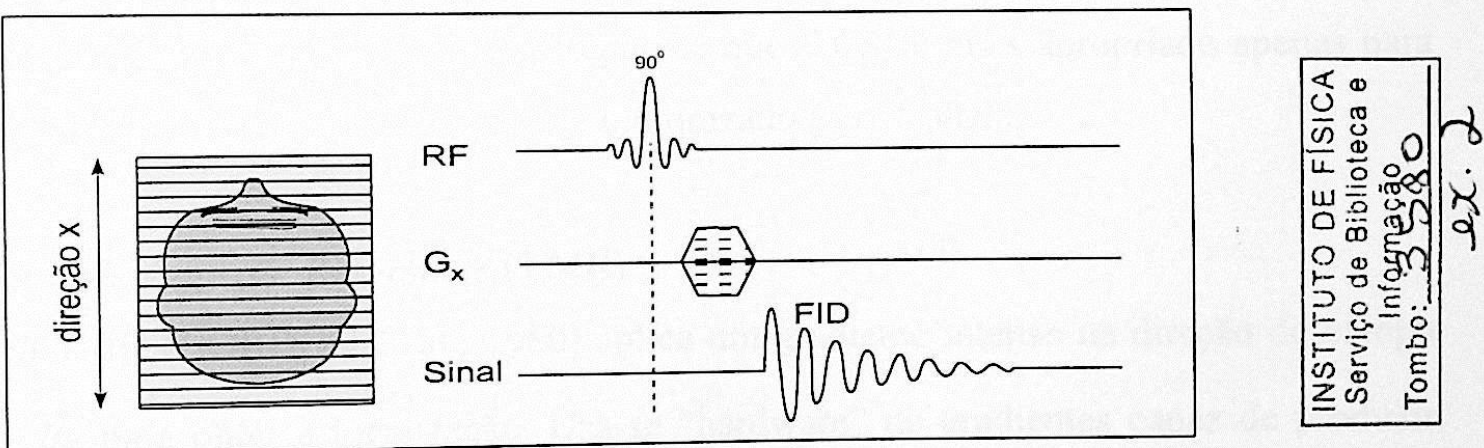

Figura 3.6 Seqüência de Pulsos utilizados para CSI unidimensional.

Estudos de CSI podem ser muito longos devido à iniciativa de uso de várias fases. $\mathrm{O}$ procedimento de CSI unidimensional com resolução de fase $\mathrm{N}$ requer pelo menos $\mathrm{N}$ aquisições separadas com diferentes amplitudes de pulsos de gradientes aplicados na direção desejada. Já um procedimento bi-dimensional com a mesma resolução requer pelo menos $\mathrm{N}^{2}$ aquisições. Os dados coletados desta maneira podem ser reconstruídos para produzir o espectro com a resolução estabelecida pelo procedimento. Entretanto, cada aquisição dá um sinal para cada elemento de volume de maneira que o tempo não é 
desperdiçado. Assim o CSI pode ser visto como um meio de obter simultaneamente o arrango completo do espectro localizado.

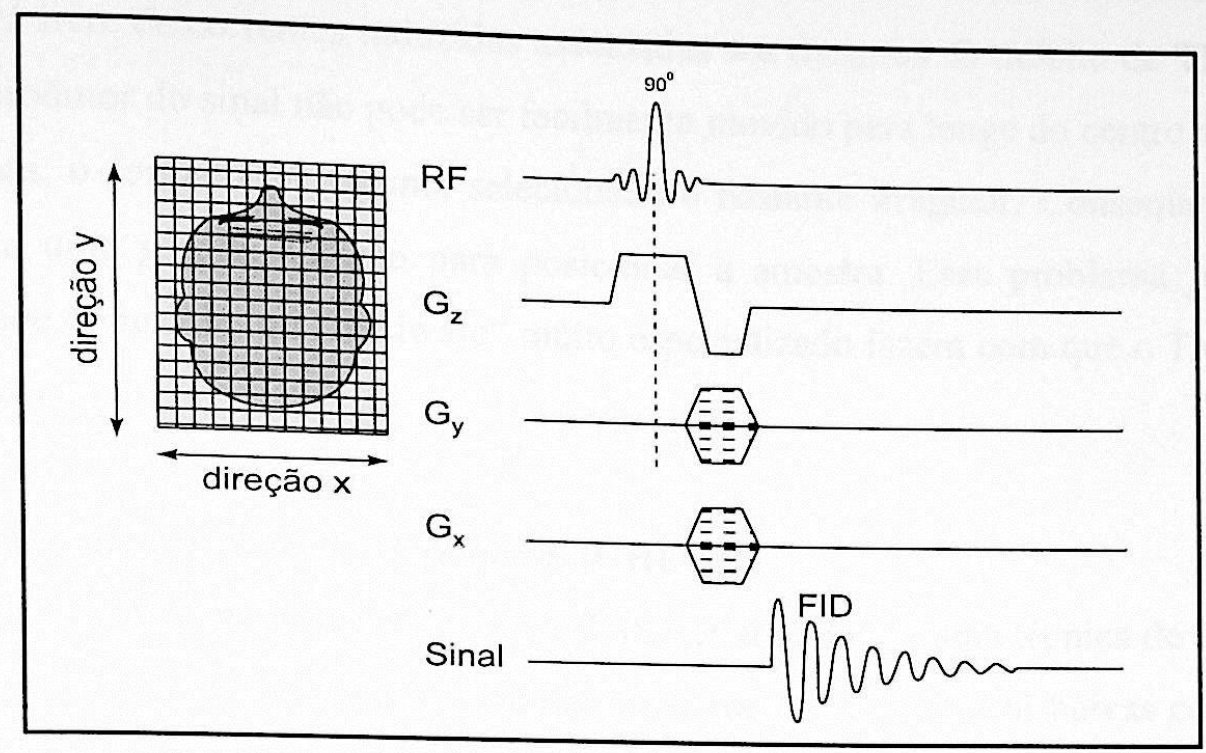

Figura 3.7 Seqüência de pulsos utilizados para CSI unidimensional.

No CSI, existem algumas desvantagens importantes. O CSI sofre do mesmo tipo de artefatos vistos com IRM associados com movimentos; o procedimento de fases falha e o sinal pode aparecer em lugar errado. Os artefatos de movimento em CSI poder ser reduzidos por procedimentos sofisticados para seguir os deslocamentos de fases introduzidos pelo movimento; entretanto parece que o CSI é mais apropriado apenas para as aplicações onde o movimento pode ser minimizado e controlado.

\subsubsection{Topical Magnetic Resonance (TMR)}

O TMR (GORDON et al., 1980) aplica um gradiente intenso na direção do campo estático $\vec{B}_{0}$ para obter a localização. Usa-se "hardware" de gradientes capaz de produzir campos $\vec{B}_{0}$ que dependem fortemente de $z^{2}$ e $z^{4}$ onde $z$ é a distancia medida ao longo do eixo do magneto a partir do centro. Essas dependências funcionais fazem com que o campo $\vec{B}_{0}$ seja razoavelmente homogêneo perto do centro do magneto (para valores pequenos de z), e mais inomogêneo para regiões distantes do centro (grandes valores de $z$ ). Quando esses gradientes estão presente, o sinal de RMN da região vizinha ao centro do magneto é estreito enquanto que o de regiões distantes são consideravelmente largos. Os sinais largos não são detectados de forma eficiente devido ao ruído e não podem ser resolvidos muito 
bem no espectro, de maneira que o volume do espectro adquirido com uma seqüência convencional vem predominantemente da região próxima ao centro.

O TMR tem a enorme vantagem de não usar gradientes pulsados em $B_{0}$ e desta forma está livre de correntes induzidas associadas aos mesmos. O defeito de TMR é que o volume produtor do sinal não pode ser facilmente movido para longe do centro do magneto. Mais ainda, o formato do volume selecionado é bastante irregular. Conseqüentemente, é necessária uma grande atenção para posicionar a amostra. Esse problema junto com a necessidade do uso de um "hardware" muito especializado fazem com que o TMR não seja muito usado.

\subsubsection{Chemical-shift Selective Excitation (CHESS)}

O CHESS (HAASE et al., 1985; ERNST et al., 1995) é uma técnica de supressão de água, sendo essencial quando são medidos sinais de metabólitos em baixas concentrações na presença do forte sinal da água. Nesse caso, as linhas largas da água ficam sobrepostos aos pequenos sinais de metabólitos, isso produzindo erros na fase e na linha de base que são difíceis de se corrigir. Mais ainda, em alguns casos, o ganho do receptor não pode ser ajustado no máximo porque podem aparecer problemas de digitalização ou diminuição da relação sinal-ruído. O espectro pode aumentar drasticamente quando o sinal de água é bem suprimido.

A supressão da água pela técnica CHESS é obtida com a saturação da freqüência seletiva da magnetização da água seguida por um gradiente de campo magnético. Isso pode ser feito com um pulso de RF de $90^{\circ}$ na freqüência seletiva, levando a magnetização da água para o plano transversal, enquanto que os sinais dos metabólitos permanecem não excitados. Em seguida é aplicado um gradiente de campo magnético, logrando desta maneira destruir a coerência da magnetização transversal. 


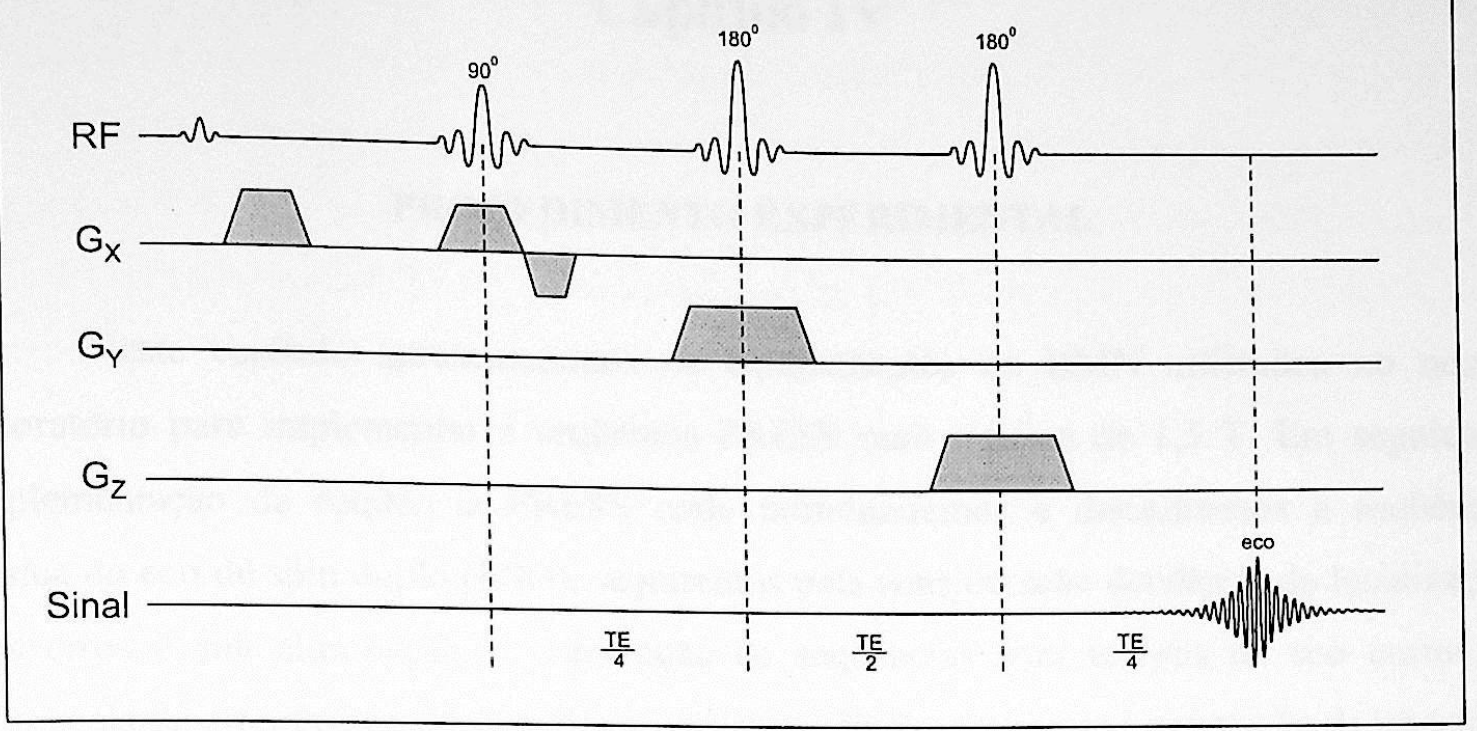

Figura 3.8 Seqüência PRESS combinada com a técnica de supressão de água CHESS.

Esta técnica de supressão de água precede as seqüências de espectroscopia localizada, como é mostrado na figura 3.8. (onde antecede à seqüência PRESS) obtendo assim os espectros do volume desejado com os metabólitos de interesse.

Os tempos de relaxação são importantes em vários métodos de localização em $\vec{B}_{0}$ devido ao tempo existente entre a localização e a deteção de sinal. Algumas seqüências de localização (por exemplo STEAM, PRESS) deixam a magnetização para localização de volume no plano transversal ao eixo rotacional ("rotating frame") quando os vários gradientes são aplicados. Nesse caso, o sinal é perdido devido à relaxação transversal, e o valor de $\mathrm{T}_{2}$ de uma dada ressonância será o fator determinante da eficiência de deteção local. Outras seqüências (por exemplo, ISIS, STEAM) deixam a magnetização para localização de volume na direção do campo $\vec{B}_{0}$ enquanto os gradientes são ligados. Nesse caso, o valor de $\mathrm{T}_{1}$ é importante para a eficiência da deteção . 


\section{Capítulo IV}

\section{PROCEDIMENTO EXPERIMEN'TAL}

Neste capítulo apresentaremos os equipamentos de RMN utilizados no nosso laboratório para implementar a seqüência PRESS num sistema de $1,5 \mathrm{~T}$, $\mathrm{Em}$ seguida a implementação da seqüência PRESS onde introduziremos e discutiremos a sequêneía básica do eco de spin duplo (ESD), seguiremos pela consideraçáo detalhada da tocalizaça dos erros e sua eliminação, a construção de sequéencias com tempos de exo curtos, a influencia de artefatos no deslocamento químico e finalmente a implementagan da interface para o usuário.

\subsection{Descricāo dos sistemas de medida.}

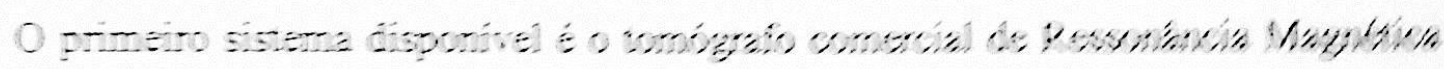

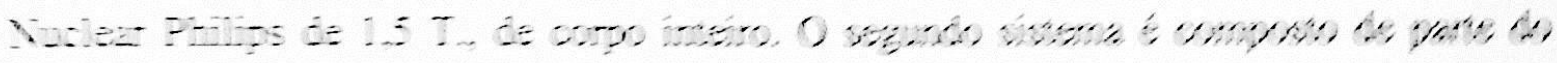

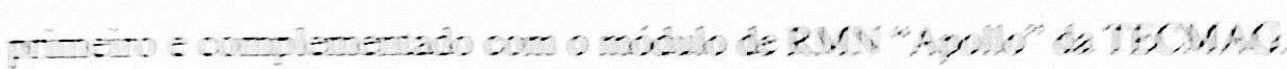

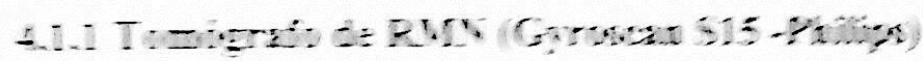

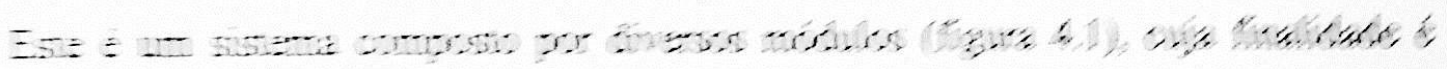

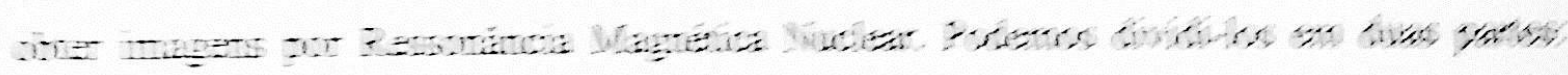

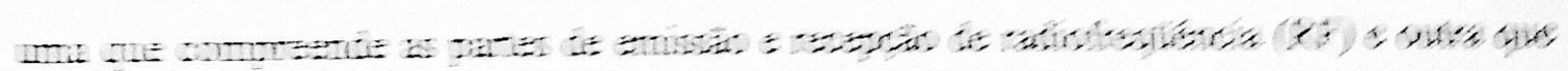

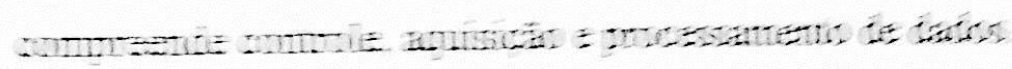

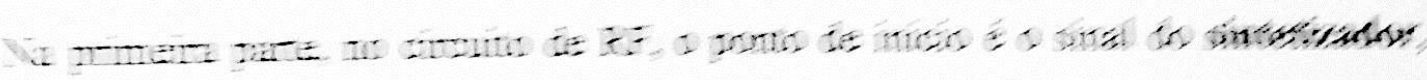

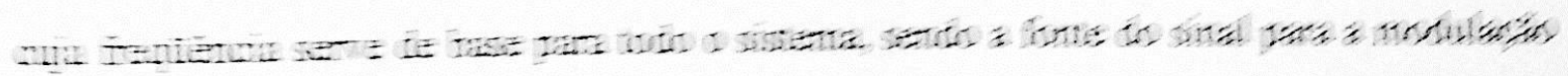

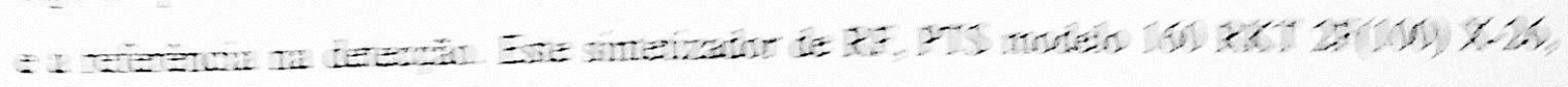

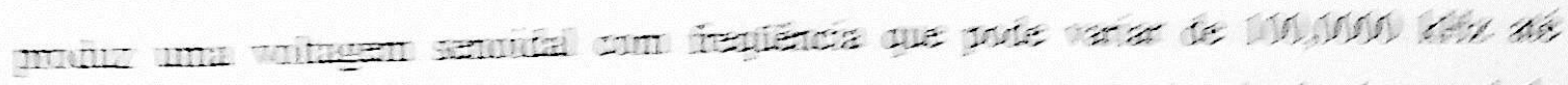

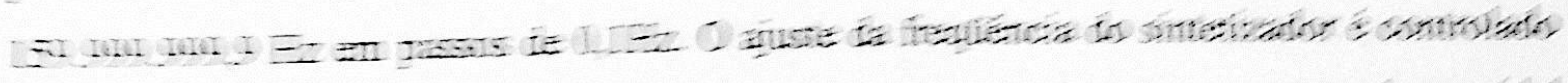

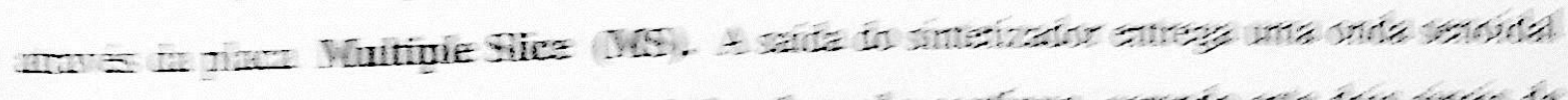

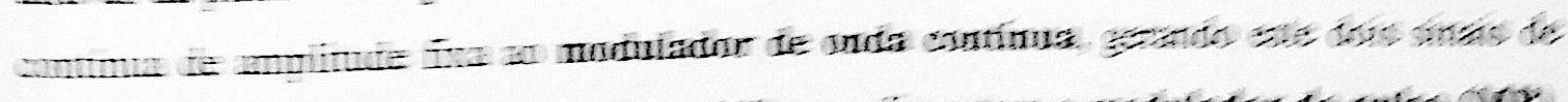

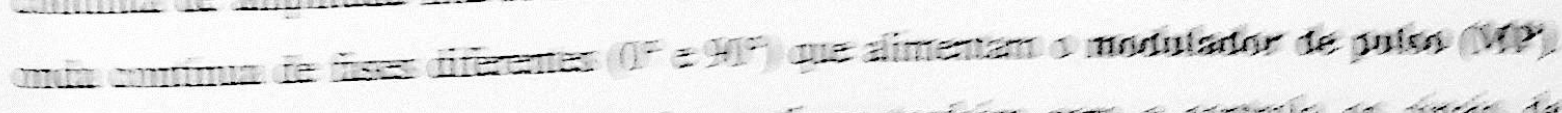

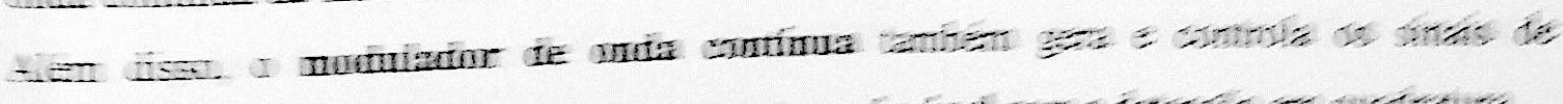

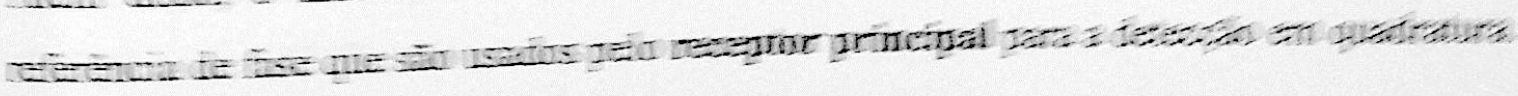


O modulador de pulso pode selecionar 4 fases de saídas diferentes, segundo a seqüência programada no programador de pulso; estas fases $\left(X+\left(0^{\circ}\right), X-\left(180^{\circ}\right), Y+\left(90^{\circ}\right)\right.$, $\mathrm{Y}-\left(270^{\circ}\right)$ ) tomam como referência o sinal de saída a $0^{\circ}$ do modulador de onda contínua. A seleção da fase de saída do modulador de pulso é controlada pela placa MS. O sinal de saída do modulador de pulso alimenta o modulador linear que, conjuntamente com o gerador de forma de onda provê pulsos de RF com amplitude modulada em DSB ("double side band"). Portanto, o sinal do RF é composto pelo sinal de saída do modulador de pulso e o sinal de baixa freqüência que vem do gerador de forma de onda, sendo este último controlado e atualizado pelo programador de pulso, que por sua vez é atualizado pela extensão do programador de pulso.

Os pulsos provenientes do modulador linear alimentam um atenuador de transmissão (controlado pela interface de RF), que controla a saída do sinal para o amplificador de $15 \mathrm{~kW}$ EHRHORN (modelo 53-S18-B) e desse modo a potência de saída. É necessário levar em conta que a potência deve ser controlada pelos seguintes motivos:

- A eficiência, qualidade das diferentes bobinas, requer ajustes de potências diferentes.

- Os diferentes volumes examinados, que são colocados nas bobinas, requerem um ajuste controlado da potência.

- Permitirá dessa maneira irradiar com a potência de RF adequada, protegendo o paciente.

O amplificador de potência de RF fornece a potência de RF para a bobina de transmissão ou transmissão/recepção, mas quando a energia do $R F$ excede um nível predeterminado o amplificador de potência de RF é desativado para proteger o paciente, o que é feito por uma unidade de monitoramento da potência (UMP). Esta unidade opera por controle de ganho do amplificador, por amostragem da RF amplificada.

Durante a transmissão a potência de RF é entregue a um duplexador, promovendo um isolamento entre o transmissor de RF e o receptor de sinais de RMN, para depois aplicá-la à bobina através do circuito de ajuste de impedância do pré - amplificador.

Após a excitação do sistema de spins o sinal de RMN é captado da bobina de transmissão ou transmissão/recepção durante o modo de recepção e pré-amplificado. Para isso faz-se uso de um pré-amplificador BRUKER modelo Z20A (12-125MHz) de ganho $43 \mathrm{~dB}$ (baixo) e $53 \mathrm{~dB}$ (alto), o qual é usado para:

a) Seleção da bobina. 
b) Seleção da condição experimental (transmissão, recepção, sintonia/ajuste de impedância, seleção de ganho)

Visando obter a melhor relação sinal/ruído, o ajuste do ganho $(5,24,38$, ou $52 \mathrm{~dB})$ do pré-amplificador é controlado pelo computador através da interface de RF.

Após a pré- amplificação, o sinal de MR é colocado dentro de um atenuador de recepção programável (atenuação entre $0-63 \mathrm{~dB}$ ), assegurando assim que a préamplificação do sinal de RF dê a amplitude desejada para a demodulação no receptor principal.

O atenuador de recepção é também controlado pela placa de interface de $\mathbf{R F}$, que converte os sinais do bus 1180 em sinais de controle para o atenuador de emissão e recepção, assim como controle de sintonia, entre outros.

O receptor principal - demodulador - compara os dois sinais de referência do modulador de onda contínua com o sinal recebido em um detector ortogonal sensível à fase. Dois sinais de referência são usados para demodulação: U(real) e V(imaginario), estando o último retardado de $90^{\circ}$ em relação ao primeiro.

Durante o modo de transmissão a entrada do receptor principal é protegida através da entrada do blanking sendo esta última controlada mediante o programador de pulso, através do driver de $\mathbf{5 0} \mathbf{O} \mathbf{h m}$. A função do driver é adaptar os sinais de saída do programador de pulso, onde cada sinal de saída tem uma polaridade e uma impedância selecionáveis.

Os dois sinais em baixa freqüência detectados são filtrados pelos filtros "passa baixa" na Unidade do Filtro de Áudio (Audio Filter Unit), antes que eles sejam amostrados pelas unidades de ADC (Analogic Digital Converter).

A unidade $\mathrm{ADC}$ recebe dois sinais analógicos $(\mathrm{U}, \mathrm{V})$ e envia dois sinais digitais para o computador, onde a faixa de amostragem (freqüência máxima de $100 \mathrm{KHz}$ ) é relacionada à resolução espacial.

Sob o comando do computador VAX-11/750 os dados são levados ao modo de saída no buffer FIFO (First In First Out) e enviados ao computador através de um módulo de interface DR11-W para reconstrução e processamento.

O módulo SPADIS (SPinoza Analogic - Digital Interface Segment) que adapta os sinais de controle (e dados) entre o computador e o subsistema de RF é uma parte do sistema, dividida em três blocos funcionais: Gerador de forma de onda, bus translator (BTR) e o ADC

O SPADIS tem as seguintes funções: 
- Controla por meio do gerador de forma de onda, além do que foi mencionado anteriormente, os sinais de forma de onda de baixa freqüência para os três gradientes.

- Converte através do ADC (16 bits) a informação analógica obtida que vem do receptor em dados digitais para posterior reconstrução da imagem.

- É responsável para a comunicação entre o computador e o subsistema de RF mediante o BUS-1180 (bus de dados de 21 bits bidirecional), gerenciado pelo bus translator.

O computador é responsável pelo gerenciamento e execução de todo software de controle e aquisição de imagens, bem como o carregamento desses programas nos respectivos módulos. Ele tem ainda como suas funções a transferência das imagens para o sistema de visualização e armazenamento dos dados e das imagens.

O computador VAX-11/750 é dividido em 4 partes, que de acordo a sua função são:

- Unidade central de processamento, que busca instruções da memória, as decodifica e em seguida executa as operações aritméticas, lógicas, e de controle.

- Subsistema da memória principal, que é um depósito para as instruções e os dados usados pelo unidade central de processamento.

- Subsistema console que permite ao operador do computador, carregar, controlar, monitorar e testar o sistema.

- Subsistema de entrada e saída que permite uma comunicação com os dispositivos dos periféricos.

Utilizamos um magneto, bobinas de gradiente e de shimming da OXFORD Modelo 2141, que consiste em um magneto supercondutor de operação em modo persistente, com um diâmetro útil de $50 \mathrm{~cm}$ e homogeneidade de campo de $13,25 \mathrm{ppm}$ em uma esfera de diâmetro de $50 \mathrm{~cm}$ e de $1,27 \mathrm{ppm}$ em uma esfera de diâmetro de $10 \mathrm{~cm}$. O sistema de bobinas de gradientes ortogonais e linear no espaço, necessários para a seleção de planos e à codificação espacial, é capaz de produzir gradientes de campo magnético com intensidade de até $10 \mathrm{mT} / \mathrm{m}$. O magneto dispõe de um conjunto de bobinas de shimming para tornar o campo magnético estático o mais homogêneo possível. A corrente nas bobinas de shimming é controlado pela tensão de saída das fontes que alimentam as mesmas, no modo local, através de um potenciômetro para cada bobina(no gabinete das bobinas de 
homogeneidade). No modo remoto a corrente é controlada pelo controlador de bobinas de homogeneidade.

O diagrama de blocos é mostrado na figura 4.1, e na figura 4.2 é mostrado o Magneto do tomógrafo comercial Philips (Gyroscan S15) que contem as bobinas de gradiente e shimming. 


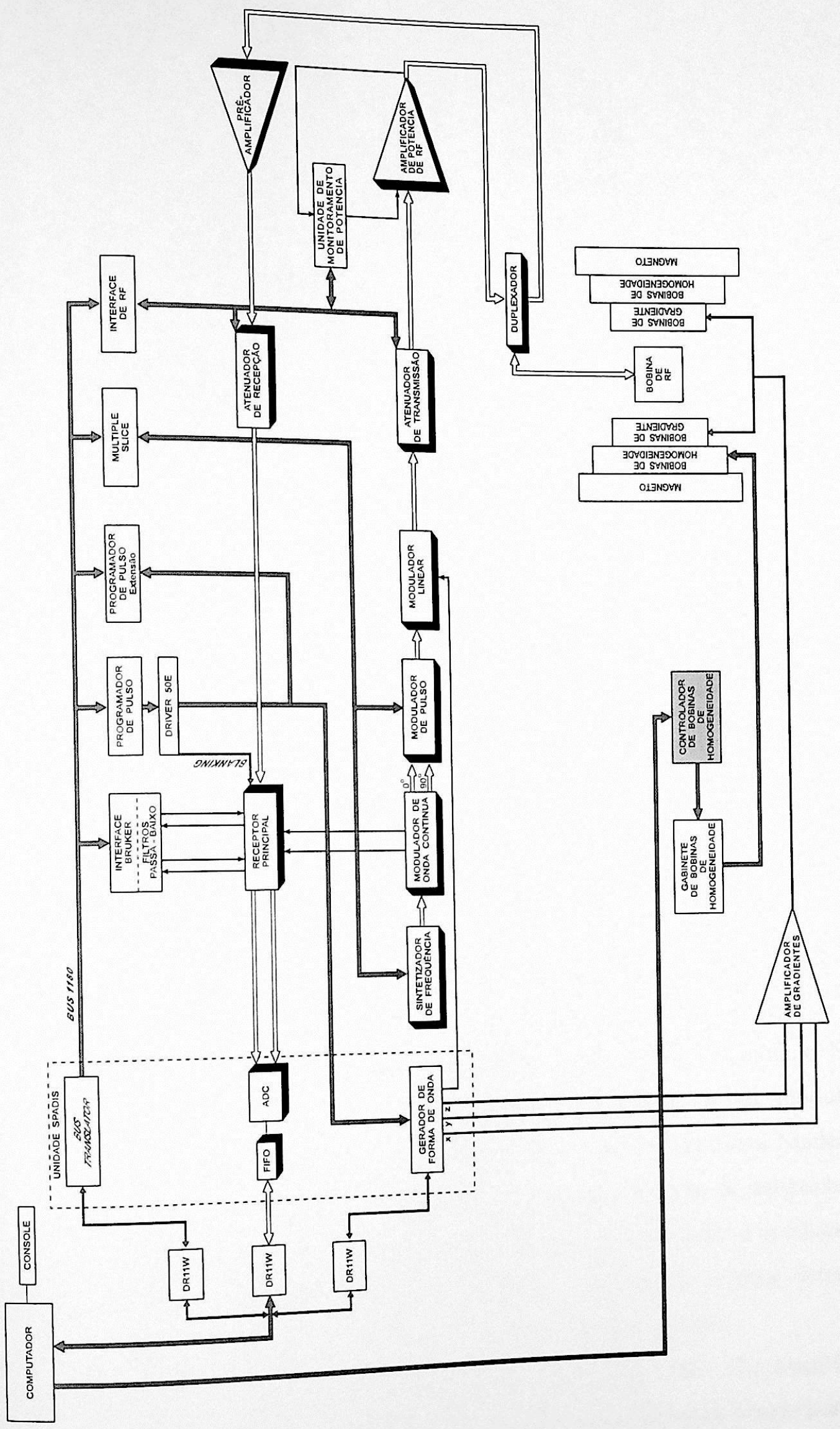

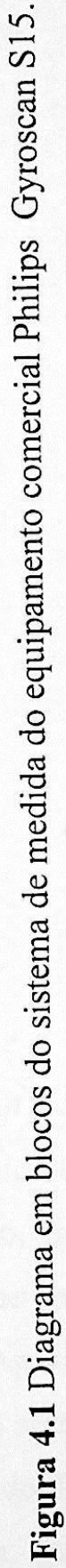




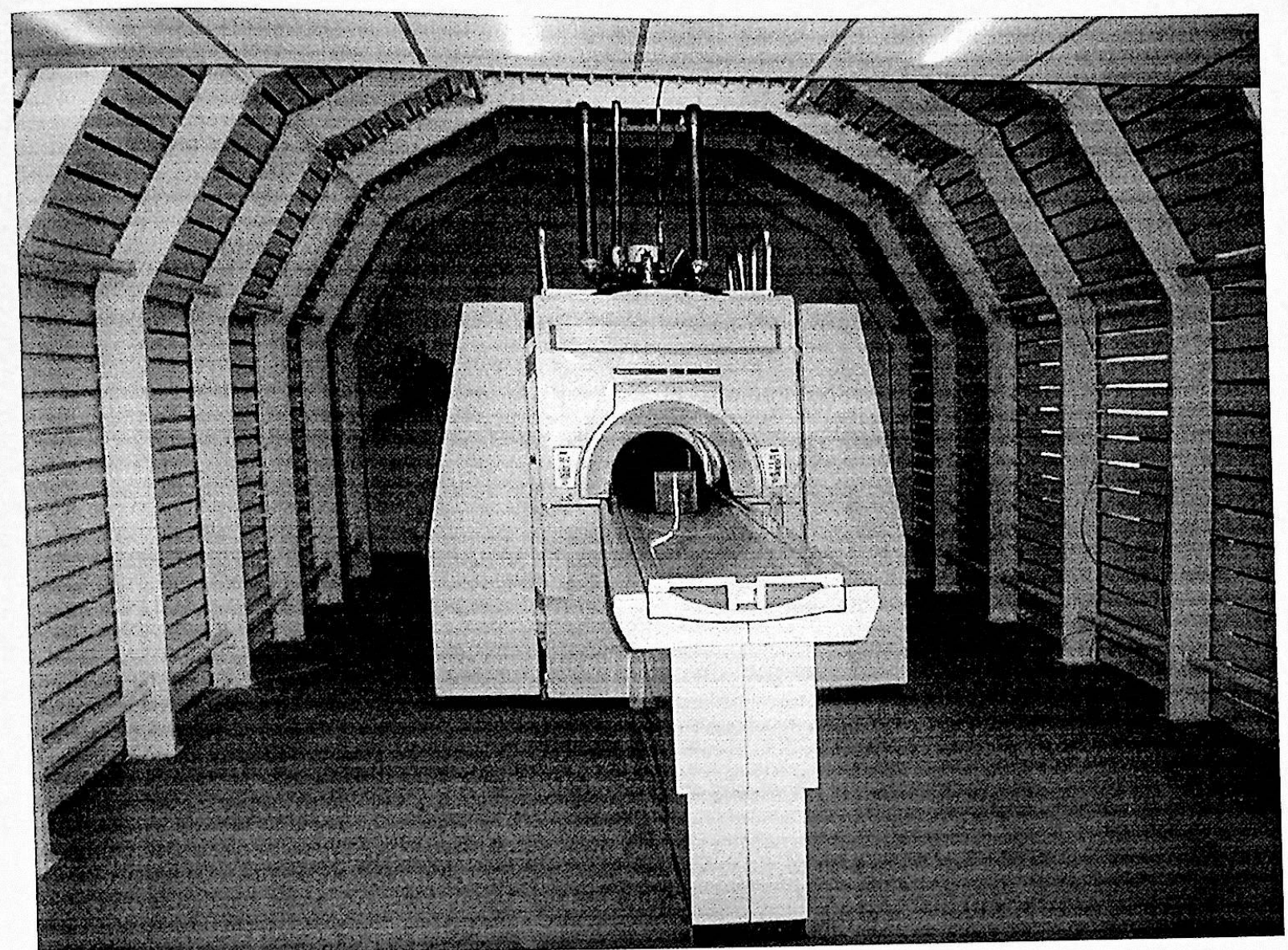

Figura 4.2 Magneto do tomógrafo comercial Philips (Gyroscan S15) que contém as bobinas de gradiente e shimming.

\subsubsection{Sistema de RMN: Gyroscan S15 da Philips - Apollo da Tecmag (GP-AT)}

É um sistema de RMN que resulta de utilizar parte do sistema do Gyroscan S15, aproveitando os amplificadores de gradientes, o imã supercondutor, bobinas de gradiente e de RF, complementando com o amplificador de potencia de $1 \mathrm{~kW}$ modelo N3446, préamplificador do MITEQ (Freqüência 10-500MHz), atenuador manual, módulo que gera formas de onda para o gradiente e o módulo de Ressonância Magnética Nuclear "Apollo" da TECMAG, que é responsável pela geração, excitação, recepção digitalização dos sinais, tendo as funções de gerar a freqüência de ressonância, controlar a modulação de RF, detectar o sinal em fase e quadratura, digitalizar e demodular o sinal detectado, gerar eventos em tempo real, e colocar os outros módulos em sincronismo.

Os pulsos provenientes do gerador de formas de onda são amplificados pelo amplificador de gradientes como mostra a figura 4.3, e só então será levado para as bobinas a fim de gerar os gradientes $x, y, z$. Cada canal $(x, y, z)$ gera pulsos independentes. 
A radiofreqüência, após de ser modulada, passa por um atenuador manual cuja função é ajustar o ângulo de excitação desejado, e depois por um amplificador de potência. A RF então é enviada para a bobina de radiofreqüência, onde a amostra é irradiada.

A recepção do sinal e feita pela própria bobina, e o sinal detectado é amplificado pelo pré-amplificador de baixo ruído da Miteq e passa por um atenuador para ajustar sua amplitude. No Apollo, este sinal é detectado numa freqüência intermediaria, digitalizado, detectado digitalmente de forma a completar a detecção até a freqüência base e os dados digitais são transferidos para uma memória interna, onde é feito o processo de promediação. A partir daí o sinal digitalizado é enviado para o computador, onde os dados são armazenados e o espectro ou imagem obtida através da transformada de Fourier, visualizada no mesmo computador.

O canal do transmissor do RF é composto por um DSP (Digital Signal Processor) conduzido por DDS (Direct Digital Synthesizer) baseado no sintetizador de freqüência e de uma placa de modulação de transmissão, onde a placa do transmissor fornece a modulação da amplitude.

O receptor digital é composto de duas seções. A primeira seção de RF demodula o sinal a uma freqüência intermediária (FI) de 11,25 MHz. Na segunda seção ocorrera digitalização direta e sobre o sinal de amostragem de FI com 12 bits de resolução, seguida por um filtragem digital com uma largura de banda de $2 \mathrm{~Hz}$ a $300 \mathrm{kHz}$, eliminando erros na deteção de quadratura e na linha de base.

O console do Apollo usa um computador Pentium II, usando o sistema operacional Windows NT e o software NTNMR de controle do espectrômetro carregados e modificados para a configuração especifica. O controle do instrumento, edição das seqüências de pulsos, processamento de dados, e visualização é realizado através da interface de NTNMR. Especificamente para a seqüência PRESS implementada foi feito uma interface gráfica.

Na figura 4.3 mostramos o diagrama simplificado do sistema de medidas GyroscanApollo da Tecmag, e na figura 4.4 mostramos o módulo Apollo da Tecmag, Gerador de funções (superior esquerda), Amplificador de RF( inferior esquerda), e o console do Apollo (Computador Pentium II). 


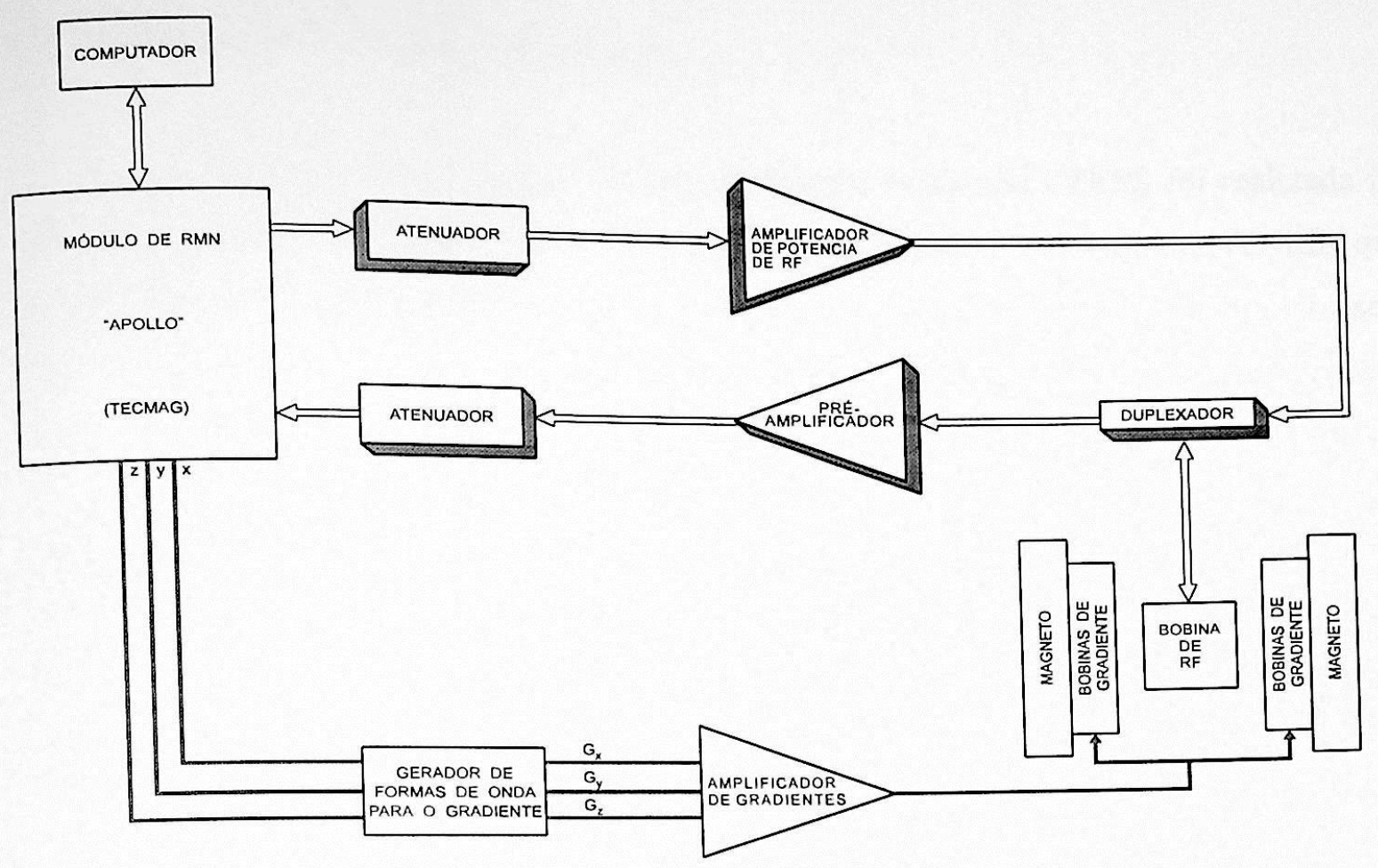

Figura 4.3 Diagrama simplificado em blocos do sistema de medida Gyroscan- Apollo da Tecmag

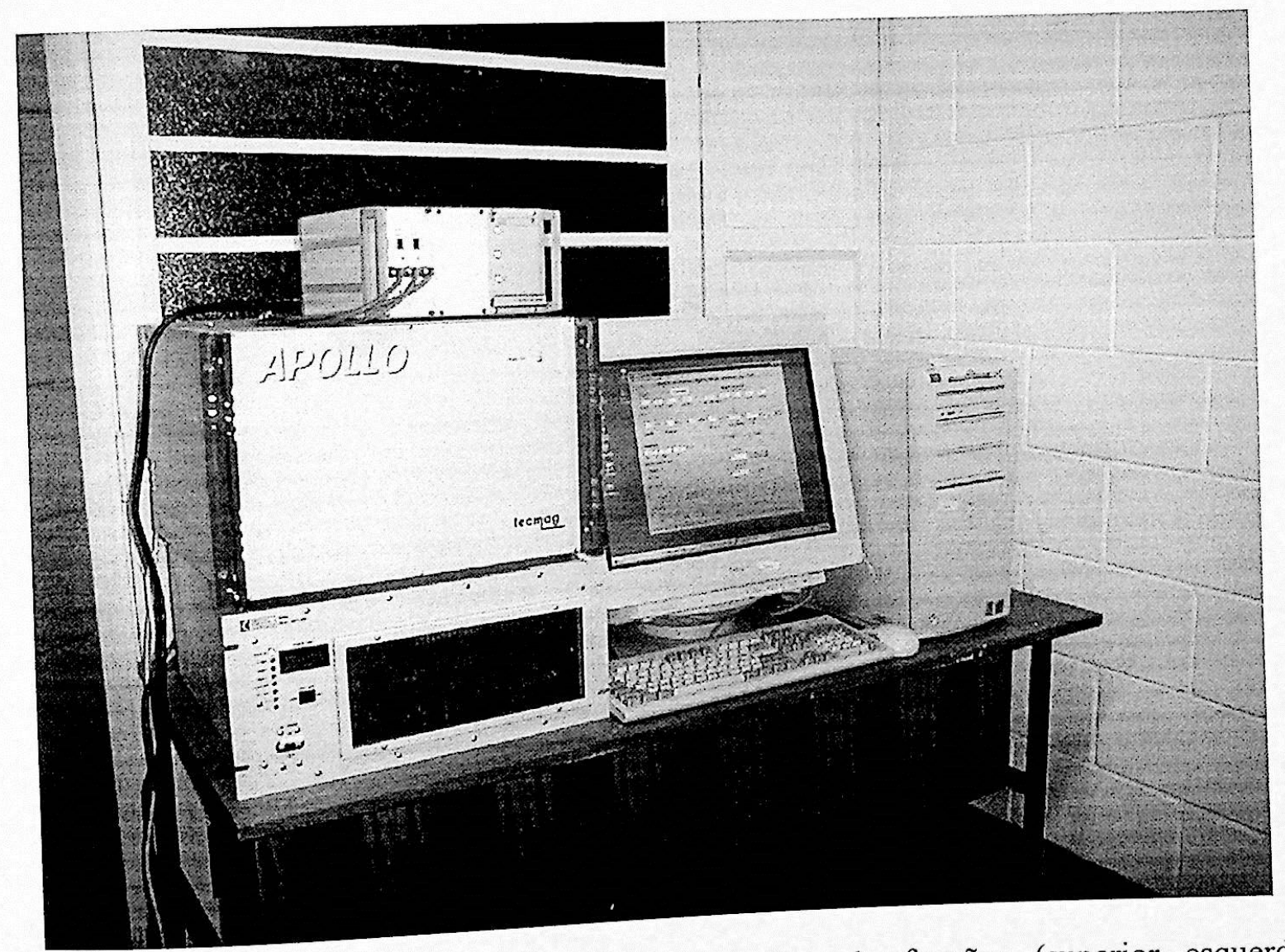

Figura 4.4 Módulo Apollo da Tecmag, Gerador de funções (superior esquerda), Amplificador de RF( inferior esquerda), e o console do Apollo (Computador Pentium II). 


\subsection{Implementação da seqüência PRESS}

A implementação da técnica de espectroscopia localizada PRESS foi realizada no sistema de RMN Gyroscan S15/HP - Apollo/Tecmag, usando o software de NTNMR que permite controlar todos os parâmetros necessários para a implementação, embora isso seja feito de uma maneira complexa, o que nos levou a implementar uma interface para o usuário, otimizando desta forma a seqüência.

Como sonda utilizamos uma bobina em configuração de gaiola (bird cage), onde o ajuste para o casamento de impedâncias (matching) e o ajuste fino da freqüência da bobina (tuning) são feitos com o sistema Gyroscan S15.

Agora nos referiremos à implementação da técnica propriamente dita. A técnica PRESS de espectroscopia localizada está baseada no método do eco de spin duplo $90^{\circ}-180^{\circ}-$ $180^{\circ}$ (BOTTOMLEY, 1987 e 1982; GORDON et al, 1984) como foi mencionado no capitulo III. Esta técnica requer uma seqüência especial de pulsos para garantir que o espectro origina-se de um volume único e bem definido - o VOI. A seqüência de eco de spin duplo é mostrada na figura 4.5 (JUNG et al., 1989, 1990 e 1996), onde os intervalos entre os pulsos devem obedecer às condições para a formação do eco, o que significa que o tempo da seqüência de pulsos é representado pelo seguinte trem de pulsos:

$$
90^{\circ}-t_{1}-180^{\circ}-\left(t_{1}+t_{2}\right)-180^{\circ}-t_{2}-e c o
$$

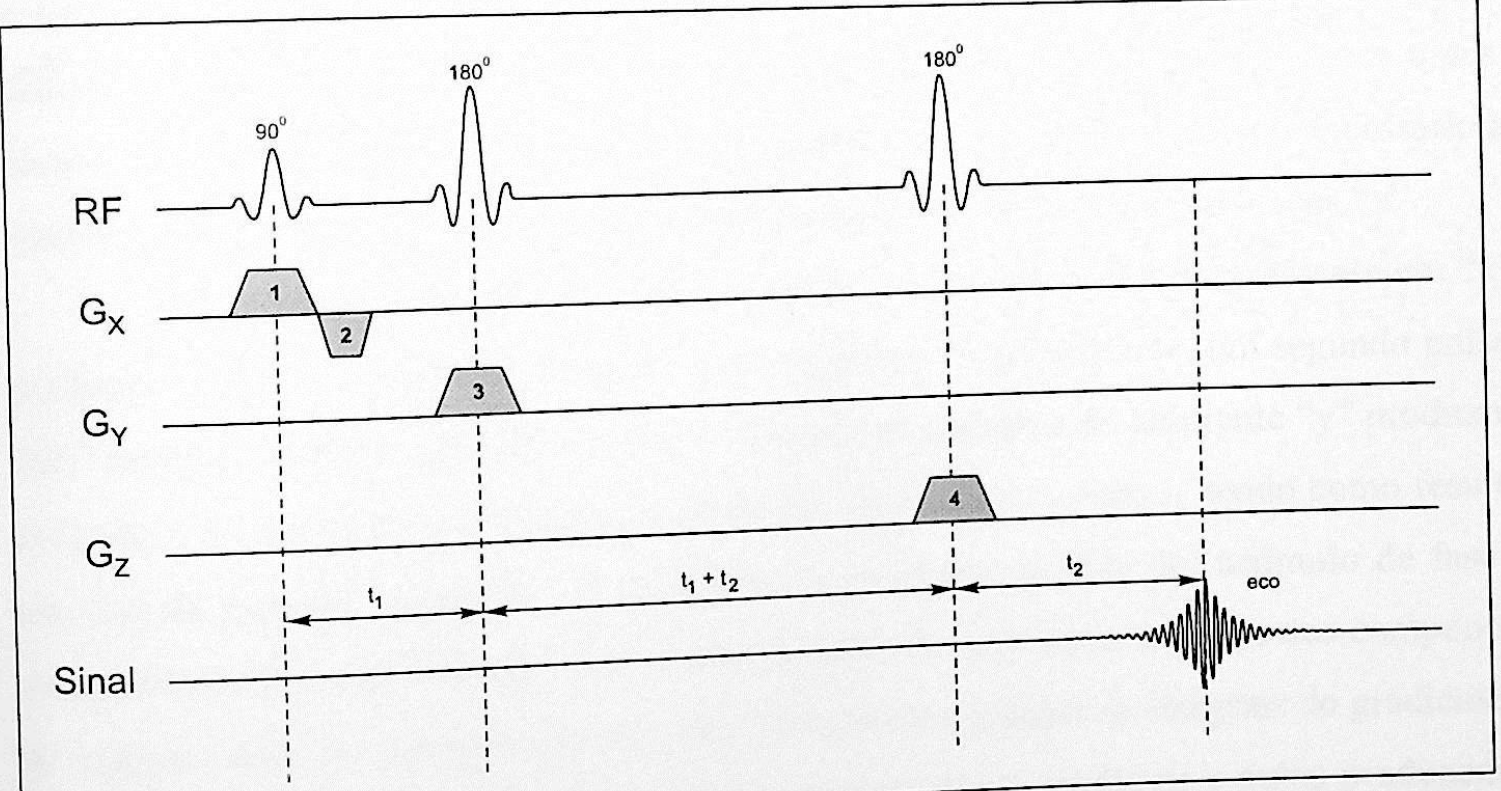

Figura 4.5 Seqüência básica de ESD sem gradientes spoilers para espectroscopia localizada: $90^{\circ}-t_{1}-180^{\circ}-\left(t_{1}+t_{2}\right)-180^{\circ}-t_{2}$-aquisição, sendo o tempo do eco $\mathrm{TE}=2 \mathrm{t}_{1}$ $+2 t_{2}$. 
Dentro desses limites os tempos $t_{1}$ e $t_{2}$ são arbitrários. O deslocamento químico e as inomogeneidades de campo são refocalizados no tempo de eco máximo. O começo da aquisição dos dados é normalmente simultâneo ao tempo de eco máximo do segundo eco obtido com o trem de pulso. O tempo de eco da seqüência do eco de spin duplo é definida como $T E=2 t_{1}+2 t_{2}$

\subsubsection{Método básico de eco de spin duplo}

O método básico ESD é mostrado na figura 4.5, onde temos um esquema indicando quando os pulsos de RF e os gradientes são aplicados. Esse esquema não reflete necessariamente as verdadeiras relações das durações e amplitudes do gradiente e dos pulsos de RF.

No começo da seqüência o primeiro gradiente em " $\mathrm{x}$ " é ligado. Quando a intensidade desejada do gradiente for obtida, ele é mantido constante. Os gradientes constantes em " $x$ " fazem com que a freqüência de Larmor aumente linearmente ao longo da coordenada "x". Então, um pulso de RF ( $\operatorname{sinc}$ ) seletivo de $90^{\circ}$ é aplicado para excitar um intervalo definido de freqüência. Apenas os componentes da magnetização com a freqüência de precessão de Larmor são afetados por esse procedimento, o que significa que uma fatia foi selecionada.

$O$ processo da seleção da fatia " $x$ " é completada pela aplicação do gradiente de refocalização (gradiente 2) aplicado na direção " $x$ ". Esse gradiente é necessário porque durante o processo de seleção da fatia os momentos magnéticos se defasam antes de alcançarem o plano transversal. Portanto, o gradiente 2 é aplicado no tempo necessário para restabelecer a fase das componentes de magnetização em todas as coordenadas " $x$ ".

Após a seleção da fatia " $x$ " pelo pulso de $90^{\circ}$, na presença do gradiente em " $x$ ", 0 gradiente 3 em "y" é aplicado. Depois que o gradiente fica constante, um segundo pulso de $180^{\circ}$ seletivo de RF é aplicado. O pulso aplicado na presença do gradiente "y" produz uma inversão das componentes de magnetização na fatia " $y$ " no tempo $t_{1}$, tendo como resultado um eco de spin no tempo $2 t_{1}$. O gradiente 3 novamente produz um acúmulo de fase nas componentes da magnetização. Entretanto, o pulso de $180^{\circ}$ inverte a fase dos componentes de magnetização de maneira que eles são refocalizados quando as integrais do gradiente são iguais antes e depois do pulso. Descritos dessa maneira, o gradiente e pulso produzem um eco de spin na intersecção das duas fatias ortogonais e uma área é selecionada. 
Decorrido um tempo $t_{2}$, após o primeiro spin eco, a terceira seleção de fatia, agora na direção "z" é feita. Os gradientes e pulso são idênticos aos usados na escolha da fatia "y". Um pulso de $180^{\circ}$, em combinação com um gradiente 4 em " $z$ ", produz um spin eco no tempo $2 t_{1}+2 t_{2}$, originário da intersecção das 3 fatias ortogonais.

Na prática, a primeira metade do eco não é registrada; isso acontece porque a aplicação do gradiente " $z$ " na última seleção de fatia distorce essa parte do sinal. Com grandes tempos de eco é obtida uma separação suficiente entre este gradiente e a primeira metade do sinal de spin eco. Desta forma assim a aquisição de todo o eco aumenta a relação sinal/ruído.

\subsubsection{Erros de localização e sua eliminação}

\section{A) Aparecimento de erros de localização}

A seqüência básica como é mostrada na figura 4.5 e que foi discutida anteriormente não dá um eco de spin que se origina apenas em um VOI bem definido. Uma explicação para isso é que os pulsos seletivos de fatias são imperfeitos.

Esse fato é mostrado na figura 4.6 para um pulso de $180^{\circ}$ pelas magnetizações transversal (MT) e longitudinal (MZ), obtidas após a aplicação do pulso sinc de $180^{\circ}$ (JUNG, 1996). A inversão do perfil do pulso de $180^{\circ}$ (representada por MZ na figura 4.6) é relativamente boa, apenas com uma pequena contribuição do volume externo à fatia escolhida. Entretanto, fora da região central da fatia selecionada o pulso de seleção de fatia produz pulsos com ângulos diferentes de $180^{\circ}$, o que resulta na magnetização transversal observada, como mostrado no lado esquerdo da figura 4.6. Chamamos esses componentes de magnetização transversal indesejados do pulso de $180^{\circ}$, de componentes do FID do pulso de $180^{\circ}$, esses componentes levam a erros de localização que devem ser eliminados. 


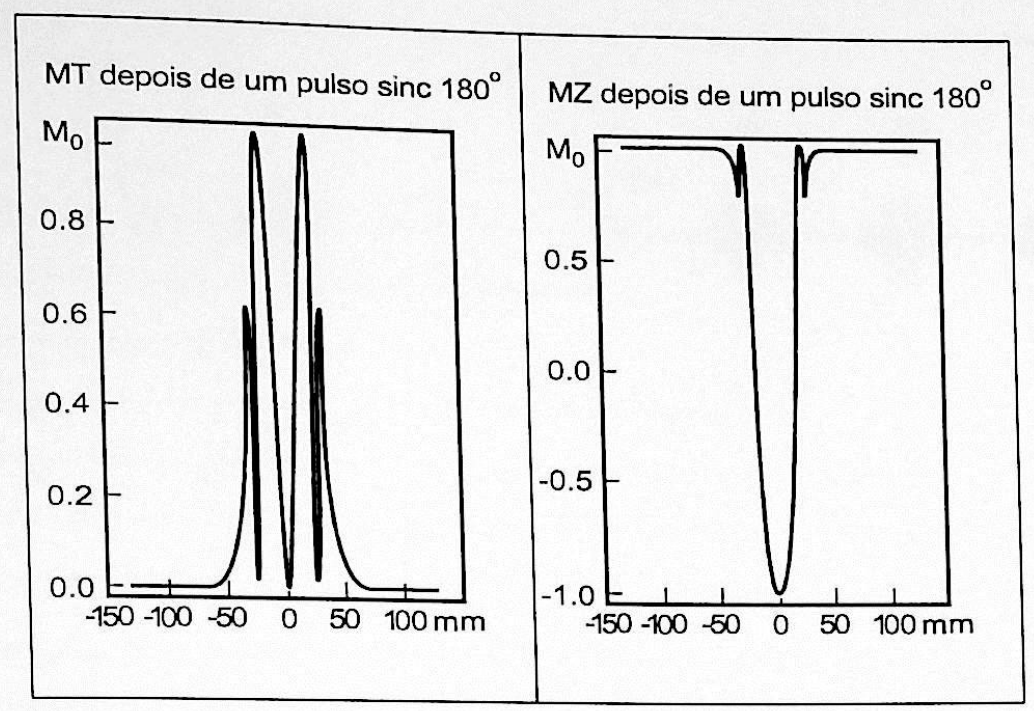

Figura 4.6 Magnetização transversal e longitudinal depois da aplicação do pulso sinc. A grande componente da magnetização transversal externa á fatia leva aos componentes indesejados na espectroscopia localizada de spin eco duplo (JUNG, 1996).

Considerando as distribuições angulares dos 3 pulsos, a seqüência de ESD aplicada pode ser escrita como um segundo trem de pulsos:

$$
\alpha-t_{1}-\beta-\left(t_{1}+t_{2}\right)-\gamma
$$

Os ângulos dos pulsos $\alpha, \beta$, e $\gamma$, dependem do ponto espacial dentro do VOI. Essa seqüência representa uma forma geral para a seqüencia dos 3 pulsos. Como mostrado primeiramente por Hahn (HAHN, 1950), vários sinais aparecem quando essa seqüência é aplicada a um sistema de spins (HENNIG, 1991a e 1991b). A aplicação da seqüência 4.2 resulta em oito sinais, como é mostrado na figura 4.7. Os três pulsos de RF produzem sinais de FID após suas aplicações ao sistema de spins: FID1 em $t=0$; FID2 em $t_{1}$, e FID3 em $2 t_{1}$ $+t_{2}$. O segundo pulso de RF dá o eco de spin SE1 do FID1 em 2t $t_{1}$. Depois do terceiro pulso de RF vários ecos aparecem, o eco estimulado (STE) ocorre em $t_{1}$ após o terceiro pulso de $R F$, em $3 t_{1}+t_{2}$. A razão para o aparecimento do STE é discutida na referência (HAHN, 1950). O sinal desejado do eco de spin duplo SE2 ocorre em $2 t_{1}+2 t_{2}$ como um eco originado de SE1 pela aplicação do terceiro pulso de RF. O SE3 ocorre em $3 t_{1}+2 t_{2}$ e representa o eco do FID2 produzido pelo terceiro pulso de RF. O SE4, em $4 t_{1}+t_{2}$, é o eco de FID1 produzido por esse pulso de RF. Se ao invés de $\beta$ e $\gamma$ forem dados pulsos perfeitos de $180^{\circ}$, apenas os FID1, SE1, SE2, e SE4 aparecerão. Assim, os quatro sinais FID2, FID3, STE e SE3 resultam do uso de pulsos de refocalização imperfeitos. 


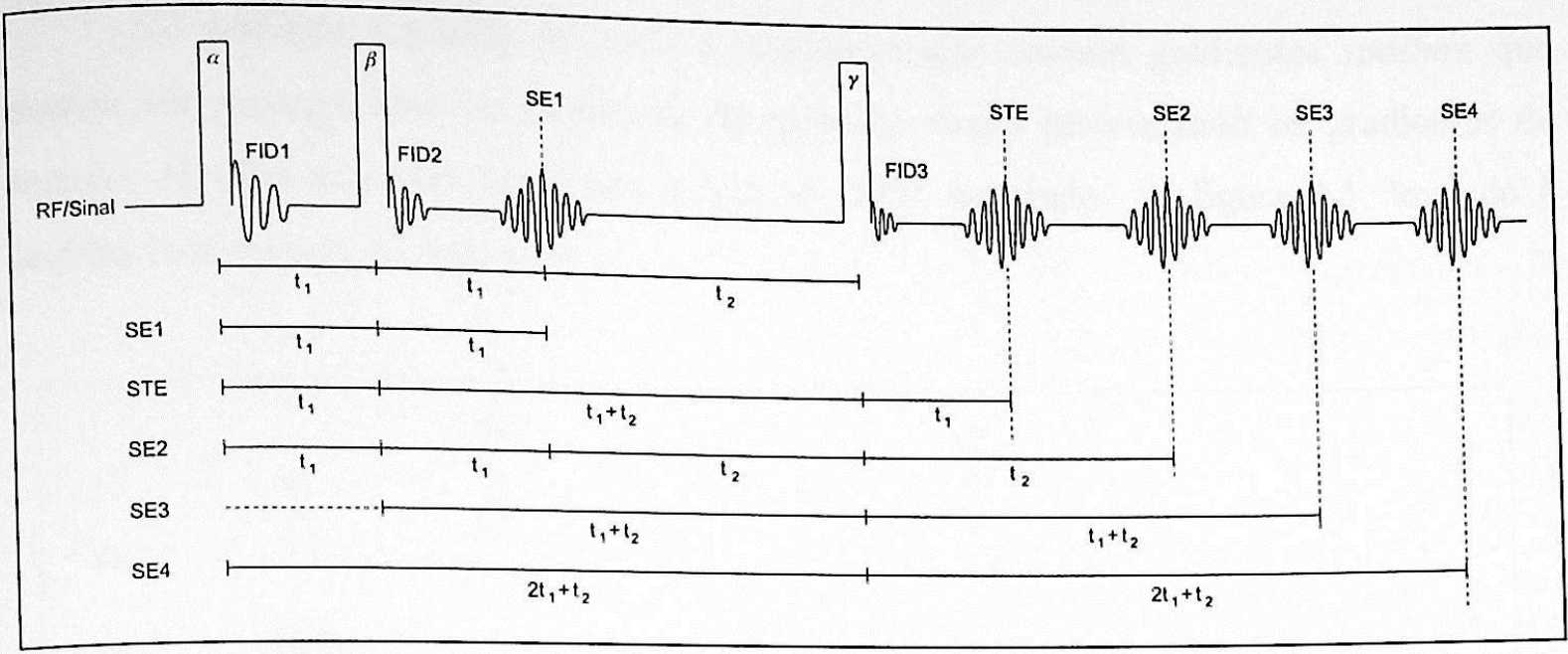

Figura 4.7 A aplicação dos três pulsos de $\mathrm{RF}(\alpha, \beta$ e $\delta$ ) resulta em três sinais de FID e em cinco sinais de eco. As intensidades não são dadas em escala porque todos os sinais dependem dos ângulos dos pulsos usados e também dos tempos de relaxação.

Os sinais das 3 fatias selecionadas podem contribuir para o sinal obtido, como é mostrado na figura 4.8 (o sinal desejado é mostrado em cor preta). Todas as outras regiões excitadas levam a contribuições indesejáveis para o sinal total. Esses sinais indesejados são os componentes de FID das 3 fatias, os sinais de spin eco de todas as intersecções possíveis de 2 fatias é o sinal de STE originário da intersecção das 3 fatias, isto é, do VOI. O sinal de STE representa normalmente uma distorção indesejada no sinal do eco de spin duplo.

\section{B) Eliminando erros por gradientes spoilers}

Existem várias maneiras de eliminar os componentes indesejados do sinal. Entre elas temos a eliminação de erros pela fase cíclica (JUNG, 1996), no qual as fases dos pulsos são escolhidas de forma que os sinais indesejados sejam eliminados após a soma das várias aquisições, enquanto que o sinal desejado é adicionado. Um exemplo: a inversão de fase do segundo pulso de RF entre 2 aquisições faz com que os sinais de FID2 tenham fase oposta, conseqüientemente eles se cancelarão quando os sinais forem somados. Por outro lado, o sinal do eco de spin duplo, SE2, possui a mesma fase nos dois casos, levando a uma adição construtiva. Esse é apenas um exemplo. Esquemas mais sofisticados de fase cíclica são bem documentados pela literatura (FREEMAN, 1988). Uma desvantagem da fase cíclica é que as condições para toda as aquisições necessárias para completar uma fase cíclica devem ser idênticas. É muito dificil obter condições idênticas, especialmente para medidas in vivo devido ao movimento do objeto e também ao fluxo sanguíneo. 
No presente trabalho foi feita a implementação usando gradientes spoilers que podem ser incorporados na seqüência de spin eco duplo prolongando os gradientes de seleção de fatia nos dois lados dos pulsos de $180^{\circ}$ mostrados na figura 4.5 , levando à sequiência mostrada na figura 4.8 .

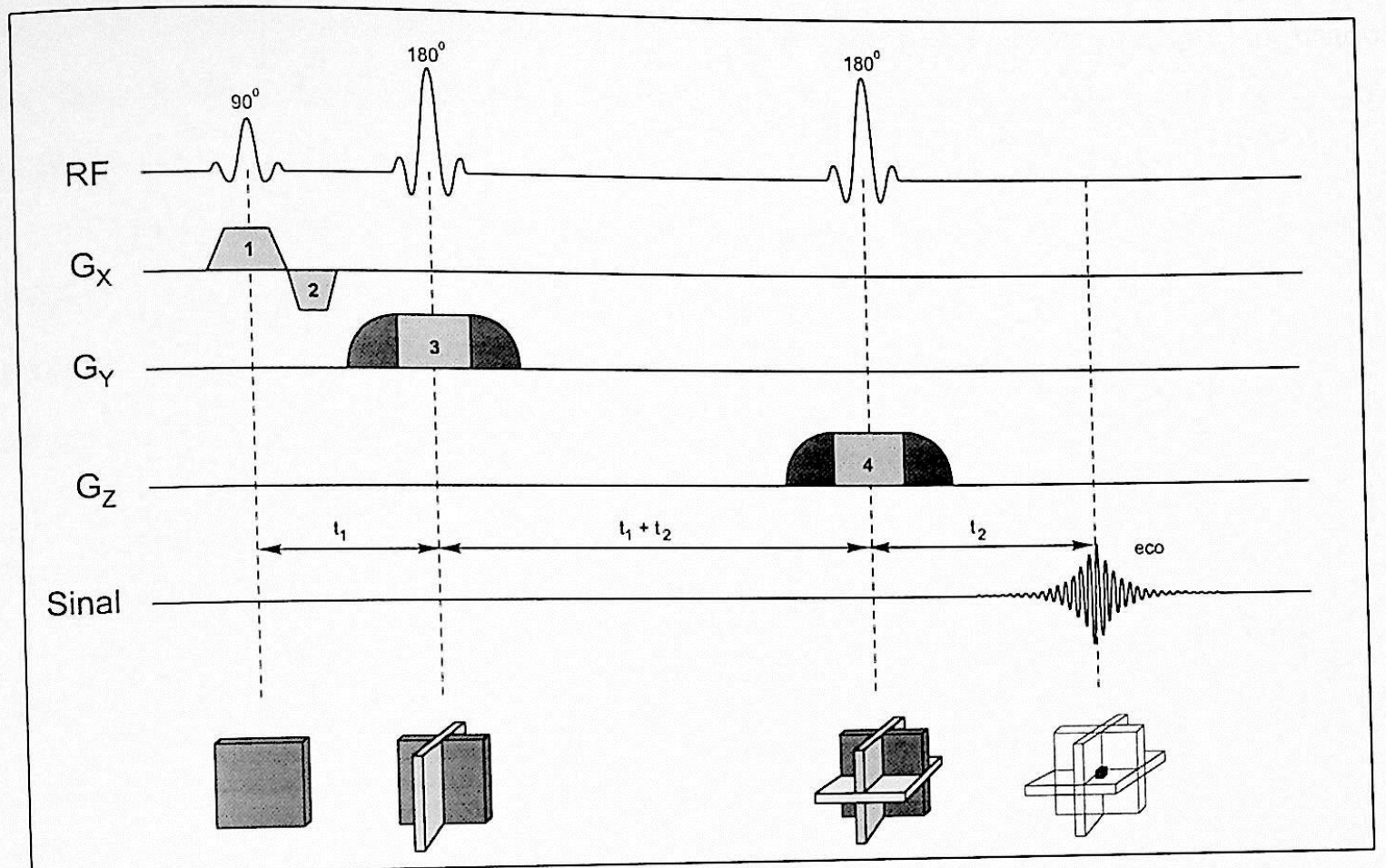

Figura 4.8 Seqüência do spin eco duplo com gradientes de seleção 3 e 4 prolongados em comparação à figura 4.5 , onde os gradientes de cor cinza são os gradientes spoilers. Na parte inferior se mostra de modo gráfico a seleção das fatias e finalmente a localização do VOI.

Os gradientes "spoilers" mostrados na figura 4.8 eliminam todos os componentes indesejados do sinal. O FID1 é um sinal desejado mas apenas na sua parte que é proveniente do VOI. As magnetizações de regiões externas ao VOI, que são excitadas pelo primeiro pulso mas não por um pulso de RF adicional, são defasadas pelo gradientes 3 e 4 , levando às suas eliminações. O FID2 é completamente eliminado pelo gradiente spoiler 3 que é aplicado depois do segundo pulso de RF. Como não se usa o gradiente em "y" nessa sequiência, o FID2 seguramente não é refasado. O FID3 é eliminado da mesma maneira que o FID2 mas pelo gradiente spoiler 4. O SE1 é um sinal desejado, porém unicamente a parte proveniente do VOI. As magnetizações das regiões externas ao VOI que possuem SE1 mas que não são excitadas pelo terceiro pulso de RF são defasadas pelo gradiente 4 . $O$ sinal de STE não depende dos gradientes aplicados entre o segundo e terceiro pulsos de RF 
(HAHN, 1950). Assim, o STE é eliminado apenas por gradientes aplicados antes do segundo ou após o terceiro pulso de RF. Isso é feito pela primeira metade do gradiente $3 \mathrm{e}$ pela segunda metade do gradiente 4. Ambos gradientes resultam em um STE defasado, pois não são refasados durante a seqüência antes do segundo pulso ou após o terceiro. O SE3 é eliminado pela segunda metade do gradiente 3, e o SE4 é eliminada pelas duas metades do gradiente 3 , porque ela não é refocalizada durante a seqüência de pulsos. O eco de spin duplo SE2 desejado é o único sinal que não é eliminado pelos gradientes spoilers usados. De fato, o sinal do eco de spin duplo é completamente refocalizado pelos gradientes spoilers.

Os gradientes spoilers permitem a localização completa em uma aquisição (scan). Assim, é possível localizar no objeto investigado diretamente o volume VOI desejado. O espectro do eco de spin duplo mostra larguras de linhas muito menores após a localização precisa do VOI do que após a localização do objeto total com a sequiência de FID.

É mais eficiente incorporar os gradientes spoilers como maiores amplitudes do que as usadas para as seleções de fatias ou usar gradientes adicionais, como mostrado a seguir.

\subsubsection{Artefatos do deslocamento químico}

O processo de seleção de fatias por gradientes é influenciado pelos deslocamentos químicos dos sinais analisados. A variação de freqüência induzida pelo gradiente é superposta à variação de frequiência devido ao deslocamento químico fazendo com que os sinais de diferentes metabólitos procedam de lugares deslocados. A diferença dos deslocamentos químicos $\Delta \delta$ resulta em 2 fatias em diferentes posições para gordura e água por exemplo que são deslocadas espacialmente por $\Delta$ dado por:

$$
\Delta s=\Delta \delta \frac{B_{0}}{G}
$$

O forte gradiente de seleção de fatia $G$ produz um deslocamento pequeno, mas o artefato produzido pelo deslocamento químico $\Delta s$ aumenta com a diferença dos deslocamentos químicos dos metabólitos e o campo magnético $B_{0}$. Portanto, este tipo de artefato pode ser diminuído incrementando o gradiente de localização. 


\subsubsection{Implementação da interface para o usuário}

No segundo sistema de medidas (item 4.1.2) foi implementada a técnica de espectroscopia localizada, mas para o controle dinâmico dos parâmetros foi desenvolvida uma interface amigável feita em "Visual Basic" mostrada na figura 4.9, permitindo ao usuário ter um controle total dos parâmetros da seqüência como posicionamento, dimensões do volume desejado (figura 4.10), tempo do eco, tempo de repetição, calibração dos pulsos entre outros.

Dado que na técnica de espectroscopia precisa-se de informação espacial de forma que o sinal do espectro localizado seja de uma região bem definida da amostra, foi preciso implementar a seqüência de eco de spin para obter uma imagem e assim localizar o VOI.

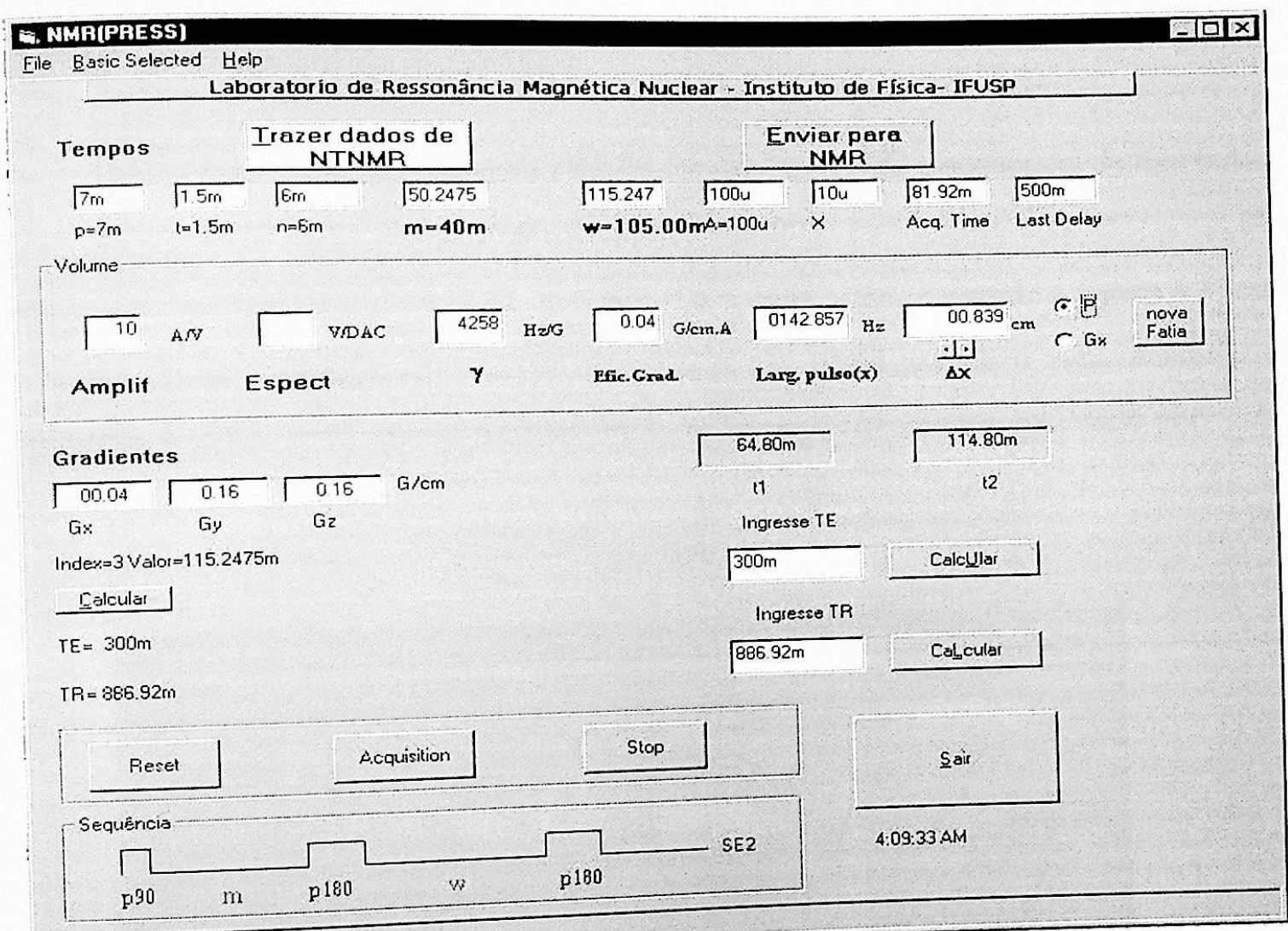

Figura 4.9 Tela da interface feito para Espectroscopia localizada "in vivo" no "Apollo". 


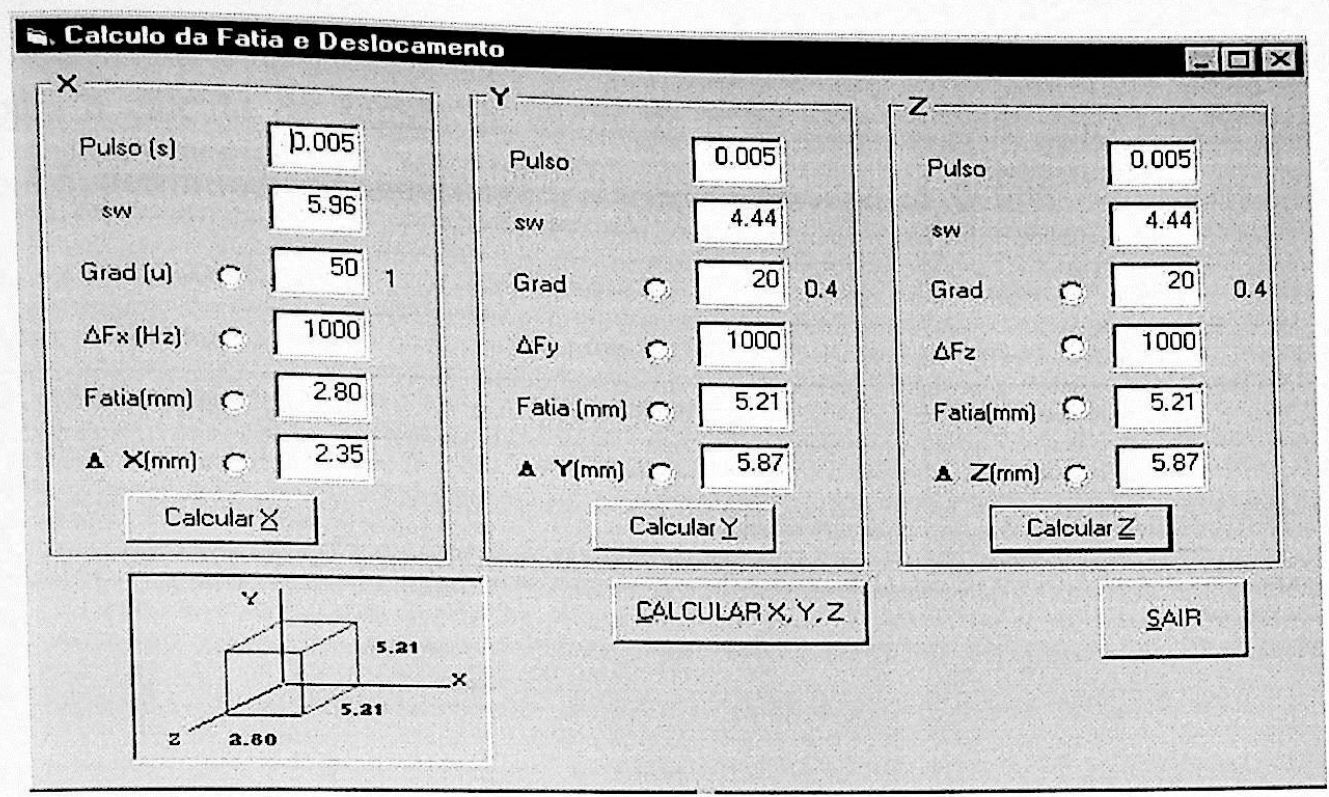

Figura 4.10 Permite obter as dimensões do VOI a partir de mudanças em parâmetros como tempo do pulso, intensidade do gradiente

Tentando otimizar a seqüência PRESS foi implementada a seqüência de três pulsos:

$$
\alpha-\tau-\alpha-3 \tau-\alpha
$$

fazendo que no trem de pulsos (4.2), $\alpha=\beta=\gamma$ e $t_{2}=2 t_{1}=2 \tau$, e usando a figura 4.7 temos que o ângulo de excitação efetivo (MUELLEN et al., 1986) usando o valor absoluto das amplitudes de SE2 e SE3 que se formam em $6 \tau$ e $7 \tau$ respectivamente, está dado por:

$$
\alpha=2 \operatorname{Arctan}\left(\frac{1}{1-S E 3 / S E 2}\right)^{1 / 2}
$$

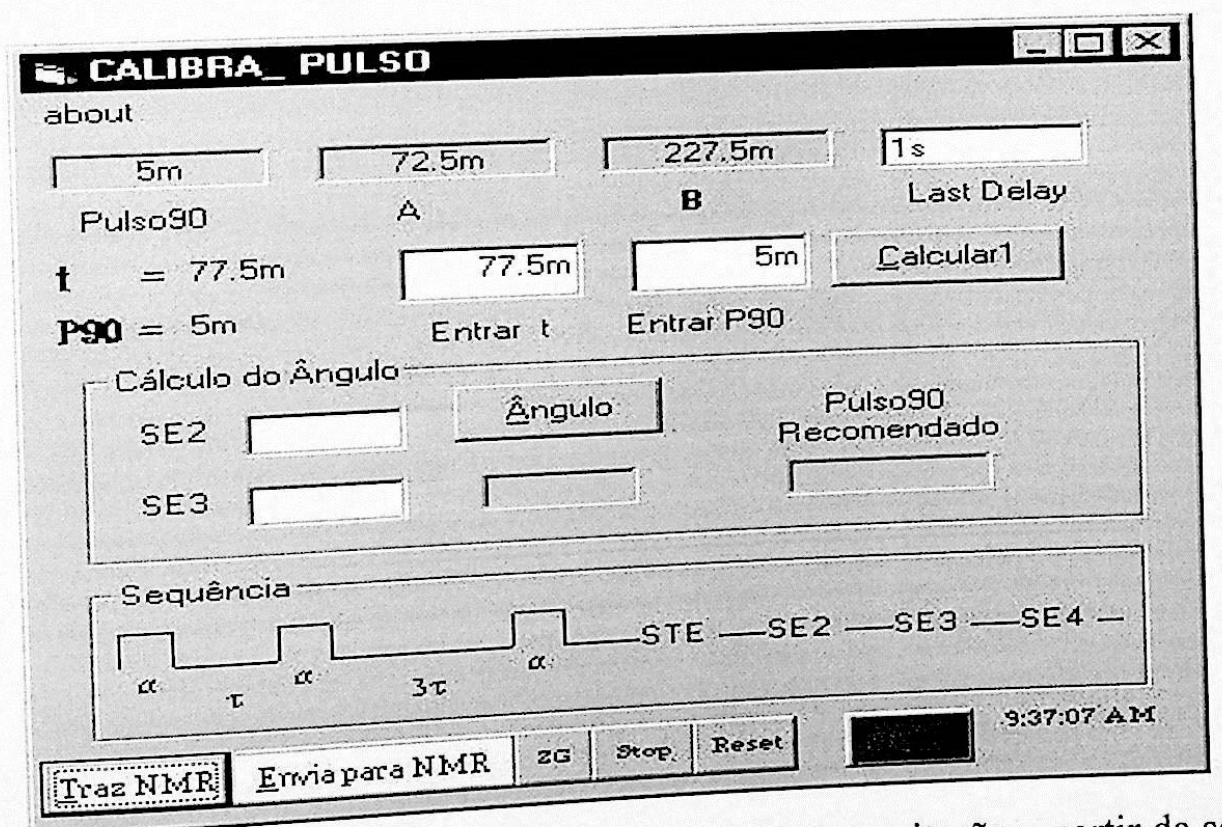

Figura 4.11 Script que permite o cálculo do ângulo de excitação a partir da seqüência 4.7, e permite obter de forma aproximada a duração do pulso de $90^{\circ}$ (recomendado). 
Para otimizar ainda mais, foi feito um script em Visual Basic, mostrado na figura 4.11, para o cálculo do ângulo de excitação e de uma maneira aproximada baseada na relação 4.5 , permitindo ademais sugerir o tempo para o pulso de $90^{\circ}$. 


\section{Capítulo V}

\section{RESULTADOS E DISCUSSÕES}

Neste capítulo vamos apresentar os resultados obtidos nos dois sistemas de medidas do nosso laboratório. No primeiro, instalamos um módulo com o objetivo de obter uma boa homogeneidade de campo, e desta maneira, espectroscopia localizada. No segundo sistema foi implementada a seqüência de espectroscopia localizada PRESS.

O primeiro sistema de medidas do nosso laboratório, como mencionado no item 4.1.1, é o Gyroscan S15 da Philips. Trata-se de um sistema que, além de ter implementado seqüências de tomografia, possui seqüências de espectroscopia localizada in vivo, contando com um conjunto de bobinas de shimming para tornar o campo magnético estático na região o mais homogêneo possível, o que é feito através de um potenciômetro para cada bobina (modo local). No modo remoto isto é conseguido através de um controlador shimming de até 16 ADC (controlador de bobinas de homogeneidade), estando a corrente que passa pelas bobinas sob controle.

Desde o início da operação do funcionamento do sistema Gyroscan S15, o módulo controlador de bobinas de homogeneidade no modo remoto se encontrava desativado e, portanto, parte do trabalho consistiu em realizar as conexões do módulo que é mostrada em cor cinza na figura 4.1, permitindo assim obter melhor homogeneidade possível, um dos requisitos mais importantes na espectroscopia, principalmente na espectroscopia localizada.

Como a maioria dos equipamentos comerciais de tomografia, Gyroscan S15 também é um sistema fechado ao usuário, permitindo só fazer algumas modificações, mas não o controle total dos parâmetros da seqüência. Para que pudéssemos ter o conhecimento da seqüência foi feita a monitoração durante a execução dos pulsos de RF e de gradiente, o que nos permitiu identificá-la como a seqüência PRESS.

Inicialmente realizamos experiências com amostras in vitro, utilizando um conjunto de substâncias (1,2-dicloro etano, tolueno, álcool etílico e piridina) reunidas em uma montagem que possibilitou a obtenção da imagem mostrada na figura 5.1. Posteriormente, através da localização individual foi possível obter seus respectivos espectros. 


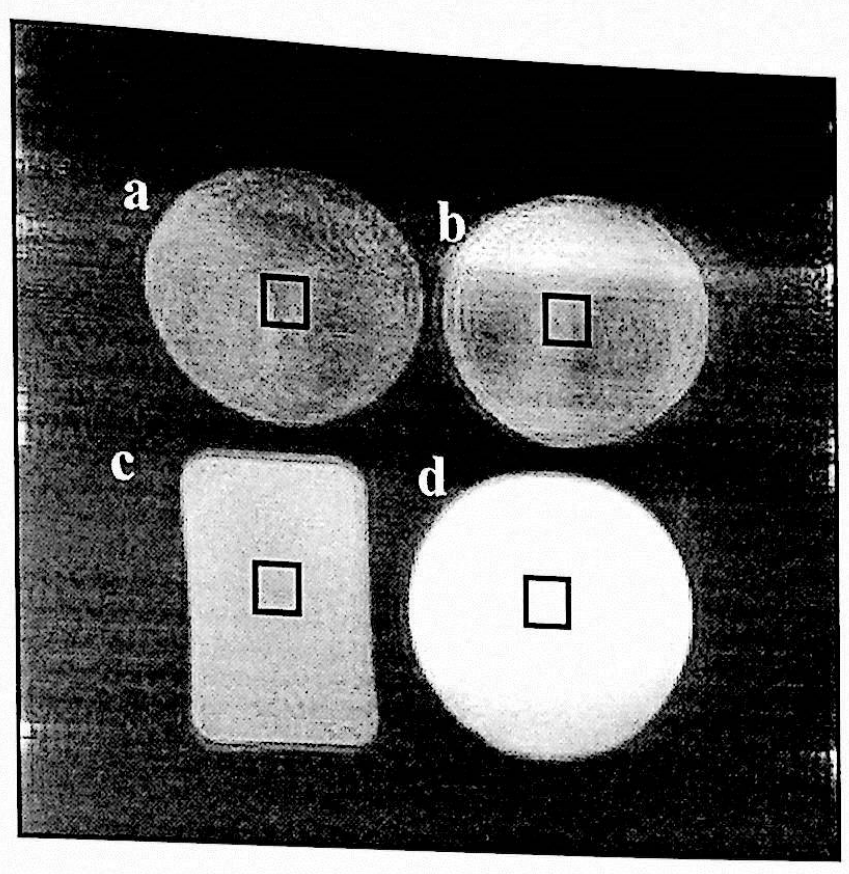

Figura 5.1 Imagem obtida no Gyroscan S15 medianţe a seqüência de eco de spin, para localizar VOIs de $2 \times 2 \times 2 \mathrm{~cm}^{3}$ em a) 1,2-dicloro etano b) Piridina c) Tolueno e d) Álcool etílico.

A implementação da seqüência PRESS feita pela Philips permite a supressão da água, processo que também foi monitorado, levando-nos a concluir que esta é feita pela técnica CHESS, tratada no item 3.3.7. Nela, a envoltória do pulso de RF é uma função gaussiana e a duração do pulso é de $20 \mathrm{~ms}$, o que resulta em uma banda de $60 \mathrm{~Hz}$ em um campo de 1,5 teslas.

Nas figuras 5.1a, 5.1b, 5.1c, 5.1d são mostrados os espectros localizados de prótons de cada uma das substâncias mencionadas. Na figura 5.1e é mostrado o espectro de clorofórmio, que foi obtido conjuntamente com a água. Todos eles foram obtidos com um tempo de eco $\mathrm{TE}=138 \mathrm{~ms}$, tempo de repetição $\mathrm{TR}=2 \mathrm{~s}$, e com um número de médias Nimed=2. 


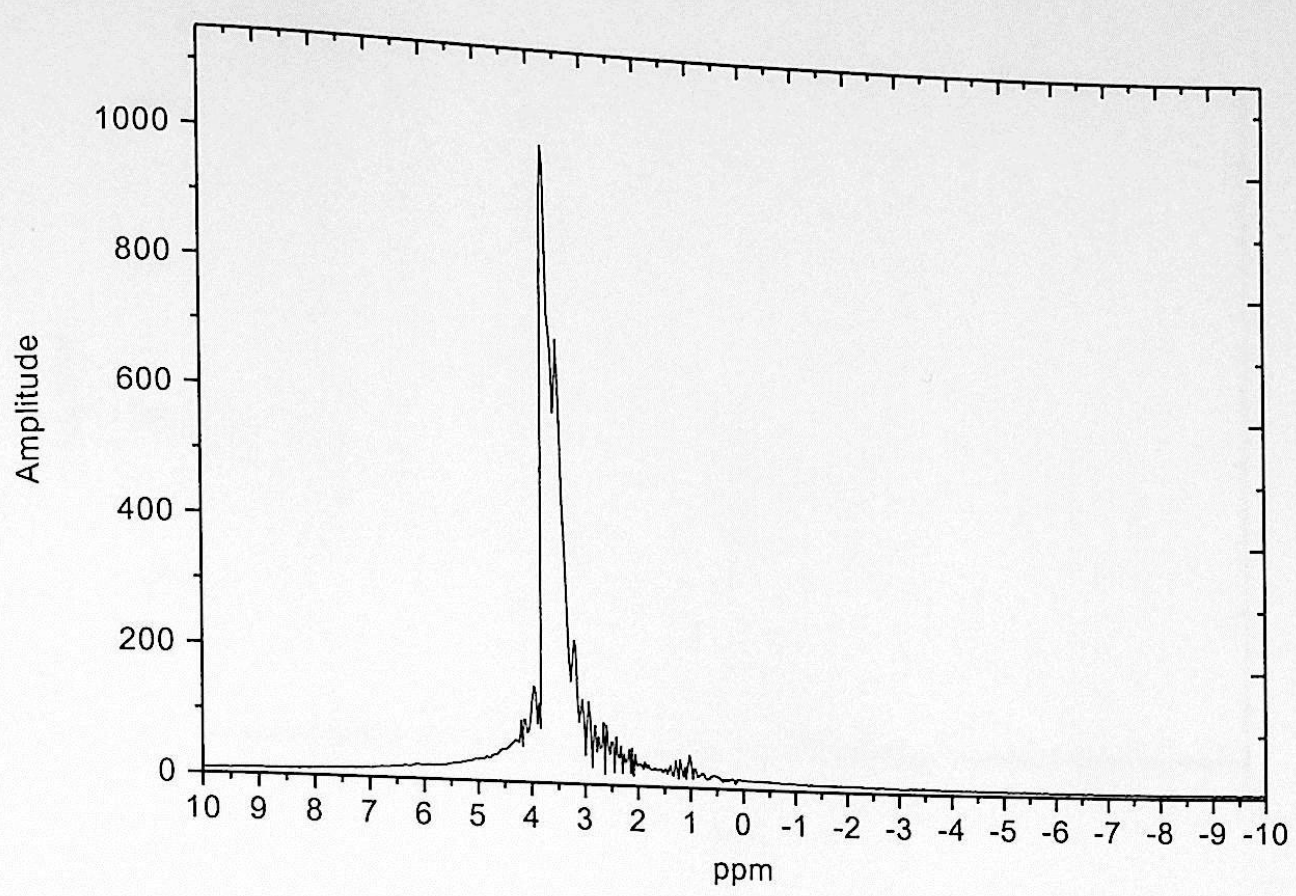

Figura 5.1a. Espectro do 1,2-dicloro etano $\left(\mathrm{ClCH}_{2} \mathrm{CH}_{2} \mathrm{Cl}\right)$, obtido com a seqüência PRESS com supressão de água, com os seguintes parâmetros: VOI $=2 \times 2 \times 2 \mathrm{~cm}^{3}, T R=2 \mathrm{~s}$, $\mathrm{TE}=138 \mathrm{~ms}$, e $\mathrm{Nmed}=2$.

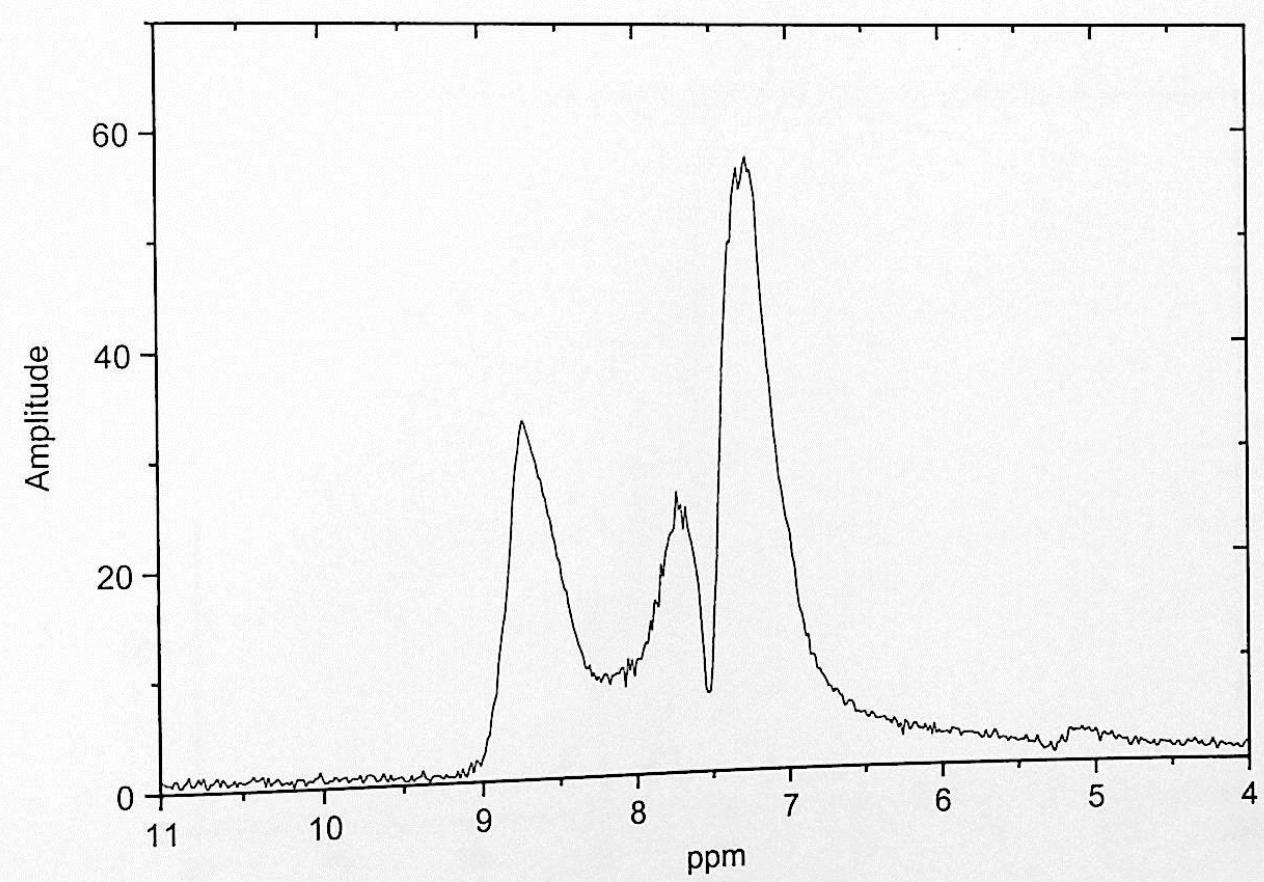

Figura 5.1b. Espectro da piridina $\left(\mathrm{C}_{5} \mathrm{H} 5 \mathrm{~N}\right)$, obtido com a seqüência CHESS-PRESS, com os seguintes parâmetros: $\mathrm{VOI}=2 \times 2 \times 2 \mathrm{~cm}^{3}, \mathrm{TR}=2 \mathrm{~s}, \mathrm{TE}=138 \mathrm{~ms}$ e $\mathrm{Nmed}=2$. 


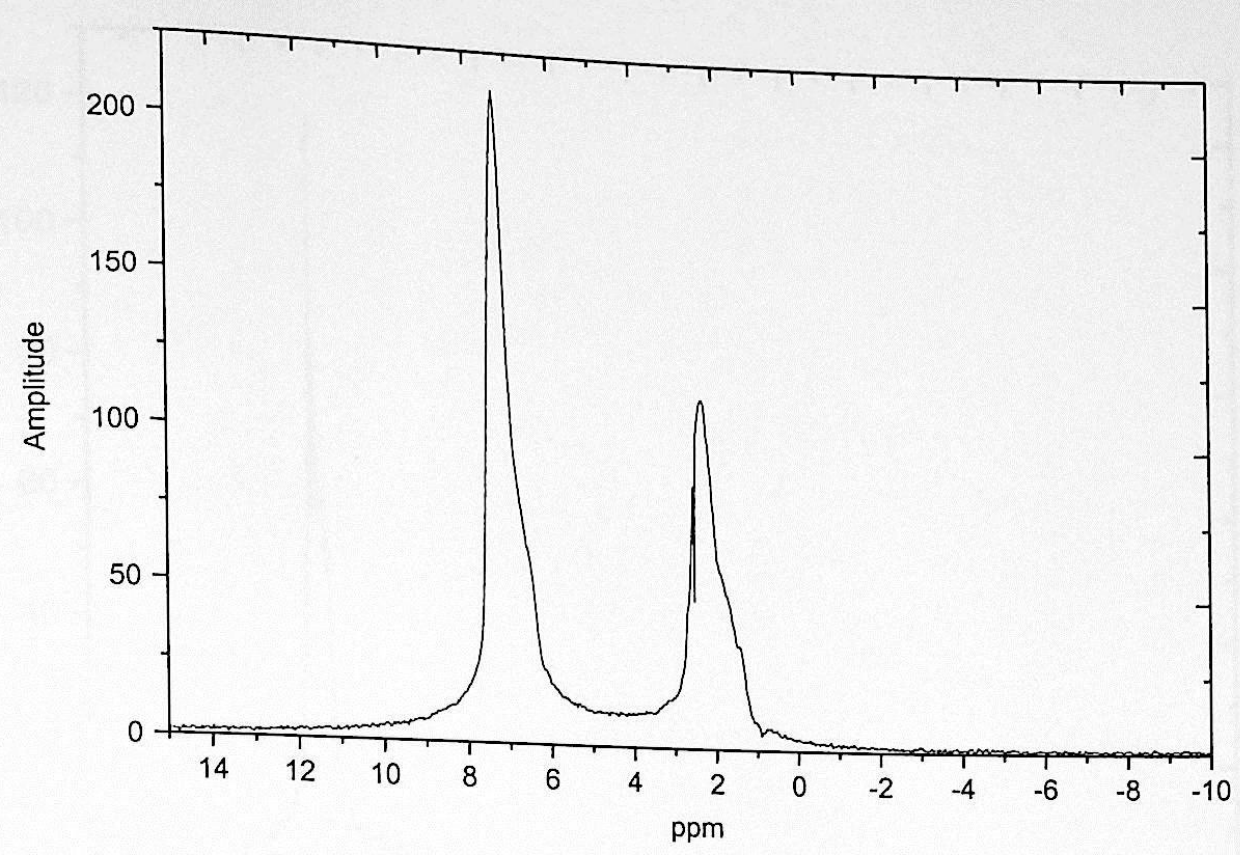

Figura 5.1c. Espectro do tolueno $\left(\mathrm{C}_{6} \mathrm{H}_{5} \mathrm{CH}_{3}\right)$, obtido com a sequiência CHESS-PRESS, com os seguintes parâmetros: $\mathrm{VOI}=2 \times 2 \times 2 \mathrm{~cm}^{3}, \mathrm{TR}=2 \mathrm{~s}, \mathrm{TE}=138 \mathrm{~ms}$, e $\mathrm{Nmed}=2$.

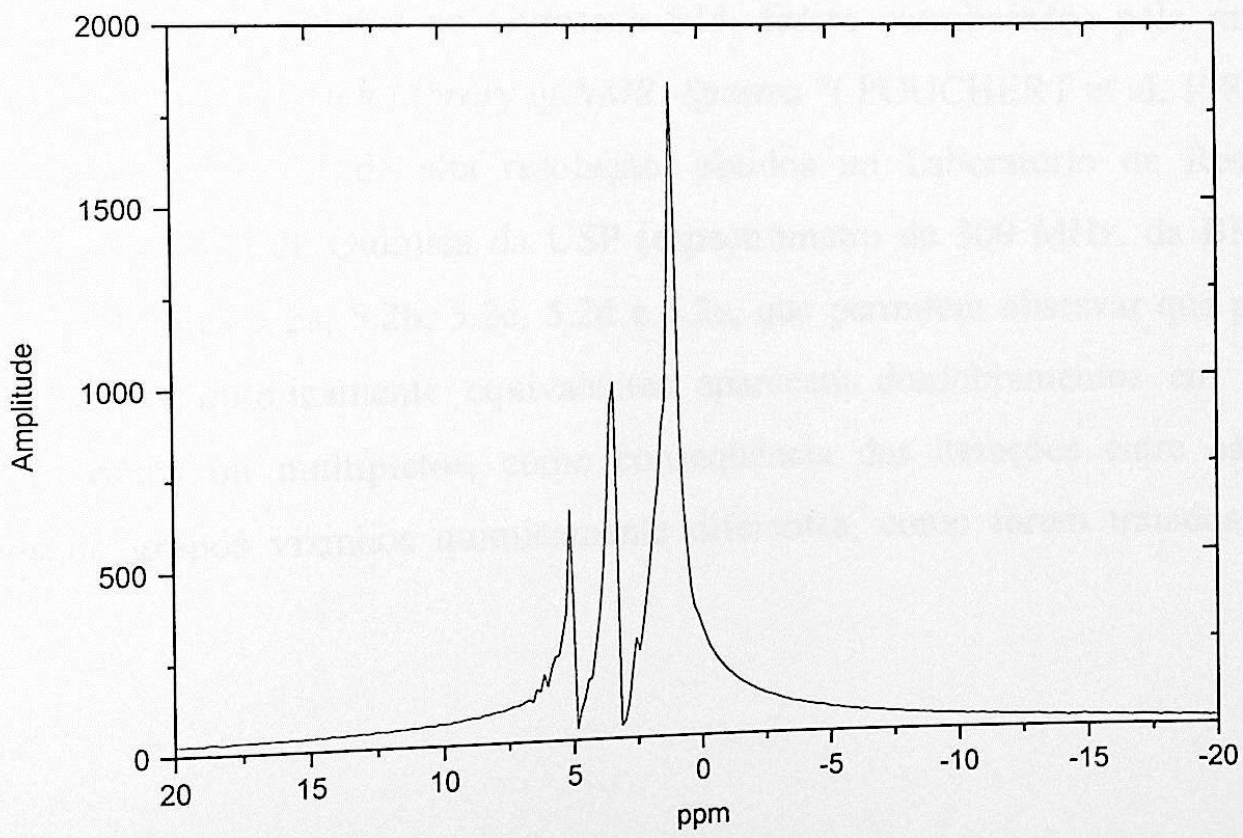

Figura 5.1d. Espectro do Álcool etílico $\left(\mathrm{C}_{2} \mathrm{H}_{5} \mathrm{OH}\right)$, obtido com a seqüência PRESS, com os seguintes parâmetros: $\mathrm{VOI}=2 \times 2 \times 2 \mathrm{~cm}^{3}, \mathrm{TR}=2 \mathrm{~s}, \mathrm{TE}=138 \mathrm{~ms}$ e $\mathrm{Nmed}=2$. 


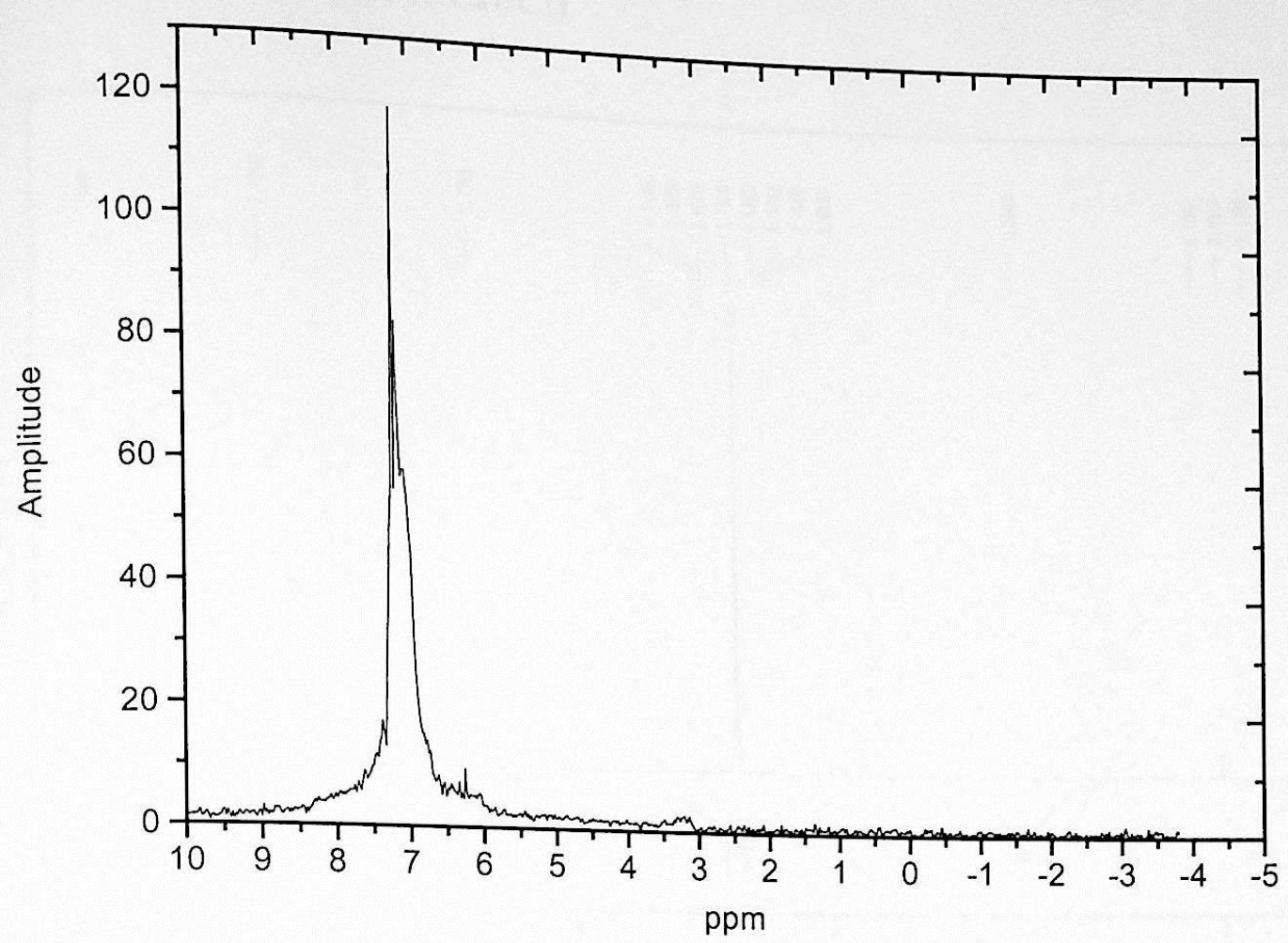

Figura 5.1e. Espectro do clorofórmio $\left(\mathrm{CHCl}_{3}\right)$, obtido com a seqüência CHESS-PRESS, com os seguintes parâmetros: $\mathrm{VOI}=2 \times 2 \times 2 \mathrm{~cm}^{3}, \mathrm{TR}=2 \mathrm{~s}, \mathrm{TE}=138 \mathrm{~ms}$ e $\mathrm{Nmed}_{\mathrm{m}}=4$.

Estes espectros, obtidos no Gyroscan S15, foram corroborados pelo manual de espectros de 'H, "The Aldrich Library of NMR Spectra "( POUCHERT et al. 1983), assim como os espectros de ${ }^{1} \mathrm{H}$ de alta resolução, obtidos no Laboratório de Ressonância Magnética do Instituto de Química da USP (espectrômetro de $300 \mathrm{MHz}$. da BRUKER), mostrados nas figuras $5.2 \mathrm{a}, 5.2 \mathrm{~b}, 5.2 \mathrm{c}, 5.2 \mathrm{~d}$ e $5.2 \mathrm{e}$, que permitem observar que para cada grupo de núcleos químicamente equivalentes aparecem desdobramentos em dupletos, tripletos, quartetos ou multipletos, como conseqüência das iterações entre os núcleos magnéticos de grupos vizinhos quimicamente diferentes, como forem tratados no item 2.1.2. 


\section{2a) 1,2-dicloroetano $\left(\mathrm{ClCH}_{2} \mathrm{CH}_{2} \mathrm{Cl}\right)$}

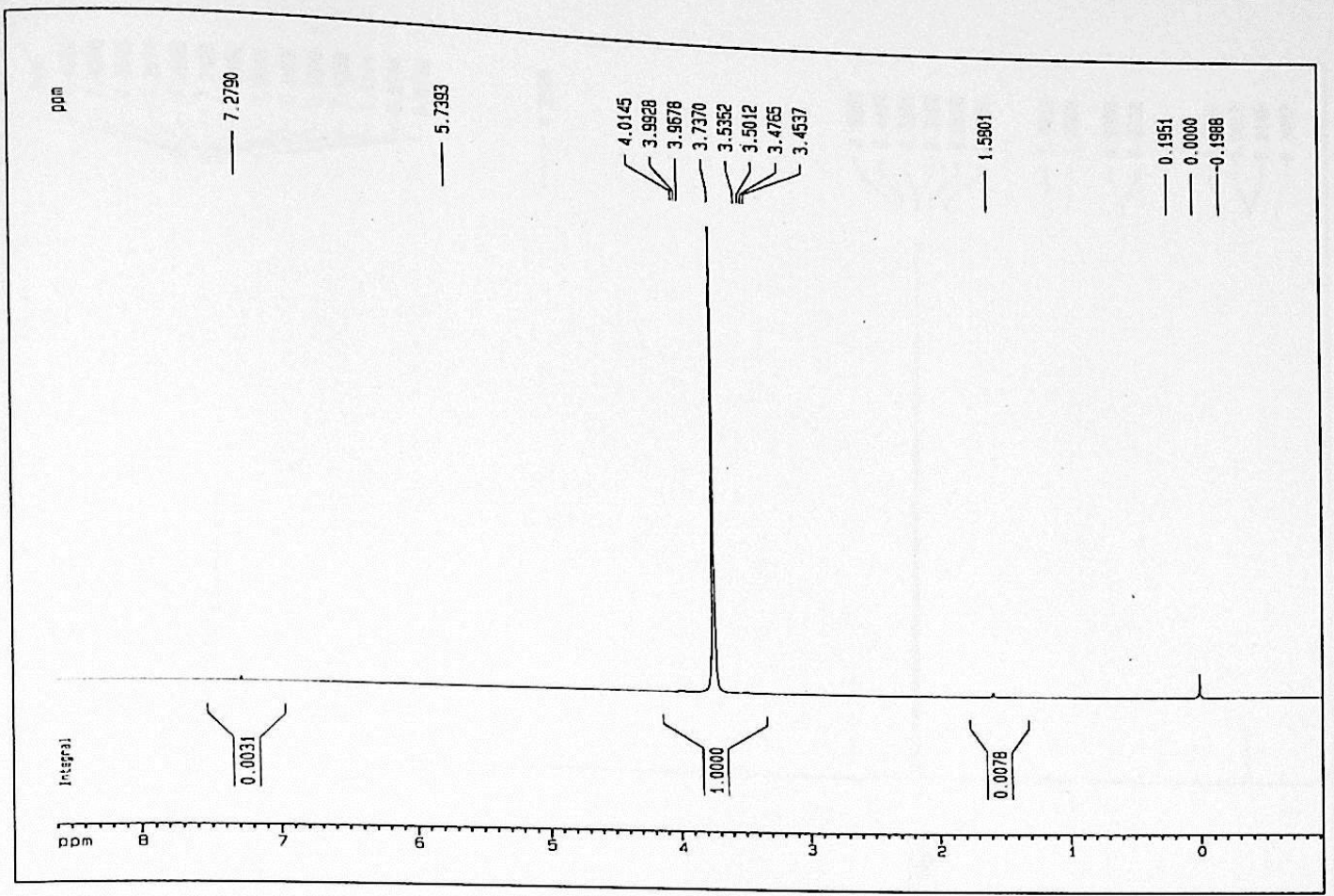

5.2b) Piridina $\left(\mathrm{C}_{5} \mathrm{H}_{5} \mathrm{~N}\right)$

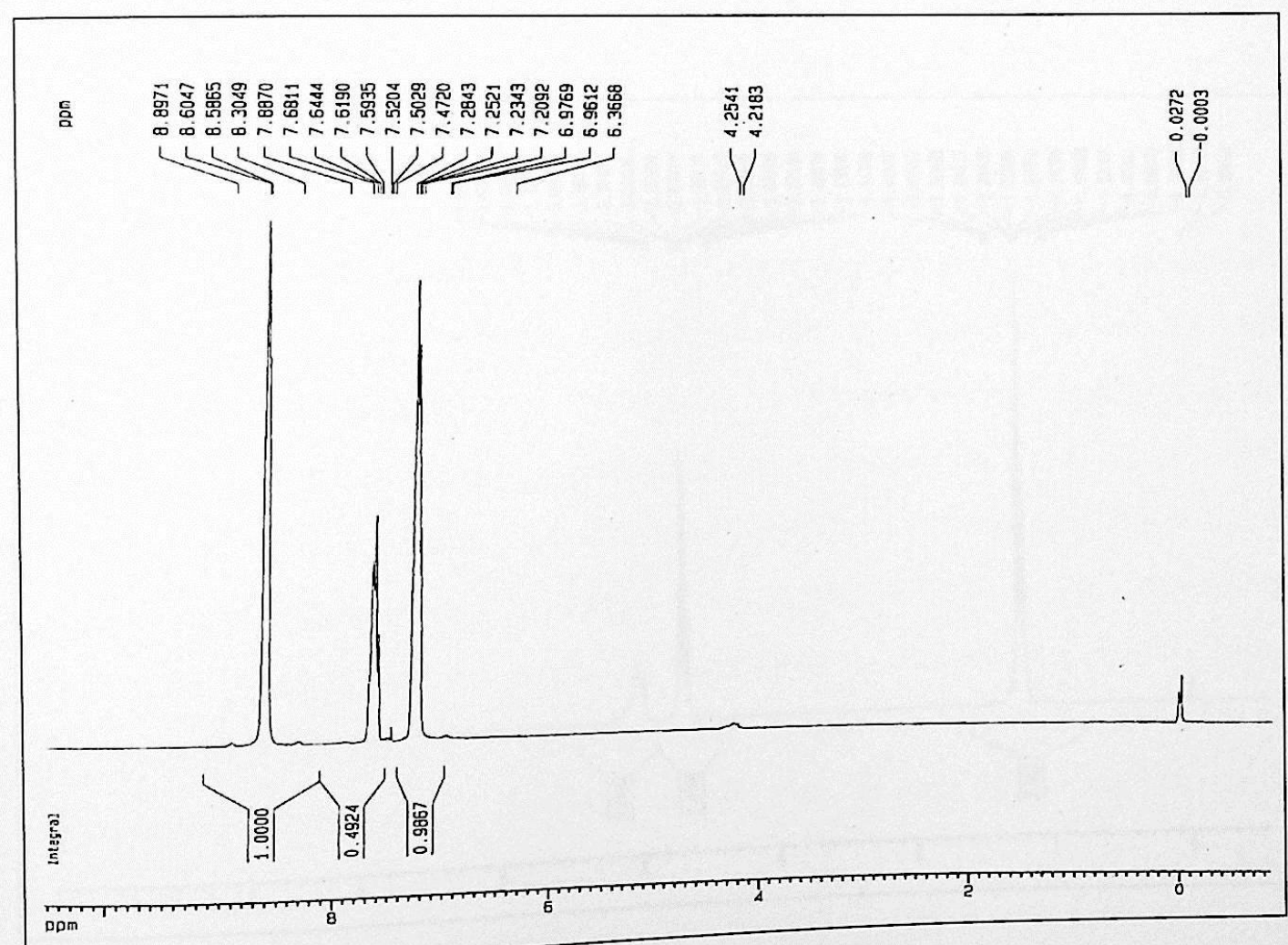


5.2c) Tolueno $\left(\mathrm{C}_{6} \mathrm{H}_{5} \mathrm{CH}_{3}\right)$

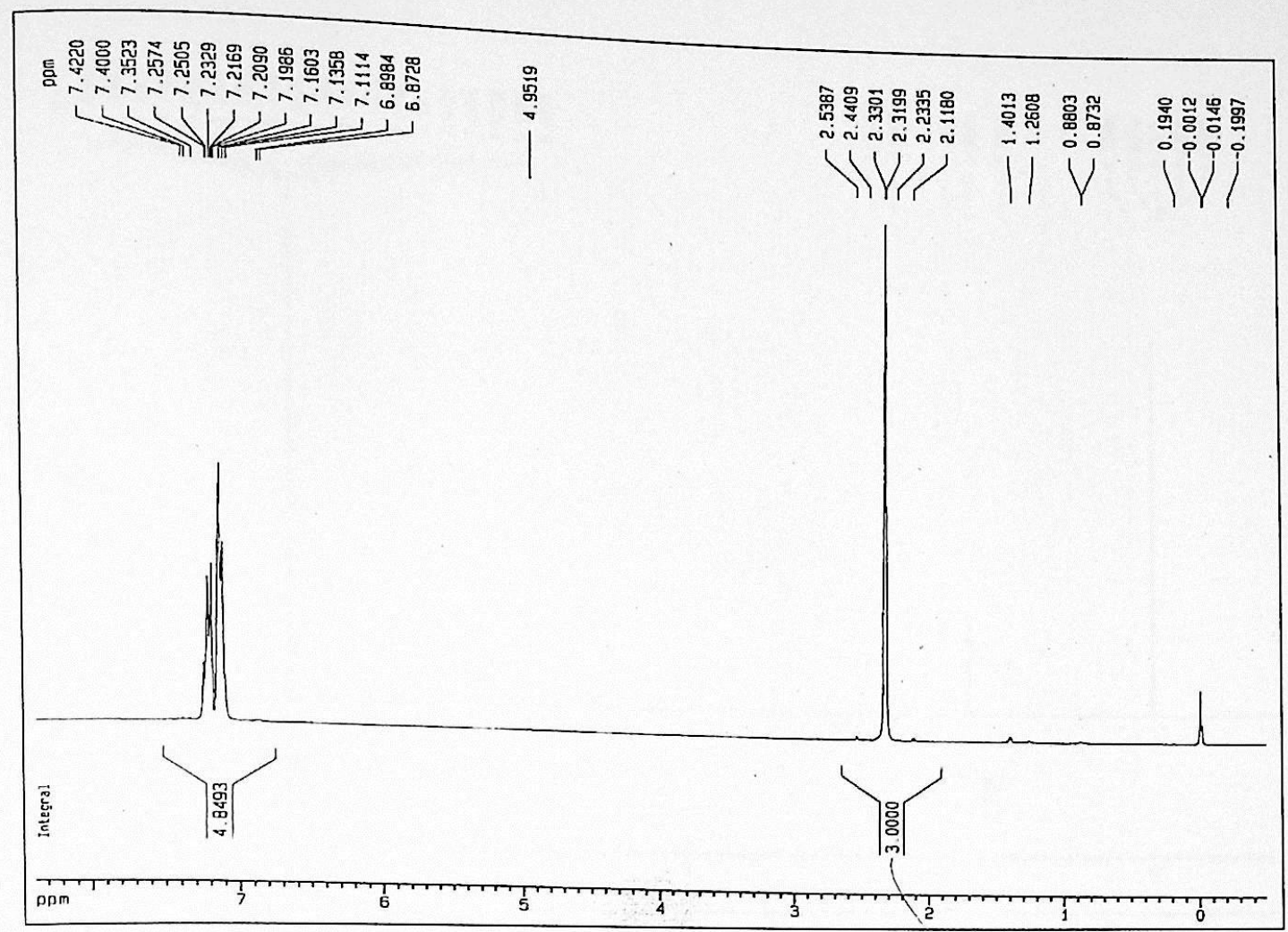

\section{2d Álcool etílico $\left(\mathrm{C}_{2} \mathrm{H}_{5} \mathrm{OH}\right)$}

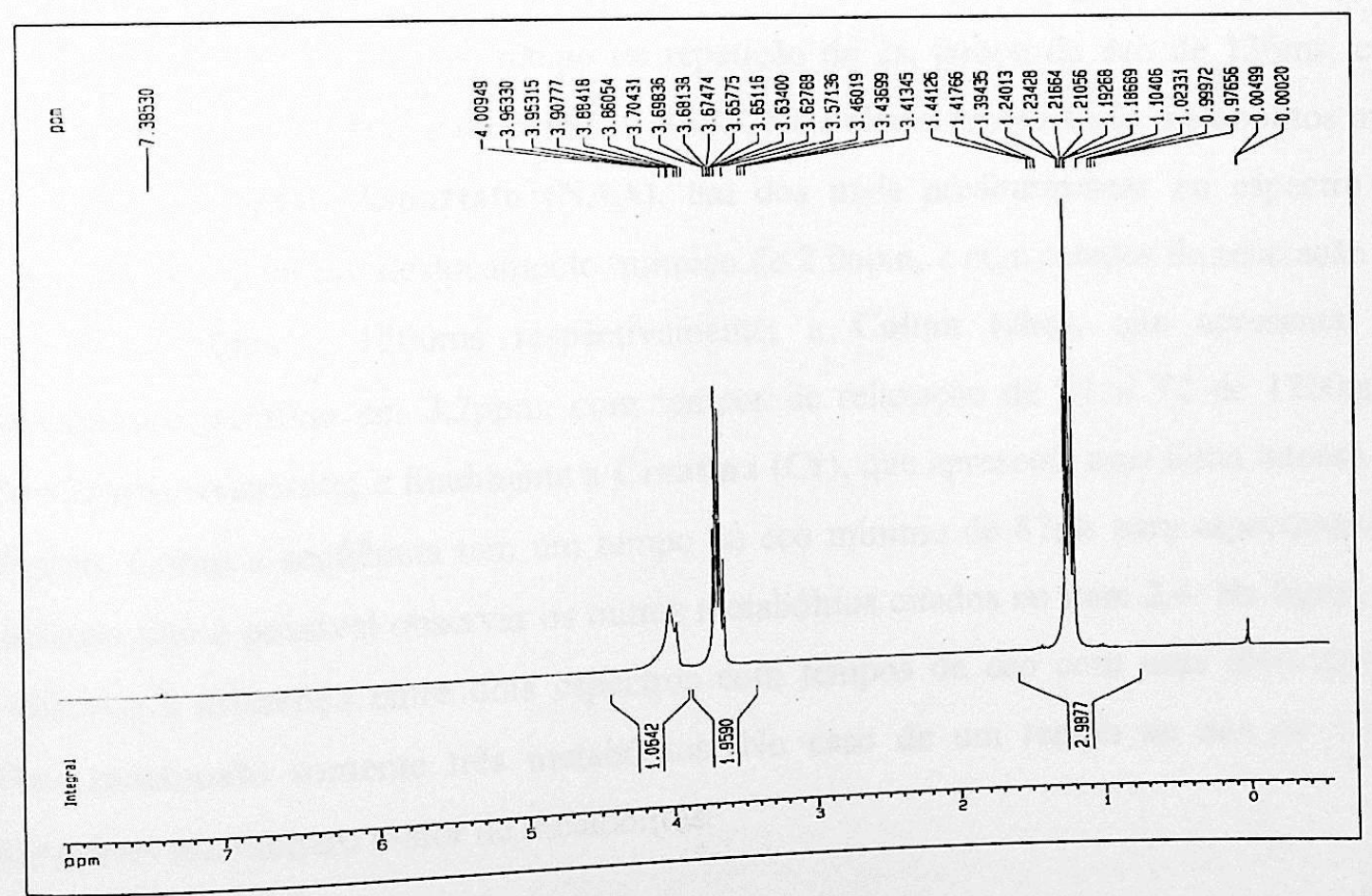




\section{1e) clorofórmio $\left(\mathrm{CHCl}_{3}\right)$}

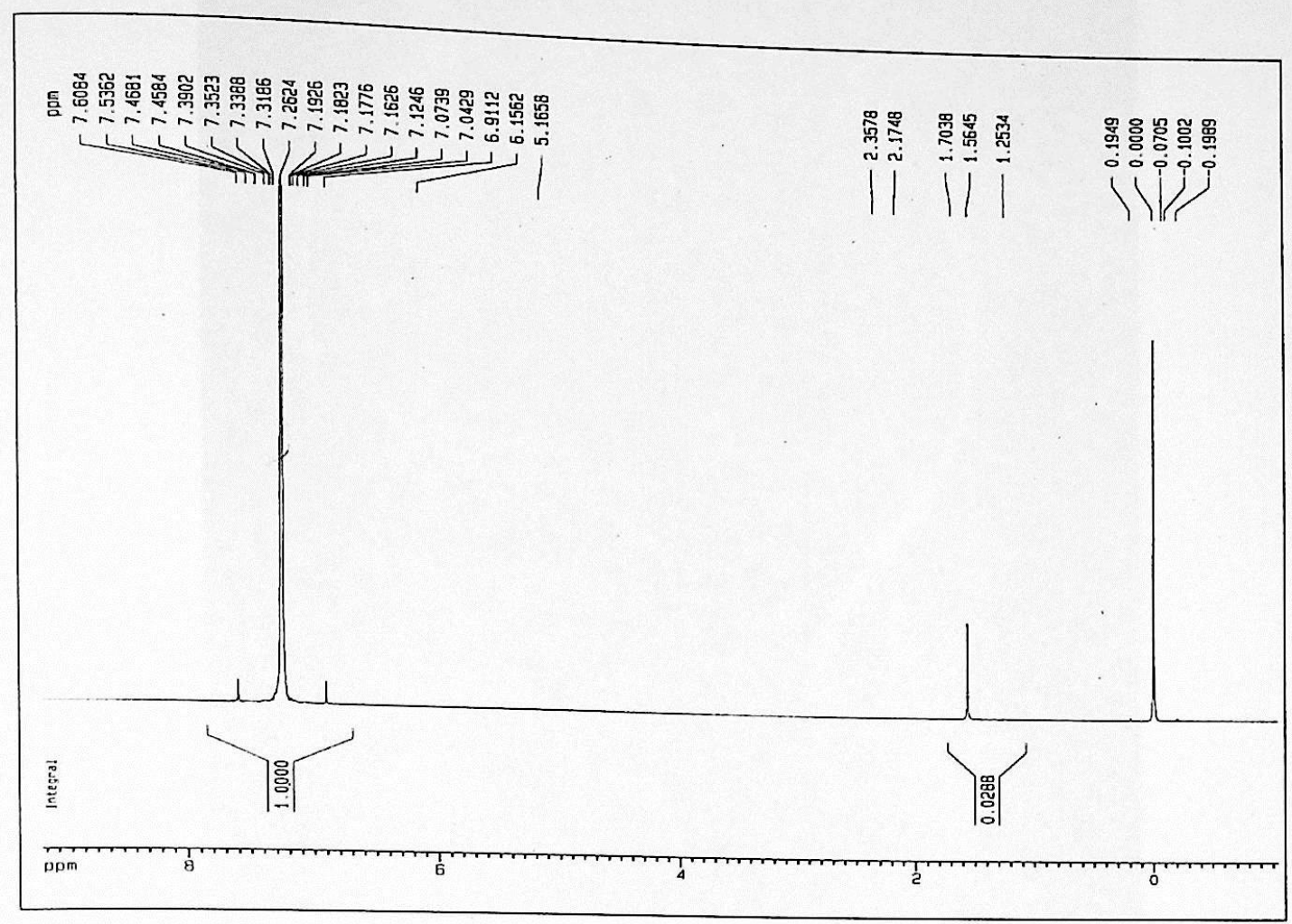

Executamos experimentos de espectroscopia localizada in vivo de ${ }^{\mathrm{I}} \mathrm{H}$, no sistema Gyroscan S15 da Philips com a seqüência PRESS, em um paciente voluntário. Na figura 5.4 é mostrado um espectro do cérebro em um VOI de $2 \times 2 \times 2 \mathrm{~cm}^{3}$ (figura 5.3), adquirindo 1024 pontos, com 128 médias, tempo de repetição de 2s, tempo de eco de $136 \mathrm{~ms}$, com supressão de água mediante a seqüência CHESS. Nele observamos os três metabólitos mais importantes; N-Acetil Aspartato (NAA), um dos mais predominantes no espectro do cérebro normal, com um deslocamento químico de 2.0ppm, e com tempos de relaxação T1 e T2 de $1550 \mathrm{~ms}$ e $1200 \mathrm{~ms}$ respectivamente; a Colina (cho), que apresenta um deslocamento químico em 3.2ppm, com tempos de relaxação de T1 e T2 de $1700 \mathrm{~ms}$ e $270 \mathrm{~ms}$ respectivamente; e finalmente a Creatina $(\mathbf{C r})$, que apresenta uma linha intensa em $3,03 \mathrm{ppm}$. Como a seqüência tem um tempo de eco mínimo de $87 \mathrm{~ms}$ para espectroscopia localizada não é possível observar os outros metabólitos citados no item 2.4. Na figura 2.2 se observa a diferença entre dois espectros com tempos de eco com uma diferença de $270 \mathrm{~ms}$ mostrando somente três metabólitos. No caso de um tempo de eco de $20 \mathrm{~ms}$, observamos um número maior de metabólitos. 


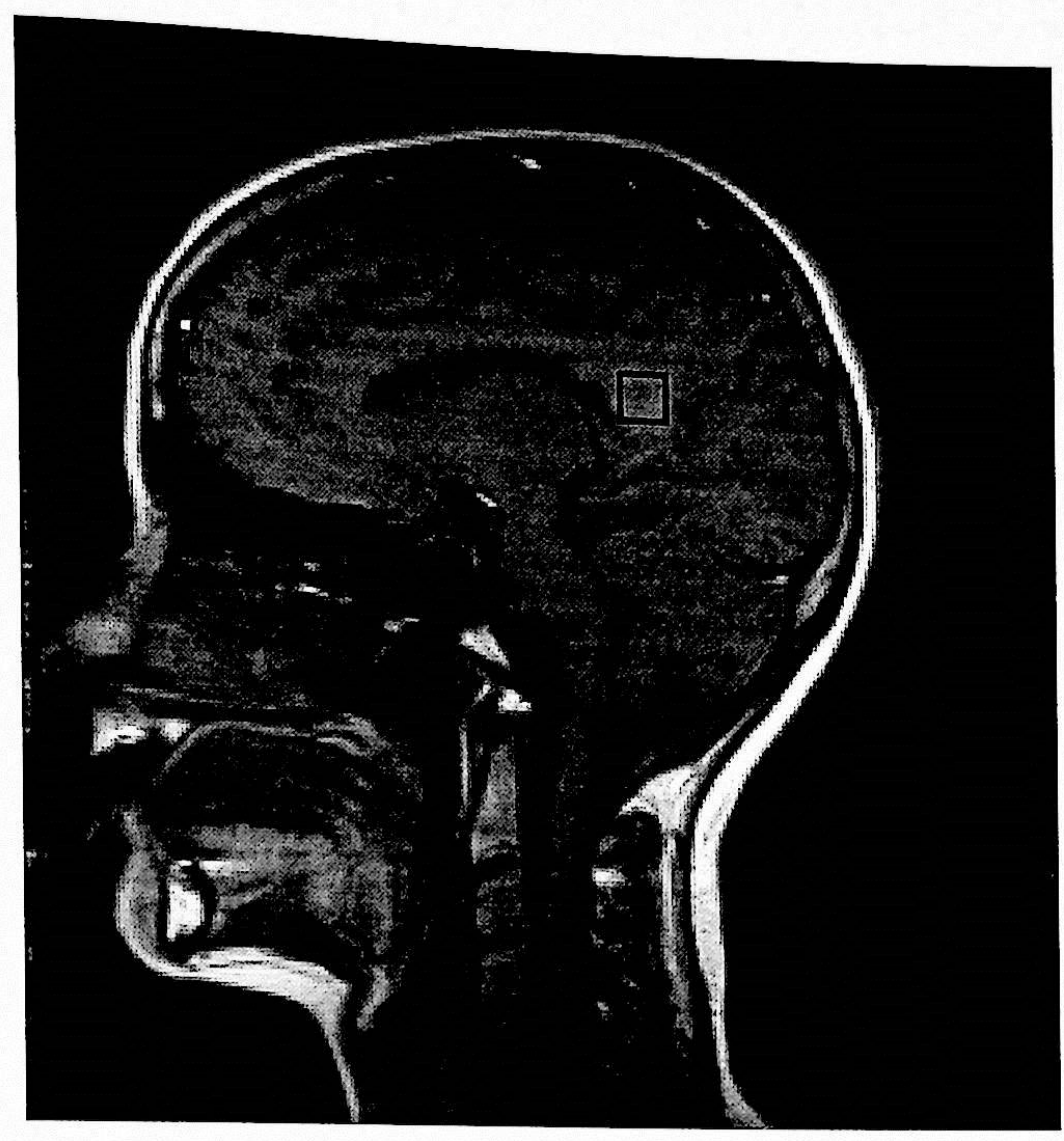

Figura 5.3 Imagem obtida de um voluntário para a localização do VOI de $2 \times 2 \times 2 \mathrm{~cm}^{3}$

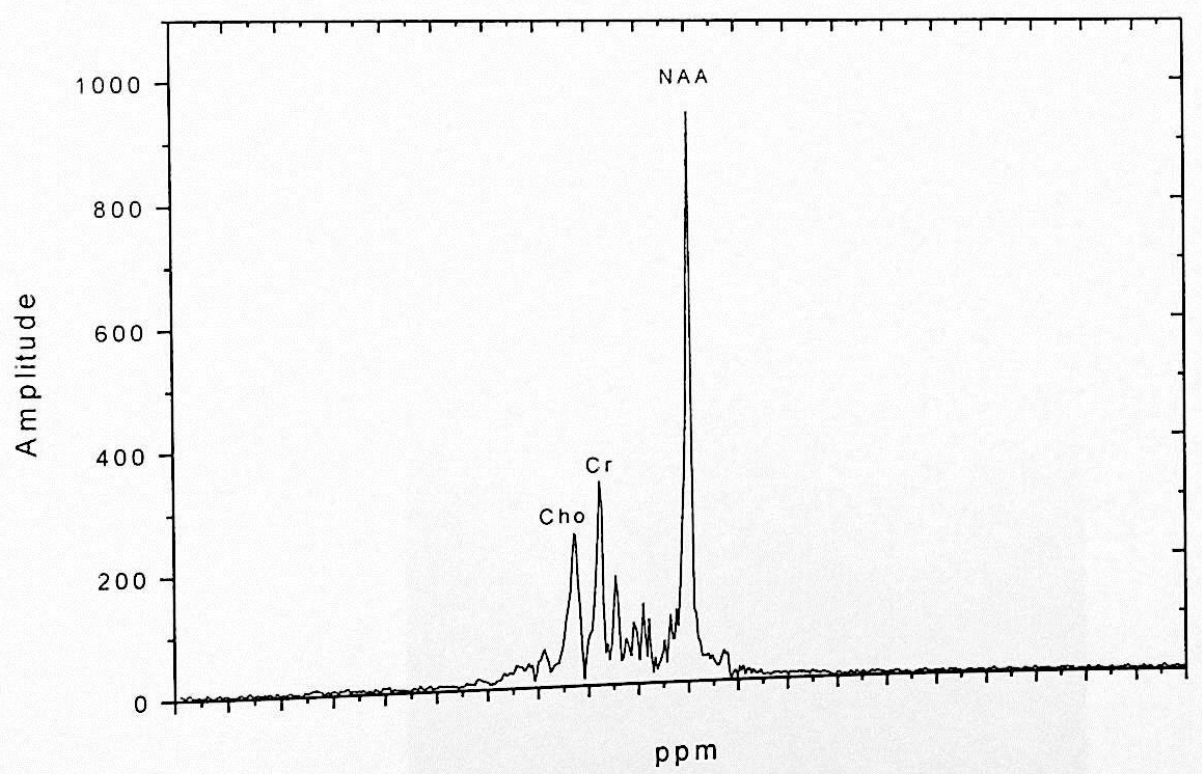

Figura 5.4. Espectro localizado do ${ }^{\prime} \mathrm{H}$, obtido pela técnica PRESS, no volume de $2 \times 2 \times 2 \mathrm{~cm}$ voluntário, mostrando os três metabólitos mais importantes, Cho, $\mathrm{Cr}$, e do cérebro de um voluntário, mostrando os tres $\mathrm{NA}$. Os parâmetros experimentais são: $T R=2 \mathrm{~s}, \mathrm{TE}=136 \mathrm{~ms}$ e $\mathrm{Nmed}=128$.
NAA 
No sistema GP-AT que foi tratado no item 4.1 .2 foi implementada a seqüência PRESS como é indicado no item 3.5 , porém os espectros obtidos com essa seqüência mostraram artefatos de eddy currents, precisando realizar modificações na seqüência de acordo com a figura 4.8, onde a variação do campo magnético durante a subida do gradiente spoiler tende a ser mais uniforme que no caso dos gradientes spoilers da seqüiência mostrada no gráfico 3.5. No entanto, para compensar a amplitude dos gradientes, é preciso incrementar a duração dos spoilers, permitindo dessa maneira minimizar os transientes provocados pela mudança da amplitude dos gradientes, o que diminuirá os efeitos das eddy currents. O incremento na duração dos spoilers incrementará o tempo de eco mínimo $\mathrm{TE}=90 \mathrm{~ms}$.

Como é mencionado no capítulo anterior, e tendo em vista a necessidade de localização do VOI, foi preciso implementar uma seqüência convencional de tomografia bidimensional de spin eco (que foram as primeiras imagens obtidas nosso laboratório, no sistema GP-AT), mostradas na figura 5.5, onde os parâmetros experimentais foram os seguintes: tempo de repetição $\mathrm{TR}=250 \mathrm{~ms}$, tempo de eco, $\mathrm{TE}=40 \mathrm{~ms}$, número de médias Nmed=2, e com uma resolução de $128 \times 128$ pontos nas direções de codificação de fase e freqüência.

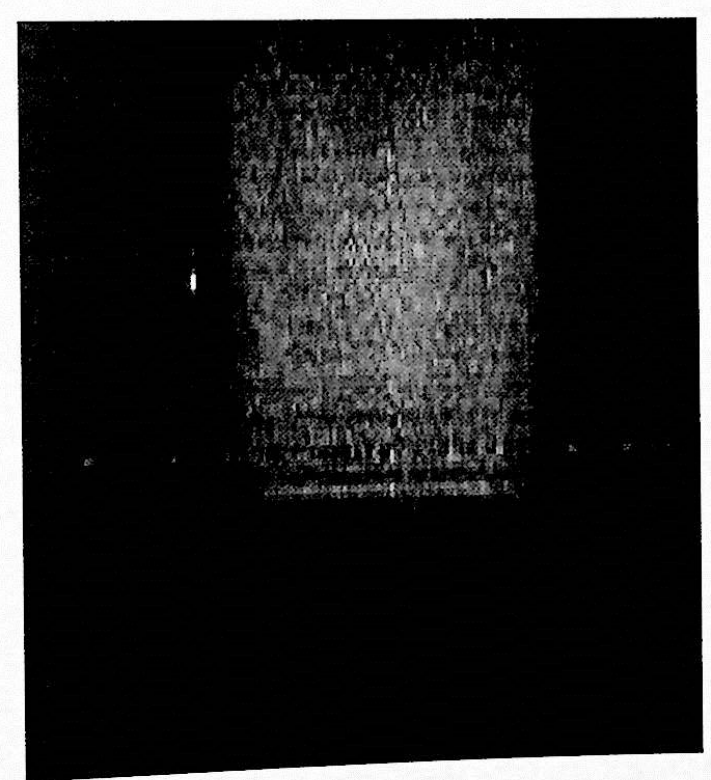

Figura 5.5 Imagem de uma garrafa com água pela seqüência eco de spin, obtida com os seguintes parâmetros: $T R=250 \mathrm{~ms}, T E=40 \mathrm{~ms}, \mathrm{Naver}=2$ e com uma resolução de $128 \times 128$. Esta foi a primeira imagem obtida no laboratório, no sistema GP-AT. 
Posteriormente, os parâmetros da seqüência foram otimizados na tentativa de eliminação de artefatos nas imagens. Para conseguir uma calibração da freqüência contra o comprimento da fatia foi preciso produzir imagens de um "phantom", das quais algumas são mostradas na figura 5.6. Para otimizar a seqüência eco de spin foi preciso elaborar um script, que permitiu o controle sobre a largura do pulso, freqüência, intensidade do gradiente e largura da fatia. Posteriormente o script foi ampliado, como é mostrado na figura 4.10, e utilizado na implementação do PRESS na localização do volume de interesse.

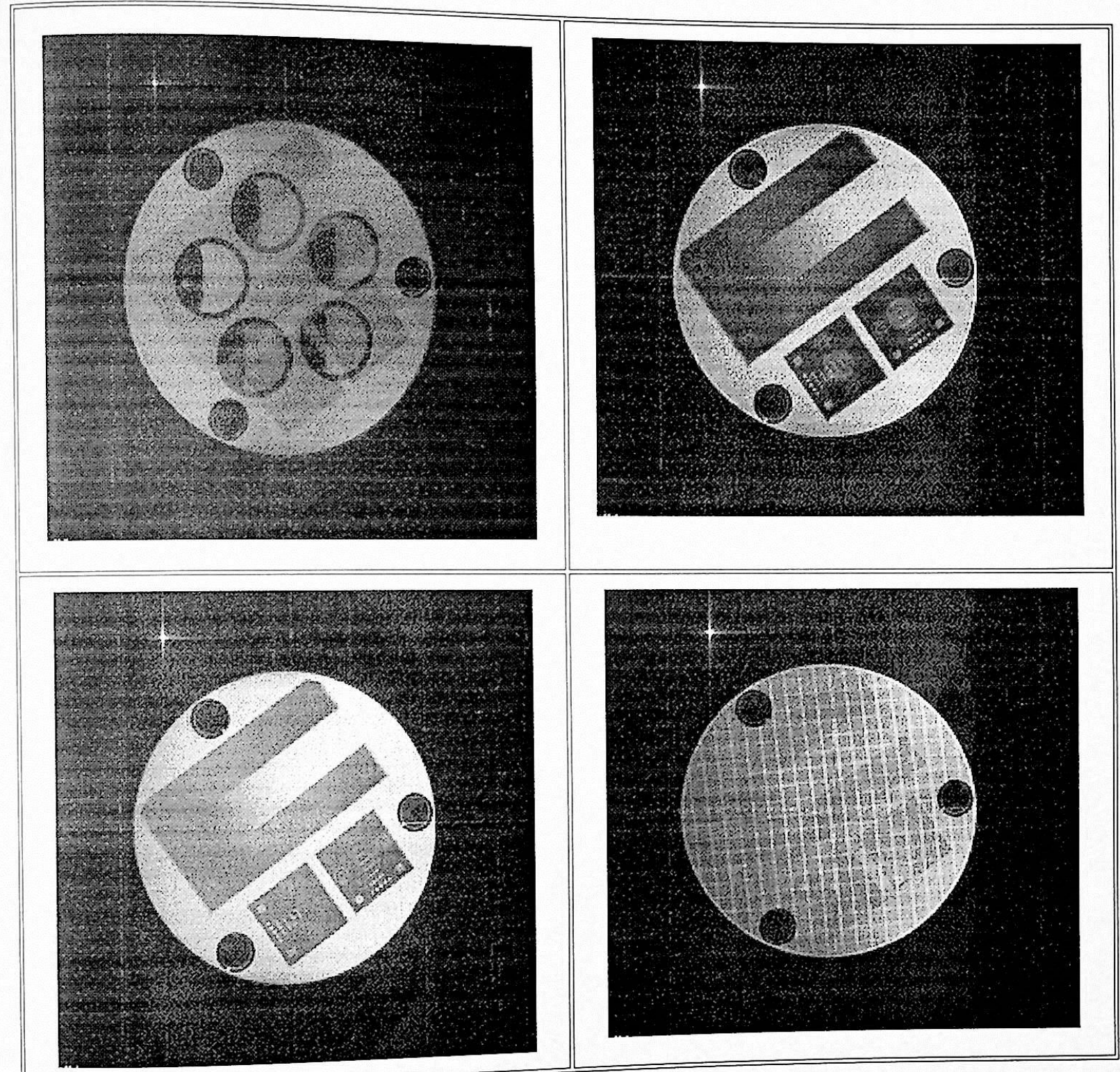

Figura 5.6 Imagens obtidas com a sequiência eco de spin multi slice, obtidas de um "phantom", com os seguintes parâmetros. TR=250ms, TE=40ms, Naver=2 e com uma resolução de $128 \times 128$. Comprimento de fatia $3 \mathrm{~cm}$. 
Uma vez otimizada a seqüência e obtidas as imagens no GPAT, foi possível obter a espectroscopia localizada de três substâncias. Para isso primeiramente foi obtida uma imagem no GPAT, como mostramos na figura 5.7, para localizar o VOI.

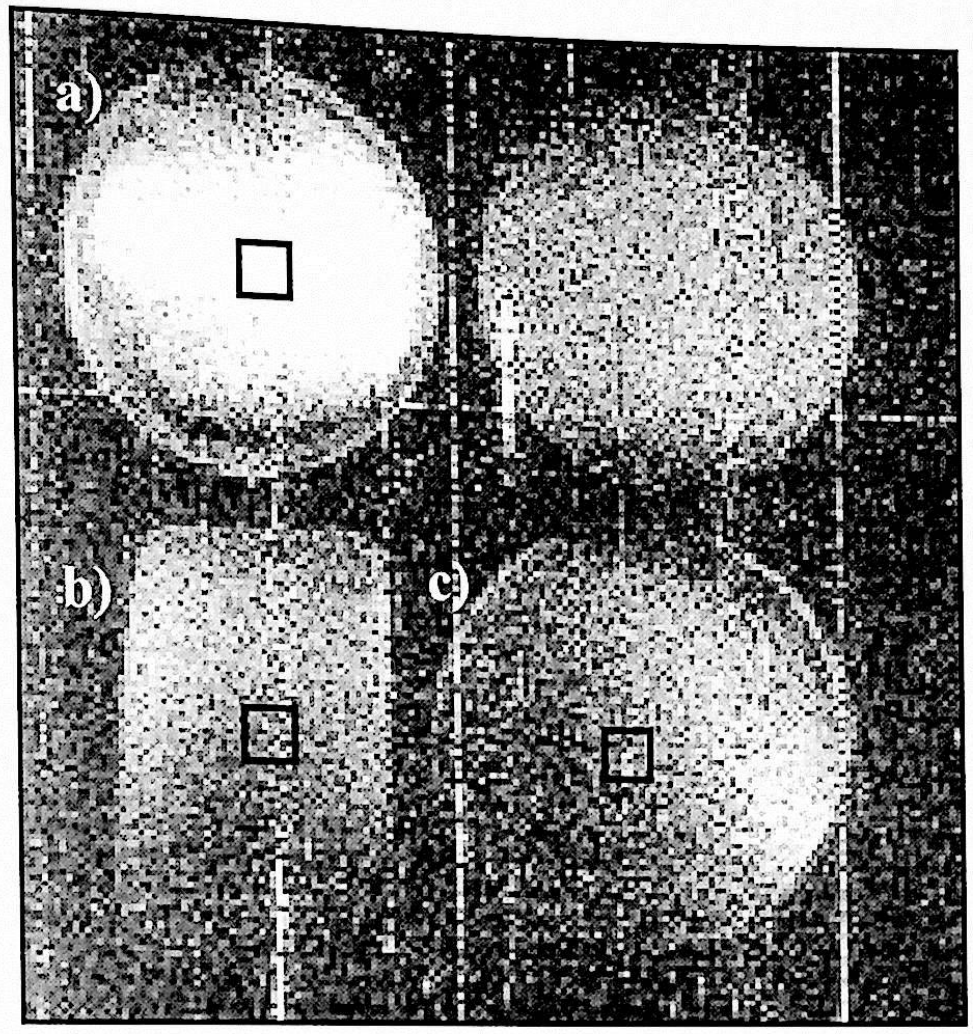

Figura 5.7 Imagem obtida para localizar VOIs de $3 \times 3 \times 3 \mathrm{~cm}^{3}$ em a) 1,2 dicloro etano b) Tolueno c) Álcool etílico. Também é mostrada a imagem do tolueno.

A partir da imagem 5.7 obtivemos os espectros de prótons localizados mediante a seqüência PRESS em volumes de $3 \times 3 \times 3 \mathrm{~cm}^{3}$ de: a) 1,2 dicloro etano, b) tolueno e c) álcool etílico. Os parâmetros experimentais foram os seguintes : tempo de eco de $136 \mathrm{~ms}$, tempo de repetição de $700 \mathrm{~ms}$ e número de médias 128. Nos espectros mostrados foi feita a supressão de água mediante CHESS, logrando dessa maneira uma melhor definição dos picos correspondentes. A intensidade do gradiente utilizado é de $2 \mathrm{mT} / \mathrm{m}$ sendo o máximo de $10 \mathrm{mT} / \mathrm{m}$.

Os espectros das substâncias da figura 5.7 são mostradas nas figuras $5.7 \mathrm{a}, 5.7 \mathrm{~b}$ e 5.7c. 
5.7a) 1-2 dicloro etano

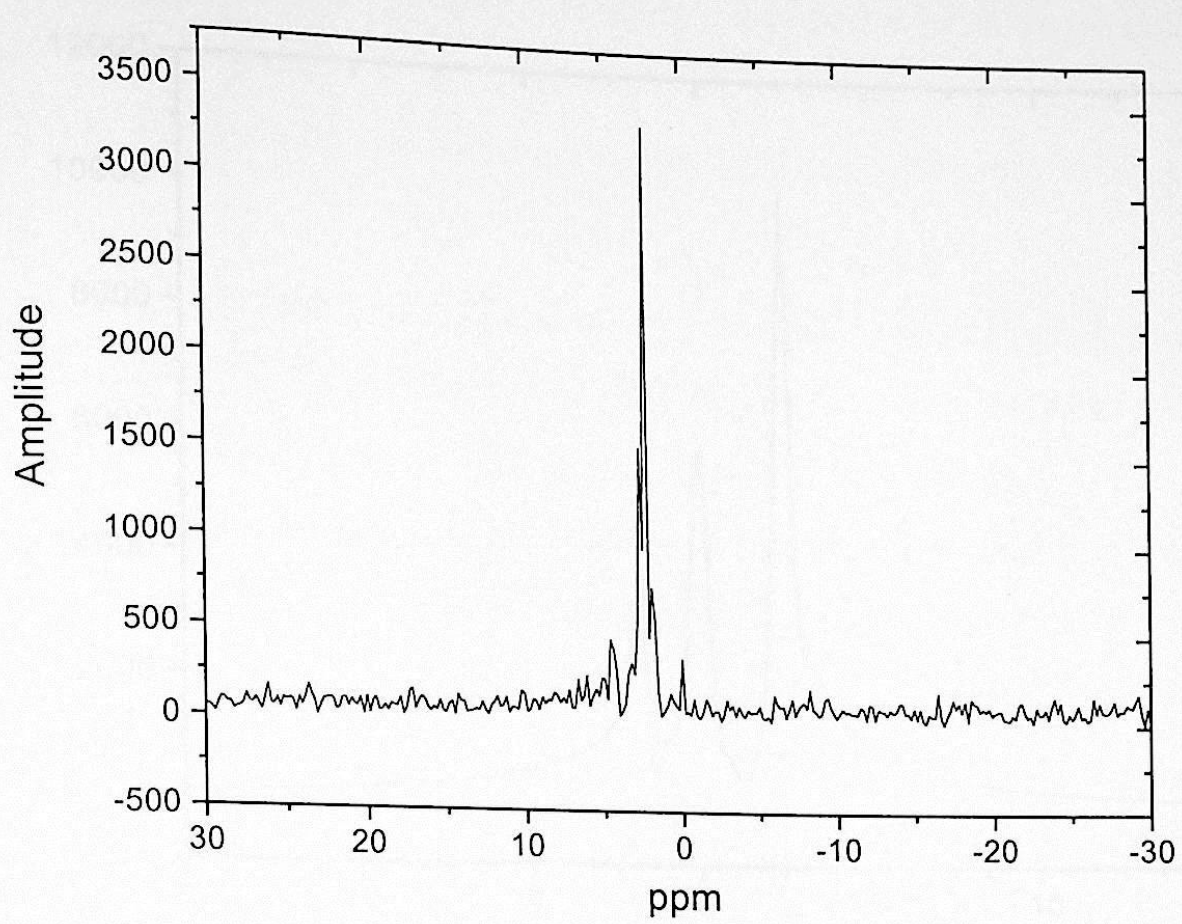

5.7b) Tolueno

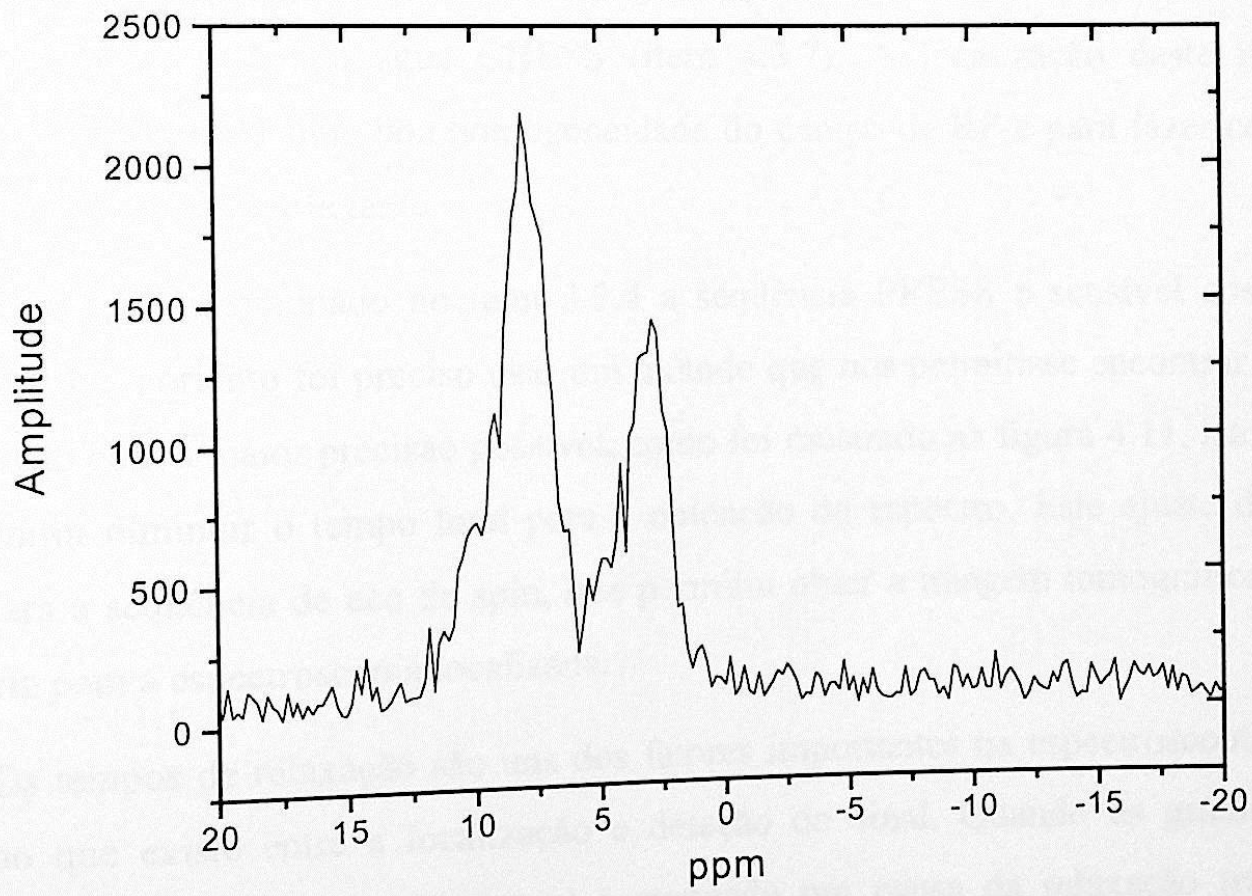


5.7c) Álcool etílico

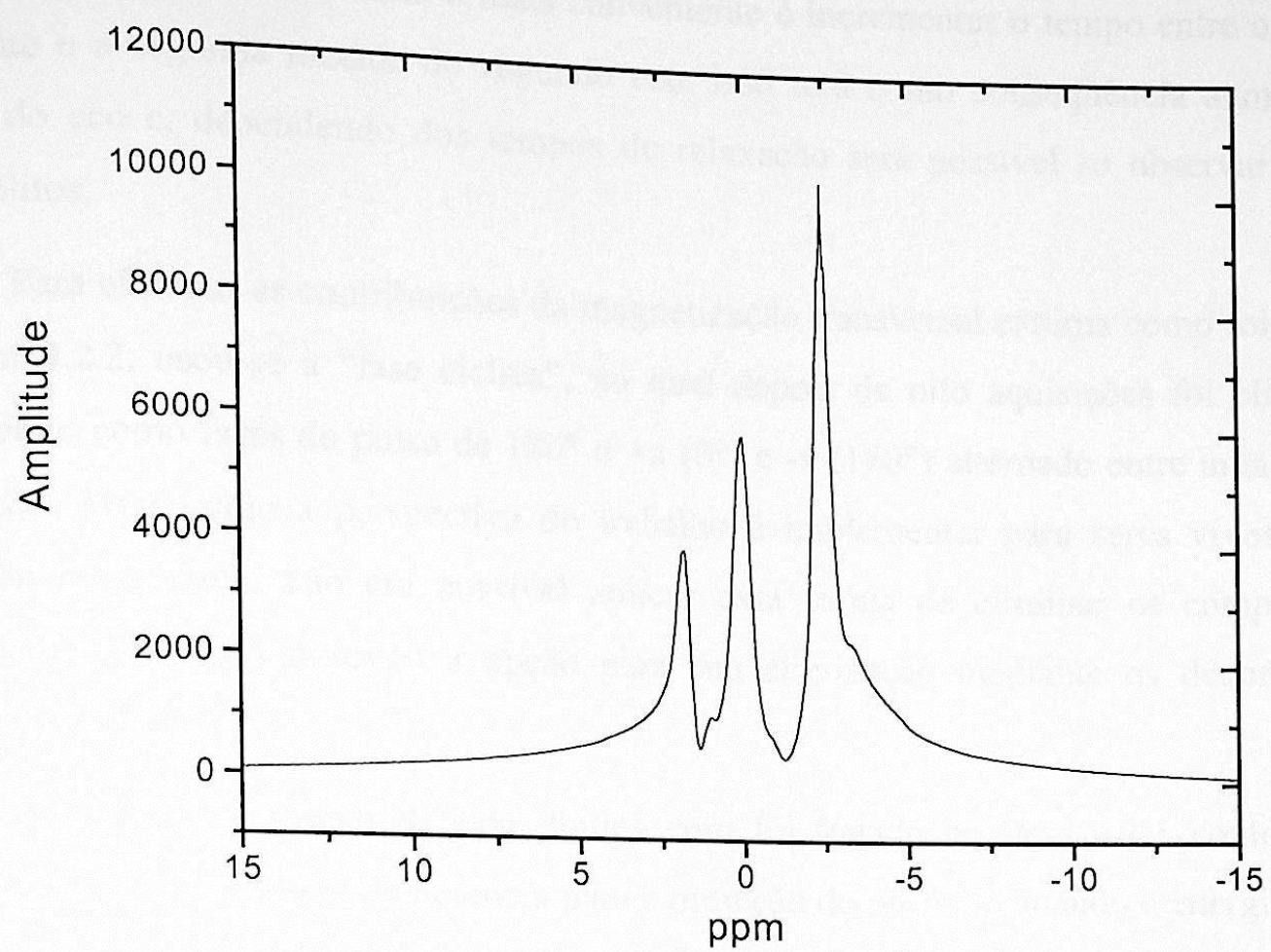

Utilizamos a técnica PRESS de espectroscopia localizada de ${ }^{1} \mathrm{H}$ precedida por um pulso para a supressão da água CHESS (item 4.3.7). A localização deste modo foi necessária para garantir uma boa homogeneidade do campo de RF e para fazer com que a supressão de água fosse eficiente.

Como foi mencionado no item 3.3.4 a seqüência PRESS e sensível aos ângulos desajustados e, portanto foi preciso usar um método que nos permitisse encontrar o ângulo de excitação com a maior precisão possível, como foi mostrado na figura 4.11, isto também nos permitiu diminuir o tempo total para a obtenção do espectro. Este ajuste do ângulo serviu para a seqüência de eco de spin, que permitiu obter a imagem tomográfica do VOI necessária para a espectroscopia localizada.

Os tempos de relaxação são uns dos fatores importantes na espectroscopia, devido ao tempo que existe entre a localização e deteção do sinal. Quando os gradientes são aplicados na seqüência PRESS, o sinal é atenuado por causa da relaxação transversal, portanto o valor de T2 é um fator que determinara a eficiência da deteção. Além disso, a intensidade do sinal RMN é uma função dos tempos de relaxação T1 e T2 e, portanto, é importante conhecer seus valores nas amostras a serem investigadas. 
A aquisição foi feita depois da metade do segundo eco porque a aplicação do último gradiente distorce o sinal; então o mais conveniente é incrementar o tempo entre o ultimo gradiente e a segunda metade do segundo eco, isso terá como conseqüência aumentar o tempo do eco e, dependendo dos tempos de relaxação será possível só observar alguns metabólitos.

Para eliminar as contribuições da magnetização transversal externa como foi tratado no item 4.2.2, usou-se a "fase cíclica", no qual depois de oito aquisições foi eliminado escolhendo como fases do pulso de $180^{\circ} \mathrm{o}+\mathrm{x}\left(0^{\circ}\right) \mathrm{e}-\mathrm{x}\left(180^{\circ}\right)$ alternado entre uma e outra aquisição. Mais como a perspectiva do trabalho é implementar para seres vivos e eles possuem movimento, não era possível aplicar essa forma de eliminar os componentes indesejados. Tal fato motivou a opção para sua eliminação mediante os denominados gradientes spoilers .

O sistema Gyroscan S15 da Philips com foi tratado no item 4.1.1 contém uma unidade de monitoramento de potência para a proteção do paciente quando a energia de RF excede um nível determinado, mas o sistema GP-AT não contém esse sistema de segurança, daí a razão da realização da implementação de espectroscopia localizada in vitro. 


\section{Capítulo VI}

\section{CONCLUSÕES E PERSPECTIVAS}

O estudo teórico das diferentes técnicas de espectroscopia localizada nos levou a escolher a técnica PRESS para a implementação, tendo em vista que nela é possível obter os espectros com a menor quantidade de artefatos, além de uma fácil implementação com respeito às outras técnicas. Uma das importantes vantagens da espectroscopia in vivo é que o espectro é obtido em uma única aquisição, eliminando assim artefatos de movimento.

O sistema GP-AT usa como console o NTNMR, mas para executar uma seqüência o tempo útil é muito elevado, razão pela qual foi desenvolvida uma interface para o usuário que possibilitou a otimização da seqüência, permitindo ademais um melhor controle dos seus parâmetros. Além da interface foram elaborados scripts que permitirão o cálculo do ângulo de excitação e da largura da fatia, possibilitando assim uma diminuição significativa do tempo de preparação da seqüência e aquisição do espectro do VOI.

Como um dos logros desta pesquisa, destacamos a obtenção das primeiras imagens no sistema GP-AT em nosso laboratório; imagens que apresentaram artefatos e que foram parcialmente corrigidas. No caso de espectroscopia localizada não há necessidade de uma imagem de boa qualidade, no entanto ela não deve apresentar deformações.

Destacamos ainda o aproveitamento de parte do sistema Gyroscan para, juntamente com o modulo do Apollo da Tecmag, agora um sistema aberto, a implementação de diversas seqüências em experiências de Ressonância Magnética Nuclear. No caso específico de espectroscopia localizada poder-se-á futuramente implementar outras sequiências, e para outros núcleos.

A partir deste desenvolvimento, uma das grandes vantagens que agora dispomos é o funcionamento do sistema Gyroscan da Philips juntamente com o sistema GP-AT. Desta forma, maximizando o aproveitamento do primeiro sistema, poder-se-á no futuro superar a dependência do computador do VAX-11/750.

O sistema Gyroscan S15 da Philips contém uma unidade de monitoramento de potência para a proteção do paciente quando a energia de RF excede um nível determinado, mas o sistema GP-AT não contém esse sistema de segurança, razão pela qual foi realizada a implementação de espectroscopia localizada in vitro. 
Com este trabalho evidencia-se a possibilidade de se realizar experiências fazendo uso de diferentes técnicas, não somente de espectroscopia como de tomografia. Desta maneira entendemos como uma contribuição à novas implementações e estudos baseados nestas técnicas.

A técnica PRESS implementada no Apollo da Tecmag, permite obter espectros de ${ }^{1} \mathrm{H}$ com boa relação sinal/ruído, mas para isso é preciso utilizar seqüências de supressão da água, conseguindo assim observar o espectro do volume de interesse.

Uma vez que tivemos de eliminar as correntes induzidas, assim como os artefatos de localização, foi necessário o uso de gradientes de spoilers em forma de um quarto de seno. De acordo com a seqüência implementada, tivemos de aumentar a duração dos spoilers; por consequiência o tempo de eco foi de $90 \mathrm{~ms}$, permitindo assim não observar nos espectros os metabólitos com tempo de relaxação curtos.

Para finalizar observamos que, com este trabalho, foi possível o conhecimento do módulo Apollo da Tecmag. Isto permitirá aos trabalhos posteriores - agora que já se tem o sistema GP-AT em funcionamento e o módulo Apollo da Tegmag é um sistema aberto serem realizados de maneira mais rápida, contribuindo assim na facilitação do processo de implementação de algumas seqüências em pesquisas futuras. 


\section{REFERÊNCIAS BIBLIOGRÁFICAS}

1. ABRAgAM, A. "Principles of Nuclear Magnetism". Clarendon Press, Oxford, 1994.

2. ACKERMAN, J. J. H.; GROVE, T. H.; WONG, G. G.; GADIAN, D. G. ; RADDA, G. K. "Mapping of metabolites in whole animals by ${ }^{31} P$ NMR surface coils". Nature 283: 167, 1980.

3. BARKER P. B.; GLICKSON J. D.; BRYAN R. N. "In vivo magnetic resonance spectroscopy of human brain tumors". Top. Magn. Reson. Imaging 5:32, 1993.

4. BENDALL, M.R. "Surface coil techniques for in vivo NMR". Bull. Magn. Reson. 8:17, 42, 1986.

5. BESSMAN, S. P.; GEIGER P. J. "Transport of energy in muscle: the phosphorylcreatine shuttle". Science 211: 448, 1982.

6. BLOCH, F. "Nuclear Induction". Phys. Rev. 70: 460, 1946.

7. BONAGAMBA, T.J. "Seleção dé planos em Tomografia por Resonancia Magnética Nuclear". Dissertação de mestrado, DFCM-IFQSC-USP, 1986.

8. BOTTOMLEY, P . A. "Selective Volume Method for Performing Localized NMR Spectroscopy". U.S. Patent 4,480,228, 1984.

9. BOTTOMLEY, P. A. "Spatial localization in NMR-Spectroscopy, in vivo". Ann. N.Y. Acad. Sci. 508: 333, 1987.

10. BOTTOMLEY, P. A. "Selective volume method for performing localized NMR spectroscopy". U. S. patent 4480 228, 1982.

11. BOTTOMLEY, P. A.; FOSTER, T. B.; DARROW, R. D. "Depth resolved surface-coil spectroscopy (DRESS) for in vivo ${ }^{\prime} H,{ }^{31} P$, and ${ }^{13} C N M R$ ". J. Magn. Reson. 59:338, 1984.

12. BROWN, T. R.; KINCAID, B. M.; UGURBIL, K. "NMR chemical shift imaging in the three dimensions". Proc Natl. Acad Sci. U.S.A. 79: 3523, 1982.

13. BUGER, C. ; BUCHLI, R.; McKinnon, G. et.al. "The impact of the ISIS experiment order on spatial contamination". Magn. Reson. Med. 26: 218, 1992.

14. CHANG, L. H.; COHEN, Y.; WEINSTEIN, P. R. "Interleaved ${ }^{\prime} H$ and ${ }^{31} P$ spectroscopic Imaging for studying regional brain imaging”. Magn. Reson. Imaging 9: 223, 1991.

15. CHANG, R. "Principios Básicos de Espectroscopia”. Editorial AC, Madrid-Espanha. 1977.

16. COHEN, S.M. "Carbon-13: NMR spectroscopy” In PARTAIN, C.L.; PRICE R.R.; PATTON, J.A. et al, Editors: Magnetic resonance imaging. Philadelphia, 1988, Saunders.

17. CONELlY, A.; COUNSEll, C.; LOHMAN, J. A. B.; ORDRIDGE, R. J. "Outer Volume Suppressed image related in vivo spectroscopy (OSIRIS), a high-sensitivity, localized technique". J. Magn. Reson. 78: 519, 1988.

18. CROOKS, L. E. "Selective irradiation line scan techiques for NMR imaging". IEEE Trans. Nucl. Sci. NS-27: 1239, 1980. 
19. DAMADIAN, R. "Tumor detection by NMR". Science, 171: 1151, 1971.

20. ERNST, R. R.; ANDERSON "Application of Fourier Transform Spectroscopy to Magnetic Resonance”. Rev. Sci. Instr. 37: 93, 1966.

21. ERNST, T.; HENNING, J. "Improved water supression for localized in vivo 'H spectroscopy" J. Magn. Reson. Series B, 106:181, 1995.

22. FRAHM, J. ; MERBOLDT, K. D; HANICKE, W. "Localized proton spectroscopy using stimulated echoes". J. Magn. Reson. 72: 502, 1987.

23. FRAHM, J.; BRUHN, H.; GYNGELL, M. L.; MERBOLDT, K. D.; HANICKE, W.; SAUTER, R. "Localized high resolution proton spectroscopy using stimulated echoes: Initial application
to human brain". Magn. Reson. Med. 9:79, 1989.

24. FREEMAN, R. "A Handbook of Nuclear Magnetic Resonance". Longman Scientific \& Technical, New York, p. 151, 1988.

25. FULHAM, M. J.; BIZZI, A.; DIETZ, M. J. "Mapping of brain of tumor metabolites with proton MR spectroscopic imaging: clinical relevance". Radiology 185: 675, 1992.

26. GONEN, O.; ARIAS-MENDOZA, F.; GOELMAN, G. " $3 D$ localized in vivo 'H spectroscopy of human brain by using a hybrid of ID-hadamard with 2D-chemical shift imaging". Magn. Reson. Med. 37: 644, 1997.

27. GORDON, R. E.; ORDIDGE, R. J. "Volume selection for high resolution NMR studies" in proceedings of the Society of Mgnetic Resonance in Medicine, Third annual Scientific Meeting, New York, p. 172, 1984.

28. GORDON, R. E.; HANLEY, P. E.; SHAW, D.; GADIAN, D. G.; RADDA, G. K.; TYLES, P.; BORE, P. J.; CHAN, L. "Localization of metabolites in animals using ${ }^{31} P$ Topical Magnetic Resonance". Nature 287: 736, 1980.

29. GRANOT, J. "Selected volume excitation using stimulated echoes (VEST), applications to spatially localized spectroscopy and imaging". J. Magn. Reson. 70: 488, 1986.

30. GUPTA, R. K. "Dynamic range problem in fourier transform NMR. modified WEFT pulse sequence". J. Magn. Reson. 24: 461, 1976.

31. HAASE, A.; FRAHM, J.; HANICKE, W.; MATTHEI, D. "'H NMR Chemical-Shift Selective (CHESS) Imaging". Phys. Med. Biol. 30: 341, 1985.

32. HAHN, E. L. “Spin Echoes". Phys. Rev. 80: 580, 1950.

33. HASHIMOTO, T.; TAYAMA, M.; MIYASAKI, M.; YONEDA, Y.; YOSHIMOTO, T.; HARADA, M.; MIYOSHI, H.; TANOUCHI, M.; KURODA, Y. "Differences in brain metabolites between patients with autism and metal retardation as detected by in vivo localized próton magnetic resonance spectroscopy". J. Child. Neurol. 12:91, 1997

34. HENNIG, J. "Echoes-How to Generate, Recognize, Use, or Avoid Them in MR-Imaging Sequences. Part I: Fundamental and Not So Fundamental Properties of Spin Echoes". Concepts Magn. Reson. 3, 125, 1991 . 
35. HENNIG, J. "Echoes-How to Generate, Recognize, Use, or Avoid Them in MR-Imaging. Sequences. Part II: Echoes in Imaging Sequences”. Concepts Magn. Reson. 3:179, $1991 \mathrm{~b}$.

36. HINSHAW, W.S.; LENT, A. H. "An introduction to NMR Imaging: From the Bloch equation to the Imaging Equation”. Proceedings of the IEEE. 71(3): 338, 1983.

37. HOULT, D. I. "Solvent peak Saturation with single phase and quadrature Fourier transformation". J. Magn. Reson. 21: 337,1976.

38. HOULT, D. I.; BUSBY, S. J. W.; GADIAN, D. G.; RADDA, G. K.; RICHARDS, R. E.; SEELEY, P. J. "Observation of tissue metabolites using ${ }^{31} \mathrm{P}$ nuclear magnetic resonance". Nature 252: 285, 1974.

39. JUNG, W-I. "Localized double spin echo proton spectroscopy". Concepts in magnetic resonance. 8 (1): 1, 1996.

40. JUNG, W-I.; GRODD, W.; LUTZ, O.; PETERSEN "Localized 'H in vivo NMR spectroscopy of small-volume elements in human brain at 1.5 T”. Magn. Reson. Med. 15: 320, 1990.

41. JUNG, W-I; LUTZ, O. "Double spin-echo volume selective NMR spectroscopy with a $1.5 \mathrm{~T}$ whole body Imager”. Z. Naturforsch., 44 a: 1183, 1989.

42. KIMMICH, R.; HOEPFEL, D. "Vulume selective multipulse spin echo spectroscopy". J. Magn. Reson. 72:379, 1987.

43. KUGEL, H.; HEINDEL, W.; ERNESTUS, R. I. "Human brain tumors: spectral patterns detected wiht localized H-I MR spectroscopy". Radiology 183:701, 1992.

44. KUMAR, A.; WELTLI, D.; ERNST, R. R. "NMR Fourier Zeugmatography". J. Magn. Reson. 18: 69, 1975.

45. LAUTERBUR, P. "Image formation by induced local interactions: example employing nuclear magnetic resonance". Nature 242: 190, 1973.

46. LUYTEN, P. R.; GROEN, J. P.; VERMEUlEN, J. W. A. H.; den HOllaNDER, J. A. "Experimental Approaches to Image Localized Human ${ }^{3 l} P$ NMR Spectroscopy". J. Magn. Reson. Med. 11: 147, 1989.

47. MANSFIELD, P.; MORRIS, P.G. "NMR Imaging in Biomedicine". Academic Press, 1982.

48. MANSFIELD, P.; PYKETT, I. L., "Biological and medical imaging by NMR", J. Magn. Reson. 29: 335, 1978.

49. MAUDSLEY, A. A.; HILAL, S. K.; PERMAN, W.H. ; SIMON, H. E., "Spatially resolved high resolution spectroscopy by four dimensional NMR", J. Magn. Reson. 51: 147, 1983.

50. MOONEN, C. T. W.; KIENLIN, M. V.; VAN ZIJL, P. C. M.; COHEN, J.; GILLEN, J.; DALY, P.; WOLF,G. " Comparison of single-shot localization methods (STEAM and PRESS) for in vivo proton NMR spectroscopy". NMR Biomed. 2:201, 1989.

51. MOONEN, C.T.W.; van Zijl, P. C. M. "Highly effective water supression for in vivo proton NMR spectroscopy (DRYSTEAM)". J. Magn. Reson 88: 28, 1990. 

52. MORRIS, P. G. "Nuclear Magnetic Resonance Imaging in Medicine and Biology", Clarendon
Press, Oxford, 1986.

53. MUELLEN, P.; YPERN, G. H. "Fifth anual meeting of the society of Magenetic Resonance in Medicine", p. 1129, 1986.

54. NARAYANA P.A ; KULKARNI M.V., METHA S.D. "NMR of ${ }^{23}$ Na in biological systems". In PARTAIN C.L.; PRICE, R. R.; PATTON, J.A.; et al., editors: Magnetic Resonance Imaging,
Philadelphia, 1988, Saunders.

55. NAVON, G.; OGAWA, S.; SHULMAN, R. G.; YAMANE, T. " "3lP Nuclear Magnetic Resonance studies of Ehrilish ascites tumor cells". Proc. Natl. Acad Sci USA 74:87, 1977.

56. NEGENDANK, W. G.; BROWN, T. R.; EVELHOSH, J. L. "MR Spectroscopy and tumor cell biology", Radiology 185:875, 1992.

57. ORDIDGE, R.J.; CONNELLY, A.; LOHMAN, A. B. "Image Selective in Vivo Spectroscopy (ISIS). A New Technique for Spatially Selective NMR Spectrocopy" J. Magn. Reson. 66: 283, 1986.

' 58. ORRISON, W. W.; LEWINE, J. D.; SANDERS, J. A .; HARTSHORNE, M. F. “Functional Brain Imaging”. Mosby-Year Book, Inc, EEUU. 1995.

59. PANEPUCCI, H.; DONOSO, J. P. ; TANNÚS, A. ; BECKMAN, N.; BONAGAMBA, T., "Novas imagens do corpo", Ciência Hoje. 4 (20): 46, 1981.

60. PARTAIN C.L.; PRICE R. R.; PATTON J.A. et al., editors: Magnetic Resonance Imaging, ed. 2, Philadelphia, Saunders, p. 1543, 1988.

61. POUCHERT, J. "The Aldrich Library of NMR Spectra", Edition II, Vol. 1, Aldrich Chemical Company, Inc. 1983.

62. PURCELl, E. U.; TORREY, H. C.; POUND, R. V. “Absorption by Nuclear Magnetic Moments", Phys. Rev. 69: 37, 1946.

63. REDFIELD, A. G.; KUNZ, S. D.; RALPH, E. K. "Dynamic range in fourier transform proton magnetic resonance", J. Magn. Reson. 50: 495, 1975.

64. SAUTER R.; SCHNEIDER M.; WICKLOW K. "Current status of clinically relevant technique in magnetic resonance spectroscopy. Electromedica 60: 31, 1992.

65. SHAKA, A.J.; KEELER, J.; SMITH, M.B.; FREEMAN, R. "Spatial localization of NMR signals in an inhomogeneous radiofrequency field". J. Magn. Reson. 61: 175, 1985

66. SKLENÁR, V.; STARCUK, Z. "A new efective method of selective excitation for próton NMR in water". J. Magn. Reson. 50: 495, 1982.

67. SLICHTER, C. P. “Principles of Magenetic Resonance”. Springer Verlag, New york, 1978.

68. SPRINGERS, C. "Measurement of metal cation compartmentalization in tissue by highresolution metal cation NMR". Ann. Rev. Biophys. Chem. 15: 357, 1987. 